\title{
Acyl-acyl carrier protein synthetases from bluegreen algae and plants
}

\author{
Dissertation \\ zur Erlangung des Doktorgrades \\ der Mathematisch-Naturwissenschaftlichen Fakultäten \\ der Georg-August-Universität zu Göttingen
}

vorgelegt von

Danuta Kaczmarzyk

aus Wroclaw, Polen

Göttingen 2008 
D 7

Referent: Prof. Dr. Ivo Feussner

Korreferent: Prof. Dr. Dieter Heineke

Tag der mündlichen Prüfung: 29.04.2008 


\section{Introduction}

1.1 Activation of fatty acids

1.2 Acyl-ACP synthetase activity in Escherichia coli, Vibrio harvei and oleaginous yeast

1.3 Acyl activation in Arabidopsis thaliana 3

1.3.1 Identification of acyl-ACP synthetase activity in Arabidopsis thaliana 3

1.3.2 Superfamily of Acyl-Activating Enzymes 4

1.4 Preceding work 5

$\begin{array}{lll}1.5 & \text { Cyanobacteria as model organisms } & 7\end{array}$

1.6 The scope of the project 8

2 Materials and Methods $\quad 10$

$\begin{array}{lll}2.1 \text { Chemicals } & 10\end{array}$

$\begin{array}{lll}2.2 & \text { Bacterial strains and culturing } & 10\end{array}$

2.3 Cyanobacteria 11

$\begin{array}{lll}\text { 2.3.1 Strains and growth conditions } & 11\end{array}$

$\begin{array}{lll}\text { 2.3.2 Preparation of frozen stocks } & 13\end{array}$

$2.4 \quad$ Arabidopsis thaliana 14

$\begin{array}{lll}2.4 .1 & \text { Arabidopsis seed surface sterilization } & 14\end{array}$

2.4.2 Cultivation of Arabidopsis on MS-Medium 14

2.4.3 Cultivation of Arabidopsis on soil 14

2.4.4 Transformation of Arabidopsis with Agrobacterium tumefaciens $\quad 15$

$\begin{array}{lll}2.5 & \text { Insect cells } & 16\end{array}$

$\begin{array}{lll}\text { 2.5.1 Cell line } & 16\end{array}$

2.5.2 Bac-to-Bac Baculovirus Expression System 16

$\begin{array}{lll}\text { 2.5.3 Cell culture } & 16\end{array}$

$\begin{array}{lll}\text { 2.5.4 Culture initiation from frozen stocks } & 17\end{array}$

$\begin{array}{ll}\text { 2.5.5 Preparation of frozen stocks } & 17\end{array}$

$\begin{array}{lll}\text { 2.5.6 Transfection of insect cells } & 18\end{array}$

$\begin{array}{lll}2.5 .7 & \text { Viral stock isolation } & 18\end{array}$

$\begin{array}{lll}2.5 .8 & \text { Viral plaque assay } & 18\end{array}$

$\begin{array}{ll}\text { 2.5.9 Viral stock amplification } & 19\end{array}$

$\begin{array}{lll}2.6 & \text { Molecular cloning } 20\end{array}$

$\begin{array}{lll}2.6 .1 & \text { Plasmids } & 20\end{array}$

$\begin{array}{lll}\text { 2.6.2 Plasmid DNA isolation } & 20\end{array}$ 
$\begin{array}{lll}\text { 2.6.3 Cyanobacteria genomic DNA isolation } & 21\end{array}$

$\begin{array}{lll}2.6 .4 & \text { Polymerase chain reaction (PCR) } & 21\end{array}$

2.6.5 PCR-based site directed mutagenesis 23

$\begin{array}{lll}2.6 .6 & \text { Primers } & 24\end{array}$

2.6.7 Estimation of the concentration of nucleic acids 24

2.6.8 Agarose gel electrophoresis, gel staining and documentation 24

2.6.9 DNA isolation from gel 25

2.6.10 Restriction digestion 25

$\begin{array}{lll}2.6 .11 & \text { Dephosphorylation } & 25\end{array}$

2.6.12 Ligation 25

2.6.13 Sequencing 26

2.6.14 Preparation of competent cells and transformation 27

$\begin{array}{lll}2.6 .14 .1 & \text { Escherichia coli } & 27\end{array}$

$\begin{array}{lll}\text { 2.6.14.2 Agrobacterium tumefaciens } & 27\end{array}$

$\begin{array}{lll}2.6 .14 .3 & \text { Cyanobacteria } & 28\end{array}$

2.6.15 Cloning strategies utilized in this study 28

2.6.15.1 Generation of aas mutants in cyanobacteria 28

2.6.15.2 Complementation of Synechocystis sp. PCC 6803 aas knockout with aas from Synechococcus elongatus 7942

2.6.15.3 Cloning of Arabidopsis AAEs into pFastBac vector 30

2.6.15.4 Cloning of the promoter sequences of AAE15 and AAE16 into pBI101.3 vector 30

2.6.15.5 Generation of pEYFP-AAE fusion constructs 31

$\begin{array}{lll}2.7 & \text { Protein analysis } & 32\end{array}$

2.7.1 Expression of recombinant protein in insect cells 32

2.7.2 Isolation and purification of recombinant protein from insect cells 32

2.7.3 Determination of protein concentration 33

2.7.4 SDS Polyacrylamide Gel Electrophoresis (SDS-PAGE) 33

2.7.5 Coomassie staining 35

2.7.6 Western Blot analysis 35

2.7.7 Enzyme activity assays 36

2.7.7.1 Acyl-ACP synthetase activity 36

2.7.7.2 Acyl-CoA synthetase activity 37

$\begin{array}{lll}2.8 & \text { Fatty acids and lipids analysis } & 37\end{array}$ 
2.8.1 Fatty acids extraction from cyanobacteria cells and culture medium $\quad 37$

$\begin{array}{lll}2.8 .2 & \text { Extraction of lipopolysaccharide } & 38\end{array}$

$\begin{array}{lll}2.8 .3 & \text { Fatty acids derivatization } & 38\end{array}$

2.8.3.1 Methylation of free fatty acids 38

2.8.3.2 Transmethylation of esterified fatty acids 39

2.8.3.3 Acidic methanolysis 39

2.8.4 Gas chromatography (GC) 40

2.8.5 Gas chromatography-mass spectrometry 40

2.8.6 Thin layer chromatography (TLC) 41

2.8.7 $\quad{ }^{14} \mathrm{C}$ labeling experiments 41

2.8.8 Temperature shift experiment 42

2.9 Histochemical staining for $\beta$-glucuronidase (GUS) activity 42

2.10 Subcellular localization studies 43

2.10.1 DNA precipitation onto gold particles 43

2.10.2 Transformation of onion epidermal cells by bombardment 44

$\begin{array}{lll}2.10 .3 & \text { Fluorescence microscopy } & 44\end{array}$

3 Results $\quad 45$

3.1 Generation of aas knockout mutants in Synechocystis sp. PCC 6803 and Synechococcus elongatus PCC $7942 \quad 45$

3.2 AAS deficient cyanobacterial cells are unable to utilize exogenous fatty acids 48

3.3 AAS deficient cells of cyanobacteria secrete fatty acids into the medium 52

3.4 3-hydroxymyristic acid found in the culture media of aas knockout strains is released from lipopolysaccharide $\quad 56$

3.5 Cyanobacteria cannot accumulate lauric acid 57

3.6 Fatty acids uptake depends on the length of carbon chain 58

3.7 Respond to temperature shift from $30^{\circ} \mathrm{C}$ to $22^{\circ} \mathrm{C}$

$3.8 \quad$ Subcellular localization of AAE15 and AAE16 63

3.9 Heterologous expression and purification of AAE15 and AAE16 64

3.10 Acyl-ACP synthetase activity assays 66

3.11 Complementation of Synechocystis sp. PCC 6803 aas knockout with AAEs from $\begin{array}{lr}\text { Arabidopsis } & 68\end{array}$

3.12 Expression profiles of AAE15 and AAE16 in Arabidopsis $\quad 74$

4 Discussion $\quad \mathbf{8 0}$

5 Summary $\quad 93$ 
Table of contents

6 References $\quad 95$

$\begin{array}{lll}7 & \text { Appendices } & 101\end{array}$

$\begin{array}{lll}7.1 & \text { List of abbreviations } & 101\end{array}$

$\begin{array}{lll}7.2 & \text { List of primers } & 104\end{array}$

$\begin{array}{lll}7.3 & \text { Vector maps } & 106\end{array}$

8 Acknowledgments 109 


\section{Introduction}

\subsection{Activation of fatty acids}

Fatty acids play several important roles in cells. They are utilized for the synthesis of complex lipids, which are on one hand side essential components of membranes but which are also important in terms of carbon and energy storage in form of neutral lipids. Moreover, fatty acids are substrates for protein modification and they are involved in different regulatory mechanisms. Nevertheless, the vast majority of synthesized fatty acids are incorporated into lipids. The concentration of free fatty acids (FFA) in cells was found to be rather low most likely due to the detergent character of these molecules. They appear in cells as lipid degradation products or in case of unicellular organisms they also may be taken up from exogenous sources. Since fatty acids are metabolically inert, they need to be activated before entering any metabolic pathway. In the process of activation, which is ATP dependent, fatty acids are converted to reactive thioesters. De novo synthesized fatty acids do not need this activation since they are released in activated form already. The growing fatty acid chain is attached to a phosphopantethein group of an acyl carrier protein (ACP) as the thioester. The objective of this study is to investigate enzymes responsible for the activation of free fatty acids. The most common mechanism of fatty acid activation occurs in two steps and leads to the formation of acyl-CoA through the reaction catalyzed by acyl-CoA synthetase. In the first step of the reaction the free fatty acid is converted to an acyl-AMP intermediate, called acyl-adenylate, through the phosphorolysis of ATP. The activated carbonyl carbon of the acyl-adenylate is then coupled to the thiol group of CoA, releasing AMP and the acyl-CoA final product (Groot et al., 1976). The alternative way proceeds according to the same mechanism but utilizes not CoA but ACP as a final acceptor of the acyl group, and is catalyzed by acyl-ACP synthetase. Acyl-ACP synthetase (AAS) activity in Escherichia coli was reported for the first time in 1976 (Ray and Cronan, 1976). Figure 1 presents the scheme of the reaction catalyzed by the enzyme. Activation by acyl-CoA synthetase is well established whereas only little information is available about acyl-ACP synthetase. The focus of this work is to investigate enzymes utilizing ACP for fatty acids activation. 


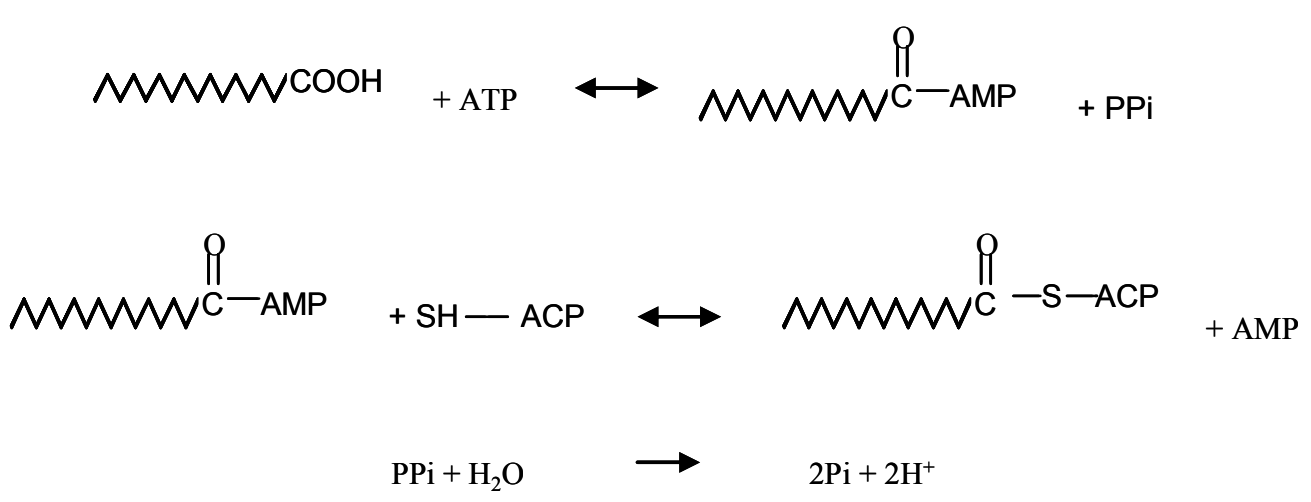

Figure 1. Scheme of the reaction catalyzed by acyl-ACP synthetase.

\subsection{Acyl-ACP synthetase activity in Escherichia coli, Vibrio harvei and oleaginous yeast}

There are only few reports concerning acyl-ACP synthetase activity in different organisms. The information currently available will be summarized in the following section. It was shown that $E$. coli is able to incorporate exogenous long chain fatty acids into phospholipids in the absence of acyl-CoA synthetase activity, and that acyl-ACP synthetase is responsible for this process (Ray and Cronan, 1976; Rock and Cronan, 1979). Further investigations revealed that two enzymatic activities, 2acylglycerophosphoethanolamine (2-acyl-GPE) acyltransferase and acyl-ACP synthetase are encoded by the aas gene in E. coli. The gene consists of a single open reading frame of 2157 base pairs predicted to encode a protein of $80.6 \mathrm{kDa}$. Sequence analysis indicated the presence of AMP-binding signature, what classify the enzyme to an AMP-binding protein family (Jackowski et al., 1994). 2-acyl-GPE acyltransferase/acyl-ACP synthetase is an integral inner-membrane enzyme and catalyzes an ATP-dependent activation and transfer of exogenous fatty acids specifically to lysophosphatidylethanolamine (Cooper et al., 1989; Hsu et al., 1991). The enzyme is involved in the reacylation of the sn-1 position of phosphatidylethanolamine during synthesis of outer-membrane lipoproteins in E. coli (Rock and Jackowski, 1985; Jackowski and Rock, 1986). In vivo acyl-ACP is a tightly bound intermediate of the E. coli enzyme, but in vitro, high ionic strength conditions promote the dissociation of acyl-ACP from the enzyme, allowing acyl-ACP synthetase activity to be monitored (Cooper et al., 1989). E. coli acyl-ACP synthetase was purified from natural source (Rock and Cronan, 1979) and the enzyme was also overexpressed and purified from E. coli (Shanklin, 2000). 
The second acyl-ACP synthetase was reported by Byers in bioluminescent marine bacterium Vibrio harveyi. A $62 \mathrm{kDa}$, soluble enzyme was isolated and purified to homogeneity from natural source and its acyl-ACP synthetase activity was confirmed by in vitro assays. The enzyme was proposed to elongate exogenous fatty acids by an ACP dependent mechanism, but the physiological function of this process was not established. Soluble nature of the enzyme, different fatty acid chain length specificity (C 6 to C 16, whereas $E$. coli enzyme prefers fatty acid $\geq 14$ carbons in length), and different response to a high ionic strength indicated that the purified enzyme was not homologous to E. coli acyl-ACP synthetase (Byers and Holmes, 1990; Fice et al., 1993). This hypothesis was supported by sequences comparison, after the gene (called aas $S$ ) encoding acyl-ACP synthetase of Vibrio harveyi had been identified (Jiang et al., 2006).

The third report provides the first evidence for the existence of acyl-ACP synthetase in eukaryotes. Acyl-ACP synthetase activity was identified as a part of a triacylglycerol biosynthetic multienzyme complex in a soluble fraction of oleaginous yeast, Rhodotorula glutinis. The enzyme responsible for the activity was isolated from the complex and purified to apparent homogeneity. Its molecular mass was approximately $35 \mathrm{kDa}$. The enzyme activity was found to be maximal with unsaturated fatty acids and showed a preference for linoleic acid. $R$. glutinis acyl-ACP synthetase has a role in the activation of fatty acids, which are channeled towards the biosynthesis of triacylglycerol (Gangar et al., 2001). Different molecular mass, cytosolic localization, different substrate specificity and the activity as part of a multienzyme complex distinguished the acyl-ACP synthetase of $R$. glutinis from those activities described previously. It should be noted that the gene encoding acyl-ACP synthetase of $R$. glutinis has not been identified so far.

\subsection{Acyl activation in Arabidopsis thaliana}

\subsubsection{Identification of acyl-ACP synthetase activity in Arabidopsis thaliana}

Acyl-ACP synthetases were found in bacteria and oleaginous yeast but, for a long time, such enzymes have not been characterized in plants. The occurrence of the acyl-ACP synthetase activity in microsomal fraction of leek (Allium porrum) epidermal cells was reported by (Lessire and Cassagne, 1979), but the enzyme responsible for this activity have not been isolated and physiological function of the process has not been elucidated. Plant 
cells are known to elongate exogenously provided fatty acids. Koo and coworkers were investigating, where exactly this process occurs in the cell and how fatty acids are activated prior to being elongated. The results of the experiments with intact Arabidopsis thaliana leaves and isolated pea chloroplasts, incubated with $\left[1-{ }^{14} \mathrm{C}\right]$ lauric acid allowed making the hypothesis that there is a plastid enzyme which directly activates fatty acids to ACP thioesters. Four candidates of AAE superfamily, which were reported to possess plastidial targeting sequences, were selected for further investigations. Leaves of Arabidopsis mutant plants were incubated with labeled fatty acids and the capability of fatty acid elongation by the mutant lines was compared with wild type. The results demonstrated that the gene product of $A A E 15$ is a major factor responsible for the elongation of exogenous mediumchain fatty acids by Arabidopsis leaves. In vitro acyl-ACP synthetase assays employing leaf extracts of wild type and aae 15 plants as a source of enzyme proved that the gene product of $A A E 15$ displayed acyl-ACP synthetase activity and is responsible for at least 40$55 \%$ of the acyl-ACP synthetase activity seen in the leaf homogenate. In addition aae16 plants were tested for elongation activity and in acyl-ACP synthetase assays, but no differences to the wild type were observed (Koo et al., 2005).

\subsubsection{Superfamily of Acyl-Activating Enzymes}

$A A E 15$ and $A A E 16$ which are of interest of this study are only two memebers of a large gene family identified in Arabidopsis. The Arabidopsis genome contains a large superfamily (63 members) of genes encoding proteins annotated as acyl activating enzymes (AAEs; (Shockey et al., 2003)). This group of enzymes was previously known as acyl adenylate-forming (Conti et al., 1996) or AMP-binding protein superfamily (Fulda et al., 1997) and they catalyze the activation of various carboxylic acid substrates through the formation of thioester bonds, via enzyme-bound acyl-AMP intermediates called acyladenylates. The presence of a certain motif (PROSITE PS00455), which appears to be absolutely necessary for binding ATP and for adenylate formation (Conti et al., 1996), unites the group of AAEs into a large superfamily. However, the identities of substrates, utilized by individual enzymes, or the ultimate acyl acceptors may vary considerably within the group. On the basis of sequences similarities all 63 AAEs were segregated into seven distinct subfamilies (Shockey et al., 2003). Because of the focus of this study, only one of them, the subfamily comprising long-chain acyl-CoA synthetase (LACS) will be introduced here. The family contains 11 genes, however only 9 of them were found to have 
LACS activity in yeast or E. coli cells overexpressing the candidate genes and were able to complement a LACS-deficient strain of yeast. The products of two other candidate genes, AAE15 (At4g14070) and AAE16 (At3g23790) were ineffective in both in vitro enzyme assays and the yeast complementation experiment. Additionally, sequences analysis showed that AAE15 and AAE16 are distinguishable from other members of the family by the different length of a certain domain, common for the other members of the LACS subfamily (Shockey et al., 2002). AAE15 was shown in another study to encode plastidial acyl-ACP synthetase (Koo et al., 2005), but the function of $A A E 16$ remained unknown.

\subsection{Preceding work}

The focus of the previous research project pursued by our group recently was the characterization of the enzymes involved in fatty acids activation in cyanobacteria. In the course of the study the cyanobacterial gene encoding acyl-ACP synthetase was identified and functional characterization of the enzyme was performed for two strains, Synechocystis sp. PCC 6803 and Synechococcus elongatus PCC 7942 (Kaczmarzyk, 2004). The results of this work are summarized in this section.

Database search revealed that Synechocystis sp. PCC 6803 genome contains only one gene, slr1609, potentially involved in the activation of fatty acids. The gene is annotated as longchain-fatty acid CoA ligase. However, with respect to the findings that acyltransferases of cyanobacteria use acyl-ACPs as substrates and acyl-CoA thioesters are not involved in the transfer of fatty acids into the lipids (Lem and Stumpf, 1984; Ohlrogge and Browse, 1995), ACP seemed to be another good candidate to be involved in the activation reaction. Therefore, both ACP and CoA were considered as possible acceptors of acyl groups in the process of fatty acid activation.

To obtain reliable results concerning the fatty acid activation in cyanobacteria in general, Synechococcus elongatus PCC 7942 was selected as a second model organism. Comparison of the amino acid sequences of putative long-chain-fatty-acid CoA ligases of Synechocystis sp. PCC 6803 and Synechococcus elongatus PCC 7942 showed that the enzymes share $50 \%$ identity and $64 \%$ similarity. Both enzymes were overexpressed in $E$. coli and isolated from membrane fraction. Purification yielded homogenous protein fractions of approximately $66 \mathrm{kDa}$. In vitro assays, conducted in the presence of radiolabeled palmitic acid, ATP and either CoA or ACP as acyl acceptor, showed unequivocally that the overexpressed enzymes displayed acyl-ACP synthetase (AAS) 
activity. It was also shown that, in contrast to E. coli AAS, high salt concentrations in the reaction mixture are not necessary to measure acyl-ACP formation. Substrate specificity was tested, using fatty acids ranging in length from 12 to 18 carbons and spanning the level of desaturation from 0 to 3 double bonds. The results demonstrated that AASs from Synechocystis sp. PCC 6803 and from Synechococcus elongatus PCC 7942 possessed broad substrate specificity. Most fatty acids were activated at similar rates by both enzymes. Only linoleic acid turned out to be an inferior substrate for both enzymes.

The sequence alignment showed that AAS of Synechocystis sp. PCC 6803 and Synechococcus elongatus PCC 7942 shared only 13\% and 14\% amino acid identity, respectively, with the AAS of E. coli. It is noteworthy that E. coli expresses an acyl-CoA synthetase as well as an AAS protein in contrast to the investigated cyanobacteria which seem to have only one gene responsible for fatty acid activation. In addition the AAS of $E$. coli is distinct from the cyanobacterial enzymes because of its dual enzymatic function as acyl-ACP synthetase and as 2-acylglycerophosphoethanolamine (2-acyl-GPE) acyltransferase. These findings suggested that cyanobacterial acyl-ACP synthetases are a separate class of enzymes which developed independently of the AAS of E. coli. Sequences displaying high levels of similarity to acyl-ACP synthetase of Synechocystis sp. PCC 6803 and Synechococcus elongatus PCC 7942 were found in other cyanobacteria and in plants only, indicating that this class of enzymes might be restricted to photosynthetic organisms. The observation of particular interest was that Arabidopsis AAE15 and AAE16 are closer related to sequences from cyanobacteria than to other Arabidopsis LACSs or AAEs. A phylogenetic tree was constructed to visualize the relationship among LACSs, AAE15, AAE16 and AAS sequences from Synechocystis sp. PCC 6803 and Synechococcus elongatus PCC 7942 (figure 2). 


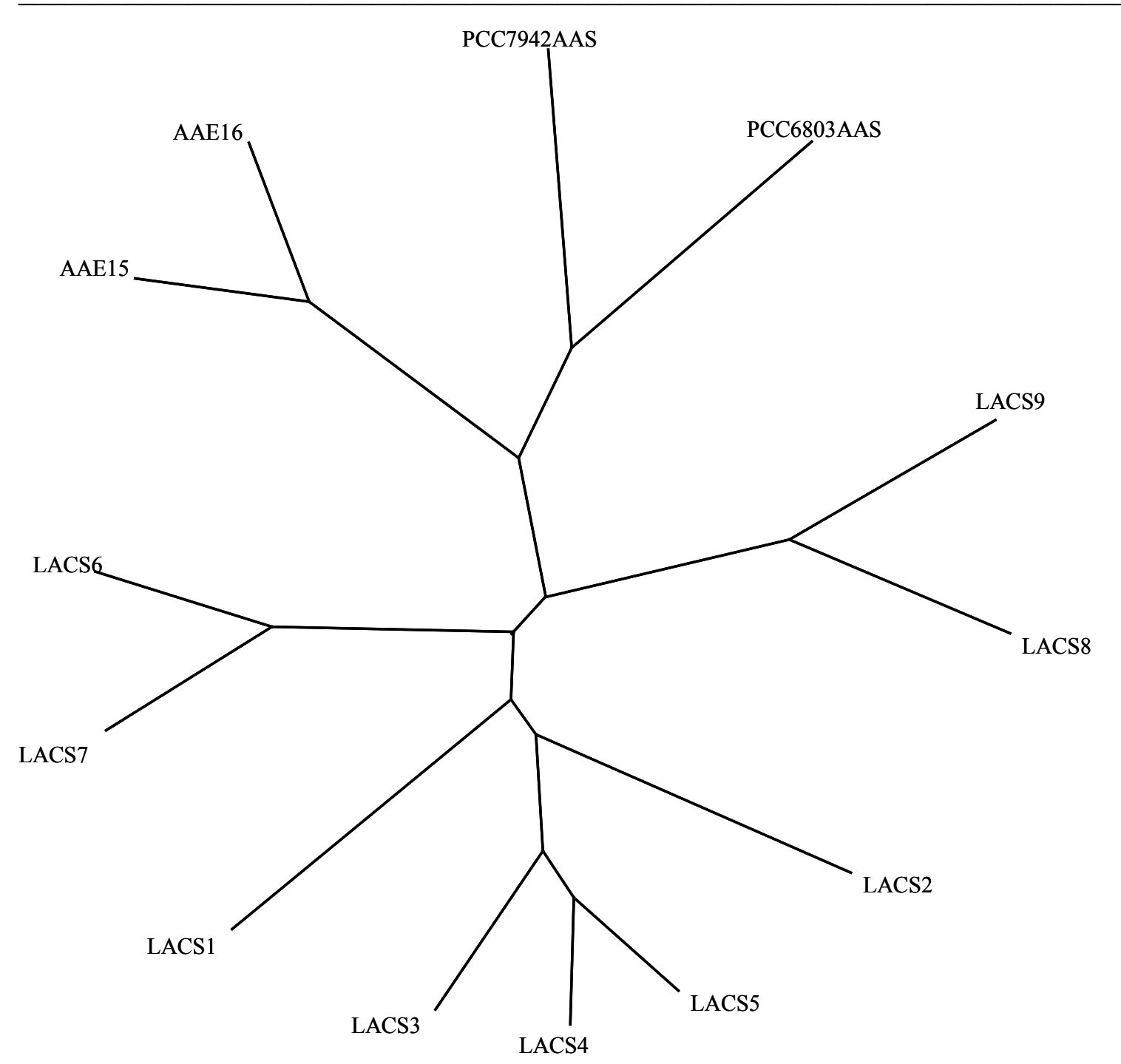

Figure 2. Phylogenetic comparison of Arabidopsis LACSs (LACS 1-9), AAE15 and AAE16 with Synechocystis sp. PCC 6803 and Synechococcus elongatus PCC 7942 AASs (PCC6803 AAS, PCC7942 AAS).

\subsection{Cyanobacteria as model organisms}

Cyanobacteria (blue-green algae) are a phylum of the kingdom bacteria. Two strains employed in this work, Synechocystis sp. PCC 6803 (genus-Synechocystis) and Synechococcus elongatus PCC 7942 (genus-Synechococcus) belong to the order Chroococcales. They are unicellular, photosynthetic inhabitants of freshwater. Several features make them especially suitable as model organisms for the present study. Both Synechocystis sp. PCC 6803 and Synechococcus elongatus PCC 7942 are naturally transformable by exogenous DNA (Shestakov and Khyen, 1970; Grigorieva and Shestakov, 1982). The capability to integrate foreign DNA into the genome by 
homologous recombination allows targeted gene replacement in these organisms. The complete genome sequences of both organisms are available. Synechocystis sp. PCC 6803 was the first photosynthetic organism for which the entire genome sequence was determined (Kaneko et al., 1996). The information is available on CyanoBase (http://www.kazusa.or.jp/cyano/cyano.html). The sequencing of the Synechococcus elongatus PCC 7942 genome was completed by the DOE Joint Genome Institute (JGI) and the information is available since 2005 on Integrated Microbial Genomes (IMG) system at JGI (http://img.jgi.doe.gov). The protocols for cyanobacteria culturing, transformation and mutagenesis are well established and available. Neither Synechocystis nor Synechococcus produce toxins, so these two strains do not bearing any health risk and can be easily handled under laboratory conditions. A particularly beneficial feature of both strains employed, in the context of presented work, is their capability to utilize exogenously provided fatty acids.

\subsection{The scope of the project}

Sequences homology indicates that acyl-ACP synthetases found in cyanobacteria and plants are a separate class of enzymes which developed independently of $E$. coli AAS and are restricted to photosynthetic organisms. However the occurrence of two candidate genes in Arabidopsis genome may suggest that AAS in plants evolved to fulfill certain roles, different than in prokaryotic organisms. To have a broaden view on AAS activity in photosynthetic organisms in general cyanobacteria and plants were selected as model organisms for this study. The project can be divided into two parts reflecting the affiliation of the enzyme to these two groups of organisms.

The major focus of the first part is to elucidate the biological function of acyl-ACP synthetase activity in cyanobacteria. In previous work the gene encoding such an activity has been identified and the enzyme has been characterized by in vitro assays for two strains, Synechocystis sp. PCC 6803 and Synechococcus elongatus PCC 7942, but the question about the physiological role of the activity has not been answered. Generation of aas knockout mutants in the background of Synechocystis sp. PCC 6803 and Synechococcus elongatus PCC 7942 will be employed to address this question in the present work. 
The second part concerns acyl-ACP synthetase activity in Arabidopsis thaliana. The gene product of $A A E 15$ is likely to be involved in the activation of fatty acids by $\mathrm{ACP}$ in plastids (Koo et al., 2005). However the enzyme itself has been neither isolated nor characterized. The physiological function of AAS activity in plants has not been clarified either. Another open question arising from the work of Koo et al. and of previous studies of our group is the role of AAE16, a close homologue of AAE15. The main goal of this project is to express AAE15 and AAE16 heterologously and to determine the substrate specificities of the enzymes to improve our knowledge about their specific functions in Arabidopsis. Analysis of the expression profiles of $A A E 15$ and $A A E 16$ genes will be a second approach to answer this question. 


\section{Materials and Methods}

\subsection{Chemicals}

All chemicals were purchased from Amersham Bioscience (Freiburg), Duchefa (Haarlem, Netherlands), Fermentas (St.Leon-Rot), Roth (Karlsruhe), Sigma-Aldrich (Steinheim) unless otherwise indicated.

\subsection{Bacterial strains and culturing}

The following E. coli strains were used in this study:

\begin{tabular}{|c|c|}
\hline Strain & Genotype \\
\hline XL1 Blue & $\begin{array}{l}\text { recA1 endA1 gyrA96 thi-1 hsdR17 supE44 relA1 lac[F'proAB } \\
\left.\text { lacI }^{q} Z \Delta M 15 \mathrm{Tn} 10\left(\mathrm{Tet}^{\mathrm{r}}\right)\right](\text { Bullock et al., 1987) }\end{array}$ \\
\hline DH10Bac & $\begin{array}{l}\text { F- mcrA } \Delta(m r r-h s d \mathrm{RMS}-m c r \mathrm{BC}) \quad \varphi 80 \text { lacZ } \Delta \mathrm{M} 15 \Delta \text { lacX74 } \operatorname{rec} \mathrm{A} 1 \\
\text { endA1 araD139 } \Delta \text { (ara, leu)7697 galU galK } \lambda \text { - } r p s \mathrm{~L} \text { nupG } \\
\text { /pMON14272 / pMON7124 (Invitrogen, Karlsruhe) }\end{array}$ \\
\hline
\end{tabular}

All microbiological work was carried out under sterile conditions.

For the purpose of plasmid amplifications, transformed XL1 Blue competent cells were spread on solid LB medium plates, containing appropriate antibiotics to select for the plasmid, and were grown overnight at $37^{\circ} \mathrm{C}$. Bacteria from the colonies were inoculated in $5 \mathrm{ml} \mathrm{LB}$ medium, containing the same antibiotic as before and grown overnight under shaking at $37^{\circ} \mathrm{C}$.

For blue-white screening $40 \mu \mathrm{l}$ of $0.1 \mathrm{M}$ isopropylthio- $\beta$-galactoside (IPTG) as inductor and $40 \mu \mathrm{l}$ of $50 \quad \mathrm{mg} / \mathrm{ml} \quad$ 5-bromo-4-chloro-3-indolyl- $\beta$-D-galactopyranoside (dimethylformamid solution) (X-Gal) were spread on the surface of LB-carbenicillin plates and allowed to absorb for $30 \mathrm{~min}$ at RT. 


$\begin{array}{lcl}\text { LB-medium: } & 10 \mathrm{~g} \quad \text { Trypton } \\ \text { (Sambrook et al., 1989) } & 5 \mathrm{~g} \quad \text { Yeast extract } \\ & 5 \mathrm{~g} \quad \mathrm{NaCl} \\ & \text { in } 1000 \mathrm{ml} \text { distilled water } \\ & \text { autoclaved }\end{array}$

LB solid medium:

$15 \mathrm{~g}$ of agar was added per 1 litre of LB-medium

SOB-medium:

$10 \mathrm{~g}$ Pepton

$2.5 \mathrm{~g}$ Yeast extract

$0.3 \mathrm{~g} \mathrm{NaCl}$

$0.09 \mathrm{~g} \mathrm{KCl}$

in $498 \mathrm{ml}$ distilled water

after autoclaving, sterile filtered:

$1 \mathrm{ml} 1 \mathrm{M} \mathrm{MgSO}_{4}$

$1 \mathrm{ml} 1 \mathrm{M} \mathrm{MgCl}_{2}$ were added

\begin{tabular}{lll}
\hline Antibiotic & Stock solution & Final concentration \\
\hline Carbenicillin (Carb) & $100 \mathrm{mg} / \mathrm{ml}$ in distilled water & $100 \mu \mathrm{g} / \mathrm{ml}$ \\
Chloramphenicol (Cm) & $34 \mathrm{mg} / \mathrm{ml}$ in ethanol & $34 \mu \mathrm{g} / \mathrm{ml}$ \\
Kanamycin (Kan) & $30 \mathrm{mg} / \mathrm{ml}$ in distilled water & $30 \mu \mathrm{g} / \mathrm{ml}$ \\
Rifampicin (Rif) & $50 \mathrm{mg} / \mathrm{ml}$ in methanol & $50 \mu \mathrm{g} / \mathrm{ml}$ \\
Tetracyclin (Tet) & $12.5 \mathrm{mg} / \mathrm{ml}$ in ethanol & $12.5 \mu \mathrm{g} / \mathrm{ml}$ \\
\hline
\end{tabular}

\subsection{Cyanobacteria}

\subsubsection{Strains and growth conditions}

The following strains were used in this study:

- glucose-tolerant Synechocystis sp. PCC 6803 (kindly provided by Dr. Kay Marin)

- Synechococcus elongatus PCC 7942 
Liquid cultures were grown photoautotrophically in $100 \mathrm{ml}$ of BG 11 media (Sigma) in $250 \mathrm{ml}$ Erlenmeyer flasks at $30^{\circ} \mathrm{C}$. The cultures were grown under constant illumination at a photosynthetic photon flux density of approximately $38 \mu \mathrm{mol}$ photons $/ \mathrm{m}^{2} \mathrm{~s}$ ) and with aeration by sterile air. The growth was monitored by measurement of $\mathrm{OD}_{750}$. For growth on solid media, BG 11 (Rippka et al., 1979) was supplemented with $20 \mathrm{mM}$ HEPES-NaOH, $\mathrm{pH} 7.5,0.3 \%(\mathrm{w} / \mathrm{v})$ sodium thiosulfate pentahydrate and $1.5 \%(\mathrm{w} / \mathrm{v})$ agar. Mutants of Synechocystis sp. PCC 6803 and Synechococcus elongatus PCC 7942 were grown in the presence of antibiotic for the selection $(15 \mu \mathrm{g} / \mathrm{ml}$ kanamycin or $10 \mu \mathrm{g} / \mathrm{ml}$ chloramphenicol).

BG-11 suplemented with 20 mM HEPES-NaOH, pH 7.5

Stock 1

$\begin{array}{ll}\text { Citric acid } & 0.3 \mathrm{~g} \\ \text { Ferric ammonium citrate } & 0.3 \mathrm{~g} \\ \text { EDTA } & 0.05 \mathrm{~g}\end{array}$

adjusted to $100 \mathrm{ml}$ with distilled water

Stock 2

$$
\mathrm{NaNO}_{3}
$$

$30 \mathrm{~g}$

$$
\begin{aligned}
& \mathrm{K}_{2} \mathrm{HPO}_{4} \cdot 3 \mathrm{H}_{2} \mathrm{O} \\
& \mathrm{MgSO}_{4} \cdot 7 \mathrm{H}_{2} \mathrm{O}
\end{aligned}
$$

$0.82 \mathrm{~g}$

$1.5 \mathrm{~g}$

adjusted to $1000 \mathrm{ml}$ with distilled water

Stock 3

$\mathrm{CaCl}_{2} \cdot 2 \mathrm{H} 2 \mathrm{O}$

$1.9 \mathrm{~g}$

adjusted to $100 \mathrm{ml}$ with distilled water

Stock 4

$\mathrm{Na}_{2} \mathrm{CO}_{3}$

$4 \mathrm{~g}$

adjusted to $100 \mathrm{ml}$ with distilled water 
Stock 5

$$
\begin{aligned}
& \mathrm{H}_{3} \mathrm{BO}_{3} \\
& \mathrm{MnCl}_{2} \cdot 4 \mathrm{H}_{2} \mathrm{O} \\
& \mathrm{ZnSO}_{4} \cdot 7 \mathrm{H}_{2} \mathrm{O} \\
& \mathrm{Na}_{2} \mathrm{MoO}_{4} \cdot 2 \mathrm{H}_{2} \mathrm{O} \\
& \mathrm{CuSO}_{4} \cdot 5 \mathrm{H}_{2} \mathrm{O} \\
& \mathrm{Co}\left(\mathrm{NO}_{3}\right)_{2} \cdot 6 \mathrm{H}_{2} \mathrm{O}
\end{aligned}
$$

$2.86 \mathrm{~g}$

$1.81 \mathrm{~g}$

$0.222 \mathrm{~g}$

$0.391 \mathrm{~g}$

$0.079 \mathrm{~g}$

$0.049 \mathrm{~g}$

adjusted to $1000 \mathrm{ml}$ with distilled water

Stock 6

0.5 M HEPES-NaOH pH 7.5

HEPES

$119.15 \mathrm{~g}$

$\mathrm{pH}$ adjusted to 7.5 with $2 \mathrm{M} \mathrm{NaOH}$

filled up to $1000 \mathrm{ml}$ with distilled water

Medium

$\begin{array}{ll}\text { Stock 1 } & 2 \mathrm{ml} \\ \text { Stock } 2 & 50 \mathrm{ml} \\ \text { Stock } 3 & 2 \mathrm{ml} \\ \text { Stock } 4 & 1 \mathrm{ml} \\ \text { Stock } 5 & 1 \mathrm{ml} \\ \text { Stock } 6 & 40 \mathrm{ml}\end{array}$

In order to prepare agar plates, all stocks were mixed and $3 \mathrm{~g}$ of sodium thiosulfate pentahydrate was dissolved in the medium. Afterwards $\mathrm{pH}$ was adjusted to 7.6 with $\mathrm{NaOH}$ and distilled water was added to a final volume of $400 \mathrm{ml}$.

In a separate bottle $600 \mathrm{ml}$ distilled water was added to $15 \mathrm{~g}$ agar.

Stocks and agar water were autoclaved separately and mixed before pouring the plates. If necessary, an appropriate antibiotic was added after the medium was cooled to about $50^{\circ} \mathrm{C}$.

\subsubsection{Preparation of frozen stocks}

To prepare frozen stocks cultures with an $\mathrm{OD}_{750}$ of 1 to 2 were used. Dimethyl sulfoxide (DMSO) was added to $2 \mathrm{ml}$ culture volume to a final concentration of $9 \%(\mathrm{v} / \mathrm{v})$ and cells were frozen at $-80^{\circ} \mathrm{C}$. 


\subsection{Arabidopsis thaliana}

\subsubsection{Arabidopsis seed surface sterilization}

Seeds (10-60 mg) of Arabidopsis thaliana, ecotype Col-0, were washed once with $70 \%$ ethanol for $1 \mathrm{~min}$. Ethanol was removed and a solution of 1\% sodium hypochlorite with $0.1 \%(\mathrm{v} / \mathrm{v})$ SDS was added. After $20 \mathrm{~min}$ of incubation under shaking the sodium hypochlorite solution was removed and seeds were washed four times with $1.5 \mathrm{ml}$ of sterile water. After the final wash the seeds were resuspended in $0.1 \%$ water agar and stored at $4^{\circ} \mathrm{C}$ for 2 to 4 days to break dormancy.

\subsubsection{Cultivation of Arabidopsis on MS-Medium}

Sterilized seeds were spread on plates containing Murashige Skoog (MS) Medium (Murashige and Skoog, 1962). The plates were wrapped with micro pore tape and put on shelves under permanent light $\left(120 \mu \mathrm{mol} / \mathrm{m}^{2} \mathrm{~s}\right)$ at $23^{\circ} \mathrm{C}$ for two weeks. Afterwards seedlings were transferred to soil (2.4.3).

1xMS-Medium

$4.3 \mathrm{~g} / 1$ Murashige and Skoog Medium including vitamins (Duchefa, Haarlem, Netherlands) $1 \%(w / v)$ Saccharose

The $\mathrm{pH}$ was adjusted to 5.9 with $\mathrm{KOH}$.

$0.7 \%(w / v)$ Micro agar (Duchefa)

The medium was autoclaved for 20 minutes and cooled to about $50^{\circ} \mathrm{C}$ before adding 50 $\mu \mathrm{g} / \mathrm{ml}$ kanamycin for selection. Only in case of freshly transformed seeds $100 \mu \mathrm{g} / \mathrm{ml}$ cefotaxim was added to inhibit the growth of Agrobacterium tumefaciens.

\subsubsection{Cultivation of Arabidopsis on soil}

Seeds of Arabidopsis were sown on soil (Fruhstorfer Erde, Industrie-Erdenwerk Archut, Lauterbach-Wallenrod) or seedlings were transferred from MS-plates to the soil and grown 
at $22^{\circ} \mathrm{C}$ with light intensity of $120 \mu \mathrm{mol} / \mathrm{m}^{2} \mathrm{~s}$ in $16 / 8 \mathrm{~h}$ light/dark cycle (long day), in $60 \%$ humidity.

\subsubsection{Transformation of Arabidopsis with Agrobacterium tumefaciens}

Floral dip is a method for Agrobacterium tumefaciens-mediated transformation of Arabidopsis thaliana (Clough and Bent, 1998). Agrobacterium is capable of transferring small segments of DNA, called T-DNA (transfer-DNA) into the plant cell. The DNA fragment is subsequently incorporated into the genome of the plant. This system can be utilized to transfer also foreign genes into the plant genome by incorporating their sequence into the T-DNA plasmid of Agrobacterium.

Arabidopsis plants were grown as described (2.4.3) to flowering stage. The first bolts were clipped to encourage the proliferation of many secondary bolts. Plants were ready for transformation 4 to 6 days after clipping. Optimal plants have a large number of unopened floral bud clusters and only a few fertilized siliques.

$400 \mathrm{ml}$ of LB medium supplemented with kanamycin $(50 \mu \mathrm{g} / \mathrm{ml})$ and rifampicin (50 $\mu \mathrm{g} / \mathrm{ml}$ ) were inoculated with $4 \mathrm{ml}$ of overnight cultured freshly transformed Agrobacterium cells (2.6.14.2). Cultures were grown for 18 to 24 hours at $28^{\circ} \mathrm{C}$ under shaking at $220 \mathrm{rpm}$. The cells were harvested by centrifugation at $1700 \times g$ and resuspended in $5 \%(\mathrm{w} / \mathrm{v})$ sucrose solution to a final $\mathrm{OD}_{600}$ of approximately 0.8 . Before dipping the plants, Silwet-77 (General Electric Sarl, Antwerpen, Belgium) was added to a final concentration of $0.02 \%$ (v/v) and mixed well. The inflorescences of plants were dipped into the Agrobacterium suspension for 3 to $5 \mathrm{sec}$ with gentle agitation. Afterwards dipped plants were placed in a plastic tray and covered with a clear-plastic dome to maintain high humidity. Domes were removed $24 \mathrm{~h}$ after the treatment and plants were grown for further 4 to 6 weeks until siliques became brown and dry. Seeds were harvested and were stored at $20^{\circ} \mathrm{C}$ in the presence of silica gel for desiccation. Afterwards, seeds were either sterilized and plated on MS-media supplemented with kanamycin for the selection (2.4.1-2) or sown directly to the soil (2.4.3). Pots with seeds were then placed to $4^{\circ} \mathrm{C}$ for 2 to 4 days to break dormancy. 


\subsection{Insect cells}

\subsubsection{Cell line}

Sf9 cell line (Invitrogen, Karlsruhe) was used for transfection, purification, and amplification of recombinant virus as well as for expression of recombinant proteins. Sf9 cells are spherical with some granular appearance and have regular size. They can be grown in a monolayer and in suspension cultures with a doubling time of 72 hours. For culturing the insect cells and for protein expression with the Baculovirus Expression system protocols provided by Invitrogen were followed, unless otherwise stated.

\subsubsection{Bac-to-Bac Baculovirus Expression System}

Bac-to-Bac Baculovirus Expression System (Invitrogen) provides a method to generate recombinant baculoviruses which can be used to infect insect cells for expression of the recombinant protein of interest. The gene of interest is cloned into a donor plasmid pFastBac, which is then transformed into DH10Bac competent E. coli cells containing a baculovirus shuttle vector (bacmid) with a mini-att $\operatorname{Tn} 7$ target site and a helper plasmid. The gene of interest is inserted into the bacmid DNA by site-specific transposition between mini-Tn7 element on pFastBac vector and mini-att $\operatorname{Tn} 7$ target site on the bacmid. Recombinant bacmid DNA is isolated from selected clones and transfected into insect cells to generate a recombinant baculovirus. The baculoviral stock is amplified then and used to infect insect cells for protein expression.

\subsubsection{Cell culture}

All handling of insect cell lines was carried out under sterile conditions in a laminar flow hood. Only disposable pipettes and culture flasks were used. Cells were grown in adherent cultures in $75 \mathrm{~cm}^{2}$ (T-75) flasks in serum-free media Sf-900 II SFM (Invitrogen) at $27^{\circ} \mathrm{C}$. Fresh culture medium was equilibrated to $27^{\circ} \mathrm{C}$ before use. Cells were subcultured by sloughing when they formed a single layer over the entire surface area available for growth, so called confluent monolayer. In detail, old medium containing floating cells was removed with a Pasteur's pipette and $15 \mathrm{ml}$ of fresh medium were added to the flask. Cells 
were dislodged from the surface by gently streaming medium over them. Cells suspension was split to two fresh T-75 flasks and $7.5 \mathrm{ml}$ of medium were added to each of them. Cells were evenly distributed over a surface by rocking the flask forward and backward and side to side. The flasks were placed in a $27^{\circ} \mathrm{C}$ incubator for $20 \mathrm{~min}$ to allow cells to attach. Afterwards, the medium with floating cell was removed and $15 \mathrm{ml}$ of fresh medium were added to the cultures.

Before diluting cells to a certain density they were counted using a hemacytometer and an inverted microscope with 10-times magnification. The same magnification was used to assess cell viability, based on cell appearance. Cell viability should be at least $95 \%$ for healthy cultures.

\subsubsection{Culture initiation from frozen stocks}

Cells were thawed at $37^{\circ} \mathrm{C}$ and immediately transferred to $50 \mathrm{ml}$ Sf-900 II SFM medium. After 5 min centrifugation at $500 \mathrm{x} g$ at RT the supernatant was removed and the pellet was resuspended in $5 \mathrm{ml}$ of fresh Sf-900 II SFM medium and transferred to a $25 \mathrm{~cm}^{2}$ (T-25) cell culture flask. The flask was placed in a $27^{\circ} \mathrm{C}$ incubator for $10 \mathrm{~min}$ for the purpose of allowing the cells to attach. Afterwards the medium containing cell debris and unhealthy cells was removed with a Pasteur's pipette and the cells which adhered were fed with $5 \mathrm{ml}$ of fresh medium. The medium was changed again after 24 hours and the cells were incubated until they formed a confluent monolayer. Once the monolayer was formed the cells were subcultured and growth was continued in T-75 flasks (2.5.3).

\subsubsection{Preparation of frozen stocks}

Cells were dislodged from a confluent monolayer by sloughing and they were counted by using a hemacytometer. The cells were spun down at $500 \times \mathrm{g}$ for $10 \mathrm{~min}$ at RT and the supernatant was removed. The cells were resuspended in freezing medium containing $60 \%$ (v/v) Grace's Insect Medium (Invitrogen), 30\% (v/v) Fetal Bovine Serum (Invitrogen) and $10 \%(\mathrm{v} / \mathrm{v})$ DMSO to obtain a density of $1 \times 10^{7}$ cells $/ \mathrm{ml} .1 \mathrm{ml}$ aliquots of cells suspension were transferred to sterile cryogen vials and placed at $-20^{\circ} \mathrm{C}$ for 1 hour and then transferred to $-80^{\circ} \mathrm{C}$ for ca. 36 hours. Finally stocks were stored in liquid nitrogen. 


\subsubsection{Transfection of insect cells}

The transfection of insect cells was achieved by adopting a cationic liposome-mediated method employing Cellfectin Reagent (Invitrogen). In a 6-well cell culture plate 9x10 cells were seeded per well in $2 \mathrm{ml}$ of Sf-900 II SFM medium. Subsequently the cells were allowed to attach at $27^{\circ} \mathrm{C}$ for one hour. In a microcentrifuge tube $2 \mu \mathrm{g}$ of purified bacmid DNA were diluted in $100 \mu 1$ of unsupplemented Grace's Insect Medium. In a separate tube $9 \mu 1$ of Cellfectin Reagent were diluted in $100 \mu 1$ of the same medium. Both solutions were combined, mixed gently by inversion and incubated at RT for $45 \mathrm{~min}$. The medium was removed from the cells and the cells were washed once with $2 \mathrm{ml}$ of unsupplemented Grace's Insect Medium. In parallel $0.8 \mathrm{ml}$ of unsupplemented Grace's Insect Medium were added to the tube containing DNA/lipid complexes and mixed gently. The whole volume of the tube was then added to the well containing the cells. For each construct two 6-well plates were prepared. The cells were incubated for $5 \mathrm{~h}$ at $27^{\circ} \mathrm{C}$. Afterwards DNA/lipid complexes were removed and $2.5 \mathrm{ml}$ of Sf-900 II SFM medium containing 50 units $/ \mathrm{ml}$ penicillin and $50 \mu \mathrm{g} / \mathrm{ml}$ streptomycin were added. The cells were incubated at $27^{\circ} \mathrm{C}$ until altered cell morphology indicated a successful viral infection (7 days). At this step the P1 viral stock was isolated.

\subsubsection{Viral stock isolation}

The medium containing virus (2.5.6) was collected from each well and transferred to a 15 $\mathrm{ml}$ falcon tube. Cells and large debris were removed by 5 min centrifugation at $500 \mathrm{x} g$ at RT. The clarified supernatant was transferred to a fresh $15 \mathrm{ml}$ falcon tube and fetal bovine serum was added to a final concentration of $2 \%(\mathrm{v} / \mathrm{v})$. Viral stocks were stored at $4{ }^{\circ} \mathrm{C}$ protected from light.

\subsubsection{Viral plaque assay}

In order to determine the titer of a baculoviral stock, a plaque assay was performed. The protocol provided by Invitrogen was combined with a corresponding one of Novagen to simplify the procedure and lower costs of the experiment. In detail, cells were diluted to $5 \times 10^{5}$ cells $/ \mathrm{ml}$ in Sf-900 II SFM medium and $2 \mathrm{ml}$ of cell suspension were added into each well of 6 -well plates. Cells attached at 50 to $60 \%$ confluency after one hour incubation. Sf- 
900 Plaquing Medium was prepared by combining $30 \mathrm{ml}$ of 1.3x Sf-900 II SFM medium with $10 \mathrm{ml}$ of autoclaved 4\% (w/v) Top Vision LM GQ Agarose (Fermentas) and penicillin and streptomycin were added to final concentrations of $50 \mathrm{U} / \mathrm{ml}$ and $50 \mu \mathrm{g} / \mathrm{ml}$, respectively. The medium was placed in a water bath at $40^{\circ} \mathrm{C}$ until use. A serial dilution $\left(10^{-1}\right.$ to $\left.10^{-7}\right)$ of viral stock was prepared by diluting $100 \mu \mathrm{l}$ of viral stock (or of previous dilution step) in $900 \mu \mathrm{l}$ of Sf-900 II SFM medium in microcentrifuge tubes. Dilutions $10^{-5}$, $10^{-6}, 10^{-7}$ were used to determine the titer. Medium was removed from each well before $200 \mu 1$ of viral dilution were added immediately to the center of the well. Each sample was duplicated. The plates were incubated on a leveled surface under a laminar flow hood for one hour at RT. Every 5 to 10 minutes the liquid was gently rocked across the cells to prevent the cell layer from drying. Afterwards $2 \mathrm{ml}$ of Sf-900 Plaquing Medium cooled to $37^{\circ} \mathrm{C}$ was added to each well. After $20 \mathrm{~min}$, when the agarose was solidified, $1 \mathrm{ml}$ of Sf900 II SFM medium containing $50 \mathrm{U} / \mathrm{ml}$ penicillin and $50 \mu \mathrm{g} / \mathrm{ml}$ streptomycin was added to each well with agarose overlay to prevent the dishes from drying out. The plates were incubated at $27^{\circ} \mathrm{C}$ until visible plaques were formed ( 7 to 8 days). The plaques were counted and the titer (plaque forming units $(\mathrm{pfu}) / \mathrm{ml}$ ) was calculated according to the following formula:

titer $(p f u / m l)=$ number of plaques $\times$ dilution factor $\times \frac{1}{m l \text { of inoculum } / \text { well }}$

\subsubsection{Viral stock amplification}

The P1 viral stock is a low-titer stock. The titers of P1 stocks obtained in this study ranged from $1.5 \times 10^{6}$ to $5 \times 10^{6} \mathrm{pfu} / \mathrm{ml}$. Those stocks were used to generate high-titer P2 stocks which are necessary to achieve protein expression in subsequent experiments.

$1 \times 10^{6}$ cells were seeded to each well in 6-well plates. The medium was removed and cells were infected at multiplicity of infection (MOI) of 0.4. This value describes the number of virus particles per cell. To calculate which volume of P1 stock should be added to the cells to obtain the desired MOI, the following formula was used:

inoculum required $(\mathrm{ml})=\frac{\text { MOI }(\mathrm{pfu} / \mathrm{cell}) \times \text { number of cells }}{\text { titer of viral stock }(\mathrm{pfu} / \mathrm{ml})}$

Sf-900 II SFM medium was added then to each well to obtain a final volume of $2 \mathrm{ml}$. The plates were incubated at $27^{\circ} \mathrm{C}$ for 72 to 96 hours until carful inspection revealed signs of infection. At this step the P2 viral stock was isolated. The titers of P2 stocks obtained in 
this study ranged from $1.5 \times 10^{8}$ to $3.5 \times 10^{8}$. In established protocols titers ranging from $1 \times 10^{7}$ to $1 \times 10^{8} \mathrm{pfu} / \mathrm{ml}$ are reported to be necessary for successful expression experiments. The P2 baculoviral stocks were used to infect insect cells for expression of recombinant protein (2.7.1).

\subsection{Molecular cloning}

\subsubsection{Plasmids}

\begin{tabular}{ll}
\hline Plasmid & Selection \\
\hline pGEM-T (Promega) & Carbenicillin \\
pUC19 (Fermentas) & Carbenicillin \\
pFastBac HT (Invitrogen) & Carbenicillin \\
pBI101.3 (Clontech) & Kanamycin \\
pCAT EYFP & Carbenicillin \\
\hline
\end{tabular}

\subsubsection{Plasmid DNA isolation}

Plasmid DNA was isolated from E. coli cells using Nucleo Spin Plasmid Kit (MachereyNagel, Düren) according to manufacturer's instructions. Alternatively a less time consuming method, called "boiling preps" (Riggs and McLachlan, 1986), was used. However the purity of DNA obtained with this method was not sufficient for DNA sequencing. $3 \mathrm{ml}$ overnight cultures were centrifuged at $11000 \mathrm{x} g$ for $1 \mathrm{~min}$. The pellet was resuspended in $70 \mu \mathrm{l}$ of lysis buffer, heated for $1 \mathrm{~min}$ at $100^{\circ} \mathrm{C}$, and then incubated on ice for $5 \mathrm{~min}$. The mixture was centrifuged at $16000 \mathrm{x} g$ for $10 \mathrm{~min}$. The supernatant was recovered and $5 \mu 1$ of it was used for digestion by restriction enzymes.

$\begin{array}{lll}\text { Lysis buffer: } & 10 \mathrm{mM} & \text { Tris-HCl, } \mathrm{pH} 8.0 \\ 1 \mathrm{mM} & \text { EDTA, } \mathrm{pH} 8.0 \\ 15 \% & \text { saccharose } \\ 2 \mathrm{mg} / \mathrm{ml} & \text { lysozyme } \\ 0.2 \mathrm{mg} / \mathrm{ml} & \text { RNase } \\ 0.1 \mathrm{mg} / \mathrm{ml} & \text { BSA }\end{array}$




\subsubsection{Cyanobacteria genomic DNA isolation}

The DNA was isolated from $50 \mathrm{ml}$ cultures according to the method described previously (Porter, 1988). $12 \mathrm{~h}$ before the preparation carbenicillin was added to a final concentration $200 \mu \mathrm{g} / \mathrm{ml}$. The cells were harvested by centrifugation at $3000 \times \mathrm{g}$ and resuspended in 2.5 $\mathrm{ml}$ of lysis buffer. After two freeze-thaw steps $25 \mathrm{mg}$ of lysosyme were added. The lysate was mixed and incubated for $45 \mathrm{~min}$ at $37{ }^{\circ} \mathrm{C}$. Afterwards SDS was added to a final concentration of $1 \%(\mathrm{v} / \mathrm{v})$ and proteinase $\mathrm{K}$ to a final concentration of $100 \mu \mathrm{g} / \mathrm{ml}$. After overnight incubation at $50^{\circ} \mathrm{C}$ three phenol:chloroform $(2: 1)$ extractions, followed by three chloroform extractions, were carried out. Subsequently 1/3 volume of $10.5 \mathrm{M}$ ammonium acetate and 2 volumes of isopropanol were added to the aqueous phase from the final chloroform extraction to precipitate DNA. After centrifugation for $10 \mathrm{~min}$ at $16000 \mathrm{x} \mathrm{g}$, at $4^{\circ}$, the pellet was washed once with $70 \%$ ethanol, then dried at $37^{\circ} \mathrm{C}$ and resuspended in $100 \mu 1$ of sterile water.

Lysis buffer:

$$
\begin{aligned}
& 50 \mathrm{mM} \text { Tris- } \mathrm{HCl}, \mathrm{pH} 8.0 \\
& 25 \% \text { saccharose } \\
& 100 \mathrm{mM} \text { EDTA }
\end{aligned}
$$

\subsubsection{Polymerase chain reaction (PCR)}

The polymerase chain reaction enables the amplification of specific DNA sequences. The method is based on a cyclic repetition of thermal DNA denaturation, hybridization with primers and elongation by thermostable polymerase which results in exponential increase of the desired sequence(Mullis and Faloona, 1987). The reactions were carried out in thermocyclers from Eppendorf (Hamburg). The components and the conditions of PCR were as described below:

Proof reading polymerase: PfuUltra ${ }^{\mathrm{TM}}$ High-Fidelity Polymerase (Stratagene, La Jolla, USA)

Non proof reading polymerases: $\quad$ Takara Ex Taq ${ }^{\mathrm{TM}}$ DNA Polymerase (TAKARA BIO) Tfl-PolymeraseTM (Biozym, Hess. Oldendorf) 
Standard reaction mixtures:

PfuUltra

$1 \mu 1$ DNA (1-100 ng/ $\mu 1)$

$5 \mu$ l buffer (10x)

$1 \mu 1 \mathrm{dNTP}(10 \mathrm{mM})$

$1 \mu \mathrm{l}$ forward primer $(10 \mu \mathrm{M})$

$1 \mu 1$ reverse primer $(10 \mu \mathrm{M})$

$1 \mu 1$ PfuUltra Polymerase

$40 \mu 1$ sterile water

Tfl

$1 \mu 1$ DNA $(1-100 \mathrm{ng} / \mu \mathrm{l})$

$2.5 \mu 1$ buffer $(25 \mathrm{x})$

$5 \mu 1 \mathrm{MgCl}_{2}(25 \mathrm{mM})$

$4 \mu 1 \mathrm{dNTP}(2.5 \mathrm{mM})$

$1 \mu \mathrm{l}$ forward primer $(10 \mu \mathrm{M})$

$1 \mu 1$ reverse primer $(10 \mu \mathrm{M})$

$1 \mu 1$ Tfl Polymerase

$34.5 \mu 1$ sterile water

Standard PCR program:

temperature

$95^{\circ} \mathrm{C}$

$95^{\circ} \mathrm{C}$

$50-68^{\circ} \mathrm{C}$

$72^{\circ} \mathrm{C}$

$72{ }^{\circ} \mathrm{C}$
ExTaq

$1 \mu 1$ genomic DNA (100 ng/ $\mu \mathrm{l})$

$5 \mu 1$ buffer (10x)

$4 \mu \mathrm{dNTP}(2.5 \mathrm{mM})$

$1 \mu \mathrm{l}$ forward primer $(10 \mu \mathrm{M})$

$1 \mu 1$ reverse primer $(10 \mu \mathrm{M})$

$0.5 \mu 1$ ExTaq Polymerase

$37.5 \mu 1$ sterile water 


\subsubsection{PCR-based site directed mutagenesis}

The QuikChange II Site-Directed Mutagenesis Kit (Stratagene, USA) was used to introduce point mutations. The basic procedure utilizes a supercoiled double-stranded DNA (dsDNA) vector containing an insert of interest and two synthetic oligonucleotide primers, both encoding the desired mutation. The oligonucleotide primers, each complementary to opposite strands of the vector, are extended during temperature cycling by PfuUltra HF DNA polymerase, without primer displacement. Extension of the oligonucleotide primers generates a mutated plasmid containing staggered nicks. Following temperature cycling, DpnI is added to the PCR reactions to digest the parental DNA and to select for those molecules containing the mutation. DNA isolated from most E. coli strains is dam methylated and therefore susceptible to DpnI digestion. The nicked vector DNA with the desired mutations is then transformed into XLI blue E. coli competent cells.

Reaction mixture:

$1 \mu 1 \quad 25 \mathrm{ng} / \mu \mathrm{l}$ template DNA

$1.25 \mu 1 \quad 100 \mathrm{ng} / \mu 1$ forward primer

$1.25 \mu \mathrm{l} \quad 100 \mathrm{ng} / \mu \mathrm{l}$ reverse primer

$1 \mu \mathrm{l} \quad 10 \mathrm{mM}$ dNTP mix

$5 \mu 1 \quad 10 x$ reaction buffer

$1 \mu \mathrm{l} \quad 2.5 \mathrm{U} / \mu 1$ PfuUltra ${ }^{\mathrm{TM}}$ High-Fidelity Polymerase

$39.5 \mu 1 \quad$ sterile water

Cycling parameters for the QuickChange II Site-Directed Mutagenesis method:

temperature duration

$96^{\circ} \mathrm{C} \quad 2 \mathrm{~min}$

$\left.\begin{array}{ll}94^{\circ} \mathrm{C} & 30 \mathrm{sec} \\ 55^{\circ} \mathrm{C} & 25 \mathrm{sec} \\ 72^{\circ} \mathrm{C} & 5 \mathrm{~min} 20 \mathrm{sec}\end{array}\right\} 18$ cycles

$72^{\circ} \mathrm{C} \quad 10 \mathrm{~min}$ 


\subsubsection{Primers}

Single stranded oligonucleotides (primers) were used to amplify DNA fragments. Forward and reverse primers are complementary respectively to the beginning and the end of the desired DNA sequence and contain a free 3'OH terminus to enable the polymerase to start DNA synthesis. The primers were ordered from Biomers (Ulm) or Invitrogen (Karlsruhe).

\subsubsection{Estimation of the concentration of nucleic acids}

The concentration of DNA solutions was estimated by measuring the absorbance at $260 \mathrm{~nm}$ (Ultrospec 1100 pro, Amersham Bioscience, Freiburg). A solution containing $50 \mu \mathrm{g}$ per ml of double strand DNA has an absorbance of 1.0 at a wave length of $260 \mathrm{~nm}$.

\subsubsection{Agarose gel electrophoresis, gel staining and documentation}

Agarose gel electrophoresis was used to separate DNA fragments produced by PCR or restriction digestion. All gels were prepared by dissolving 1\% (w/v) agarose in TAE buffer. DNA samples were mixed with 1/6 volume loading dye solution (Fermentas, St.Leon-Rot) before loading into wells of the gel. $4 \mu \mathrm{l}$ of $1 \mathrm{~kb}$ DNA Ladder (Fermentas, St.Leon-Rot) was loaded to at least one well in each gel and was used as a size marker. The electrophoresis proceeded in a horizontal apparatus at $100 \mathrm{~V}$ for 30 to $45 \mathrm{~min}$ with $1 \times \mathrm{TAE}$ as a running buffer. Afterwards gels were submerged for ca. $20 \mathrm{~min}$ in an aqueous solution containing $25 \mu \mathrm{g} / \mathrm{ml}$ of ethidium bromide (EtBr) and then washed briefly in a water bath to remove excess of the dye. DNA bands were visualized and photographed under UV light (312nm) using a transilluminator (Raytest IDA; Herolab, Wiesloch).

50×TAE Buffer: $\quad 242 \mathrm{~g} \quad$ Tris base

$\begin{array}{ll}57.1 \mathrm{ml} & \text { glacial acetic acid } \\ 100 \mathrm{ml} & 0.5 \mathrm{M} \mathrm{EDTA}\end{array}$

filled up with distilled water to $1000 \mathrm{ml}, \mathrm{pH}$ adjusted to 8.5 


\subsubsection{DNA isolation from gel}

DNA fragments were isolated from the gel using GFX PCR DNA and Gel Band Purification Kit (GE Healthcare, Freiburg) according to manufacturer's protocol.

\subsubsection{Restriction digestion}

Restriction enzymes recognize a specific sequence of nucleotides and produce a cut of both strands in double stranded DNA. For analytical purposes about $0.5 \mu \mathrm{g}$ of DNA were digested with 1 to 2 units of restriction enzyme (MBI Fermentas, St.Leon-Rot). For preparative purposes 1 to $3 \mu \mathrm{g}$ of DNA were subjected to restriction digestion. The reaction was performed according to the protocol provided by the manufacturer.

\subsubsection{Dephosphorylation}

The enzyme Antarctic Phosphatase (New England Biolabs, Frankfurt) catalyzes the removal of 5'phosphate groups from DNA ends. Following restriction digestion vectors after were subjected to dephosphorylation in order to reduce self-ligation. The reaction was performed according to the protocol provided by the manufacturer.

\subsubsection{Ligation}

The ligation reaction was used to insert DNA fragments into plasmids. T4 DNA Ligase (Fermentas, St.Leon-Rot) was employed to establish covalent phosphodiester bonds between 3'hydroxyl and 5'phosphate ends of double strand DNA fragments with blunt or cohesive-end termini. The reaction was performed at $16^{\circ} \mathrm{C}$ or at RT overnight. The reaction mixture $(10 \mu \mathrm{l})$ contained $1 \mu \mathrm{l}(1 \mathrm{U} / \mu \mathrm{l})$ of T4 DNA Ligase, $1 \mu \mathrm{l}$ of $10 \mathrm{x}$ ligase buffer (Fermentas, ST.Leon-Rot) and 1 to $10 \mathrm{ng} / \mu \mathrm{l}$ of DNA. The molar ratio of insert DNA termini to vector DNA varied from 10:1 to $3: 1$.

PCR products were cloned into the pGEM-T vector (pGEM-T-Vector System II Kit, Promega, Madison, USA) according to protocol provided by the manufacturer. The pGEM-T vector contains overhanging 3'-Ts. To render the ligation effectively, 3 'terminal adenine was added to PCR products via an A-tailing reaction. The reaction mixture 
contained $7 \mu \mathrm{l}$ of PCR product, $1 \mu 1$ 1U/ $\mu 1$ Tfl-polymerase (Biozym, Hess. Oldendorf), 0.5 $\mu 120 \times$ TFL buffer, $1 \mu 125 \mathrm{mM} \mathrm{MgCl}_{2}, 0.5 \mu 14 \mathrm{mM}$ dATP. The reaction was performed for $15 \mathrm{~min}$ at $70^{\circ} \mathrm{C}$.

Ligation products were used for transformation of $E$. coli cells (2.6.14.1).

\subsubsection{Sequencing}

DNA was sequenced according to method described previously (Sanger et al., 1977). The sequencing reaction was carried out with ABI Prism BigDye Terminator Cycle Sequencing Ready Reaction Kit v1.1 (Applied Biosystems, Foster City, CA, USA)

Sequencing reaction mixture:

$\begin{array}{ll}1 \mu \mathrm{l} & \text { DNA }(\sim 250 \mathrm{ng}) \\ 2 \mu \mathrm{l} & \text { Ready Reaction Mix } \\ 1 \mu \mathrm{l} & \text { primer }(10 \mu \mathrm{M}) \\ 6 \mu \mathrm{l} & \text { distilled water }\end{array}$

Sequencing program: $\quad 96^{\circ} \mathrm{C} 1 \mathrm{~min}$

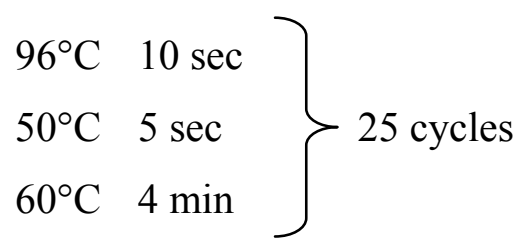

Products of the sequencing reaction were purified according to the following procedure: $2.5 \mu 1125 \mathrm{mM}$ EDTA and $30 \mu 1$ 100\% ethanol were added, the mixture was incubated for $15 \mathrm{~min}$ at RT and then centrifuged for $15 \mathrm{~min}$ at $16000 \times \mathrm{g}$ at $4^{\circ} \mathrm{C}$. Supernatant was removed and $30 \mu 1$ of $70 \%$ ethanol were added. The centrifugation was repeated as above and the pellet was dried for $1 \mathrm{~min}$ at $90^{\circ} \mathrm{C}$ and resuspended in $30 \mu 1$ of distilled water. The samples were sequenced using an ABI PRISM 3100 Genetic Analyzer (Applied Biosystems, Foster City, USA). 


\subsubsection{Preparation of competent cells and transformation}

\subsubsection{Escherichia coli}

The competent E. coli cells were prepared according to the described method (Inoue et al., 1990). $1 \mathrm{ml}$ of an overnight culture was inoculated in $100 \mathrm{ml}$ of SOB medium in a $500 \mathrm{ml}$ flask and grown with vigorous shaking at $37^{\circ} \mathrm{C}$ for $2 \mathrm{~h}$, the temperature was then lowered to $16^{\circ} \mathrm{C}$. When the $\mathrm{OD}_{600}$ reached 0.4 the flask was placed on ice for $10 \mathrm{~min}$, before the cells were harvested by centrifugation at $2000 \mathrm{x} g$ for $10 \mathrm{~min}$ at $4^{\circ} \mathrm{C}$. The supernatant was removed, the cells were resuspended gently in $30 \mathrm{ml}$ of ice-cold TB-buffer and incubated on ice for $10 \mathrm{~min}$. The cells were harvested again by centrifugation at $1000 \mathrm{x} g$ and the pellet was resuspended gently in $8 \mathrm{ml}$ of ice-cold TB-buffer. $560 \mu 1$ of DMSO were added and the cells were incubated for additional $10 \mathrm{~min}$ on ice. Afterwards $200 \mu \mathrm{l}$ aliquots were transferred to pre-cooled microcentrifuge tubes and frozen immediately in liquid nitrogen.

For transformation the competent cells were thawed slowly on ice and $5 \mu 1$ of the ligation reaction or ca. $100 \mathrm{ng}$ of plasmid DNA were added. Tubes were incubated on ice for 20 min. After heat-shock at $42^{\circ} \mathrm{C}$ for $50 \mathrm{sec}$, the tubes were returned to ice for $1 \mathrm{~min}$ and 800 $\mu 1$ of pre-warmed SOB were added. The cells were incubated at $37^{\circ} \mathrm{C}$ for $45 \mathrm{~min}$. Subsequently they were plated onto selective LB-plates and incubated overnight at $37^{\circ} \mathrm{C}$.

$\begin{array}{lll}\text { TB-buffer: } & 10 \mathrm{mM} & \text { PIPES } \\ & 15 \mathrm{mM} & \mathrm{CaCl}_{2} \\ & 250 \mathrm{mM} & \mathrm{KCl} \\ & 55 \mathrm{mM} & \mathrm{MnCl}_{2}\end{array}$

$\mathrm{MnCl}_{2}$ was added after adjusting $\mathrm{pH}$ to 6.7 with $\mathrm{KOH}$

Buffer was sterile filtered.

\subsubsection{Agrobacterium tumefaciens}

Starter cultures of Agrobacterium tumefaciens EHA105-cells (Hood et al., 1993) were grown overnight in $5 \mathrm{ml} \mathrm{LB}$ medium at $28^{\circ} \mathrm{C}$ under shaking at $220 \mathrm{rpm}$. Next day $60 \mathrm{ml}$ LB were inoculated with $0.5 \mathrm{ml}$ of starter culture and incubated at $28^{\circ} \mathrm{C}$ under shaking at 225-250 rpm overnight. The culture was cooled on ice for $10 \mathrm{~min}$. Afterwards the cells were harvested by centrifugation at $3500 \mathrm{xg}$ for $10 \mathrm{~min}$ at $4^{\circ} \mathrm{C}$, supernatant was removed and the pellet was rinsed with ice-cold $5 \mathrm{ml} 20 \mathrm{mM} \mathrm{CaCl}_{2}$ and centrifuged briefly again. 
The cells were resuspended in $1 \mathrm{ml} 20 \mathrm{mM} \mathrm{CaCl}_{2}, 150 \mu \mathrm{l}$ aliquots were frozen in liquid nitrogen and placed in $-80^{\circ} \mathrm{C}$ for storage.

For transformation $1 \mu \mathrm{g}$ of plasmid was added directly onto frozen cells. The cells were thawed at $37^{\circ} \mathrm{C}$, flicked several times to mix and frozen in liquid nitrogen. After 5 min incubation the cells were removed from nitrogen and thawed on the bench top. Thawed cells were transferred to $1 \mathrm{ml} \mathrm{LB}$ in $20 \mathrm{ml}$ sterile tube and incubated at $28^{\circ} \mathrm{C}$ with $220 \mathrm{rpm}$ shaking. After 4 hours of incubation the cells were plated on LB plates containing appropriate antibiotics and incubated at $28^{\circ} \mathrm{C}$. Colonies were visible after two days.

\subsubsection{Cyanobacteria}

The strains used in this study are naturally transformable. Cells were transformed according to the method described previously (Williams, 1988). In detail, cells of $2 \mathrm{ml}$ culture (exponential or early stationary phase) were collected by centrifugation at $2000 \mathrm{x} g$ and resuspended in $2 \mathrm{ml}$ of fresh BG11 medium. 1-2 $\mu \mathrm{g}$ of plasmid DNA were added to cells suspension and the culture was incubated for 3 to 4 hours on platform shaker at RT in light conditions. Afterwards cells were centrifuged again and resuspended in $200 \mu \mathrm{l}$ of BG11 medium. For the initial selection of transformants the DNA/cells mixture was plated on BG11 solid medium $(50 \mathrm{ml})$ and one day later an appropriate antibiotic $(0.45 \mathrm{mg}$ kanamycin or $0.2 \mathrm{mg}$ chloramphenicol) was added into three holes made in the agar. Single colonies were visible after about 10 days. Homozygous mutants were obtained by successive streaking on BG11 plates containing the antibiotic of choice.

\subsubsection{Cloning strategies utilized in this study}

\subsubsection{Generation of aas mutants in cyanobacteria}

The aas mutants in the background of Synechocystis sp. PCC 6803 and Synechococcus elongatus PCC 7942 were created by replacing part of the coding region with a kanamycin resistance cassette via homologous recombination. The constructs were prepared as follows: The ORF of slr1609 was amplified from genomic DNA of Synechocystis sp. PCC 6803 with the specific primer pair GGAATTCATATGGACAGTGGCCATGGCGCT (MF50) and AGAATTCTCGAGAAACATTTCGTCAATTAAATGTTG (MF51) and was 
subsequently cloned into SmaI site of pUC19 vector. A 230 bp fragment was excised from the gene by digestion with NaeI and SmaI and replaced by a kanamycin resistance cassette released from the vector pKRP11 by SmaI. An analogous strategy was applied to prepare the construct for disruption of a homologue gene from Synechococcus elongatus PCC 7942. Genomic DNA was used as a template to amplify an ORF together with its $957 \mathrm{bp}$ upstream and 645 bp downstream region using primers ACACGCATGCTTAAATGACTTCTTGTGGAAAG (Elo_kof1_Sph) and AGAGATCTAGAGACGGCACCTCAACTCCTAGGT (Elokor_5520). The obtained PCR product was cloned into pGEM-T and, after removing a $1704 \mathrm{bp}$ fragment of the ORF by digestion with EcoRV and SmaI, the kanamycin resistance cassette was inserted into the vector. The resulting plasmids were used for cell transformation (2.6.14.3).

\subsubsection{Complementation of Synechocystis sp. PCC 6803 aas knockout with aas from Synechococcus elongatus 7942}

A variant of the construct for generation Synechocystis sp. PCC 6803 aas knockout mutant, in which not a kanamycin but a chloramphenicol cassette had been introduced to disrupt the gene, was modified to obtain the complementation construct. Fragments of Synechocystis sp. PCC 6803 DNA, flanking the chloramphenicol cassette, served as borders for homologous recombination. In one of the flanking fragments 25 bps distant from the chloramphenicol cassette $3 \mathrm{bps}$, were changed (2.6.5) in order to introduce an EagI restriction site. A 3209 bps fragment, including aas ORF from Synechococcus elongatus 7942 plus promoter and terminator, was amplified by PCR with forward and reverse primers, introducing NotI restriction sites. The PCR fragment was cloned first into pGEM-T vector and then transferred into the newly created EagI restriction site of the complementation construct. The resulting vector was used to transform Synechocystis sp. PCC 6803 aas knockout cells.

The primers used for the fragment of Synechococcus elongatus 7942 DNA were:

ACAGCGGCCGCAAGTCAGCTCTTCACCCCAG (eloProNot2f)

ACAGCGGCCGCGGATGCACTGGATTGGCAC (eloProNot3r)

The primers used for PCR-based site directed mutagenesis were:

GATGAACTACACCAGCGGCCGCCATTTCAAGGG (SynQC3221-23fEag)

CCCTTGAAATGGCGGCCGCTGGTGTAGTTCATC (SynQC3221-23rEag) 


\subsubsection{Cloning of Arabidopsis AAEs into pFastBac vector}

A uniform strategy was used to clone two variants of $A A E 15$ and $A A E 16$ in frame with the $\mathrm{N}$-terminal 6xHis tag of the pFastBac ${ }^{\mathrm{TM}} \mathrm{HT}$. Each ORF was amplified by PCR using a forward primer introducing a NcoI restriction site and a reverse primer including the stop codon introducing a NotI restriction site. For each gene two variants were cloned. The first clone corresponds to the complete ORF including the native start codon. For the second clone the predicted plastidial targeting signal was removed leading to a $\mathrm{N}$-terminal deletion of $195 \mathrm{bp}$ and $141 \mathrm{bp}$ for $A A E 15$ and $A A E 16$, respectively.

The primers used for $A A E 15$ were:

AGATCCATGGAAATTCGTCTGAAACCT (forward 1) (AtFAA1f1), AGTACCATGGCTTGCGAGTCAAAGGAAAAAGAAG (forward 2) (AtFAA1_47Ncof), AGTAGCGGCCGCTTAACTGTAGAGTTGATCAATC (reverse) (AtFAA1NotrStop).

The primers used for $A A E 16$ were:

GAATGACCATGGCTTCAACGTCTCTCGGA (forward 1) (AtFAA2fNco), TCTAGACCATGGCGTGCGAATCCAAGATTCAGGA (forward 2), and CCTCGAGTGCGGCCGCCTACTTGTAGAGTCTTTCTA (reverse) (FAA2StopNotr).

PCR was performed using Pfu polymerase (Stratagene) and PCR products were cloned into pGEMT-vector (Promega, Mannheim). A positive clone of each construct was selected and fully sequenced to verify the absence of PCR-induced mutations. Finally the cDNAs were transferred to pFastBac HT. The vectors were transformed into competent DH10Bac E. coli cells. From positive colonies recombinant bacmid DNA was isolated and used to transfect Sf9 cells.

\subsubsection{Cloning of the promoter sequences of $A A E 15$ and $A A E 16$ into pBI101.3 vector}

For $A A E 15$ two shorter and two longer versions of the promoter were cloned. For amplification of either of the short versions two reverse primers were used, corresponding to the first ATG (rev2) and to the second ATG (rev1).

The primers used for amplification of the shorter fragments were:

AAGCTTAAAGCTGGATTATTCGTATAACTCA (forward) (AtFAA1PromfHind), 
GGATCCTCGTTGAGGAAGAGGCGATGAAGAAG (reverse1) (AtFAA1Promr1Bam), GATGGATCCTTGCAGATAAGATGAAGATGAGGACTG (reverse2) (AtFAA1Promr2Bam).

With these primers fragments of $684 \mathrm{bp}$ and $629 \mathrm{bp}$, respectively, were obtained.

The primers used for amplification of the longer fragments were:

TGCAAGCTTCTGTTCCAAGGACACTCAACCTATAC (forward) (AtFAA1Pf2Hind), GGATCCTCGTTGAGGAAGAGGCGATGAAGAAG (reverse1) (AtFAA1Promr1Bam), GATGGATCCTTGCAGATAAGATGAAGATGAGGACTG (reverse2) (AtFAA1Promr2Bam).

With these primers fragments of $1523 \mathrm{bp}$ and $1469 \mathrm{bp}$, respectively, were obtained.

The primers used for amplification of $A A E 16$ promoter were:

AAGCTTAGAACCGAATCATTCTCCATAACA (forward) (AtFAA2PromfHind), GGATCCGGCTGAGGAGATAAGAGGTTATGA (reverse) (AtFAA2PromrBam). A fragment of $1321 \mathrm{bp}$ was obtained.

Amplified fragments were cloned first into the pGEM-T vector and then transferred to pBI101.3 using HindIII and BamHI restriction sites.

\subsubsection{Generation of pEYFP-AAE fusion constructs}

A $262 \mathrm{bp} \mathrm{N}$-terminal fragment of $A A E 15 \mathrm{ORF}$ and a $214 \mathrm{bp} \mathrm{N}$-terminal fragment of $A A E 16$ ORF were amplified by PCR using forward primer introducing a NcoI restriction site and reverse primer introducing a BspLU restriction site. PCR fragments were cloned first into pGEM-T vector and then transferred to pEYFP vector.

The primers used for $A A E 15$ were:

AGATCCATGGAAATTCGTCTGAAACCT (AtFAA1f1),

GAACATGT CTCCCGAAAACGAGGAGCTTTC (AtFAA1r262BspLU)

The primers used for $A A E 16$ were:

GAATGACCATGGCTTCAACGTCTCTCGGA (AtFAA2fNco), GAACATGT CCCTTGGCAATGATAAGCGTTC (AtFAA2r214BspLU) 


\subsection{Protein analysis}

\subsubsection{Expression of recombinant protein in insect cells}

Cells were dislodged from confluent monolayer in T-75 flask and split to two T-75 flasks. After 10 min medium containing unhealthy cells, which did not attach to the surface, was removed and an appropriate volume of viral stock P2 was added to infect the cells at MOI of 3 (for the formula see: 2.5.9). Flasks were rocked gently to cover the monolayer of cells with the liquid and after 5 min incubation Sf-900 II SFM medium containing $50 \mathrm{U} / \mathrm{ml}$ penicillin and $50 \mu \mathrm{g} / \mathrm{ml}$ streptomycin was added to a final volume of $15 \mathrm{ml}$. Flasks were placed at $27^{\circ} \mathrm{C}$. After 72 hours cells were harvested and washed once with 1xPBS, pH 7.4. Cells were collected by centrifugation at $500 \mathrm{x} g$ and frozen at $-20^{\circ} \mathrm{C}$.

\subsubsection{Isolation and purification of recombinant protein from insect cells}

The cell pellet collected from two T-75 flasks (2.7.1) was resuspended in $1 \mathrm{ml}$ of extraction buffer $(50 \mathrm{mM}$ Tris- $\mathrm{HCl} \mathrm{pH} \mathrm{7.8,} 150 \mathrm{mM} \mathrm{NaCl})$ and sonicated twice for $30 \mathrm{sec}$ (output control 4, 50\% duty cycle) with Branson Sonifer Cell Disruptor B15 (Branson Sonic Power Co., Schwäb-Gmünd). Cell debris was removed by centrifugation at $16000 \mathrm{x} g$ at $4{ }^{\circ} \mathrm{C}$ for $15 \mathrm{~min}$ and the supernatant was centrifuged at $100,000 \times \mathrm{g}$, at $4^{\circ} \mathrm{C}$ for $1 \mathrm{~h}$ in order to isolate a membrane fraction. Initially membranes were resuspended in $150 \mu 1$ of extraction buffer by pipetting to avoid producing foam and an equal volume of solubilization buffer $(50 \mathrm{mM}$ Tris- $\mathrm{HCl} \mathrm{pH} 7.8,150 \mathrm{mM} \mathrm{NaCl}, 4 \%$ (v/v) Triton X-100) was added. To improve the removal of membrane-bound proteins the fraction was incubated on ice under agitation overnight before clarification by centrifugation at $100,000 \mathrm{x} g$ at $4^{\circ} \mathrm{C}$ for $30 \mathrm{~min}$. To purify the expressed protein $800 \mu 1$ of BD TALON Resin were equilibrated with column buffer (50 mM Tris- $\mathrm{HCl} \mathrm{pH} 7.8,150 \mathrm{mM} \mathrm{NaCl}, 2 \%$ (v/v) Triton X-100). The clarified solubilized membrane fraction was applied to the resin and gently agitated at $4^{\circ} \mathrm{C}$ for $4 \mathrm{~h}$ on a platform shaker to allow the polyhistidine-tagged protein to bind to the resin. The resin was transferred to a $5 \mathrm{ml}$ gravity-flow column and washed sequentially with $4 \mathrm{ml}$ of column buffer followed by $4 \mathrm{ml}$ of column buffer containing $20 \mathrm{mM}$ imidazole to remove nonspecifically bound proteins. The target protein was eluted with column buffer containing $100 \mathrm{mM}$ EDTA. Fractions of $200 \mu 1$, containing the polyhistidine-tagged protein, were collected and dialyzed overnight against $400 \mathrm{ml}$ of column buffer at $4{ }^{\circ} \mathrm{C}$. 


\subsubsection{Determination of protein concentration}

Bradford protein assays (Bradford, 1976) were used to determine the protein concentration in the fractions from early steps of preparation. $100 \mu 1$ of protein sample or standard were added to $1.9 \mathrm{ml}$ of Bradford reagent and mixed well. After $10 \mathrm{~min}$ incubation at RT, the absorbance at $595 \mathrm{~nm}$ was measured vs. water or a suitable buffer reference. A standard curve was prepared by measuring the absorbance of the following standards: $0.0 \mu \mathrm{g}, 2.5 \mu \mathrm{g}$, $5 \mu \mathrm{g}, 10 \mu \mathrm{g}, 15 \mu \mathrm{g}, 20 \mu \mathrm{g}$ of BSA.

$\begin{array}{rrl}\text { Bradford reagent: } & 100 \mathrm{mg} & \text { Coomassie-Brilliant-Blue G-250 } \\ 50 \mathrm{ml} & \text { methanol } \\ 100 \mathrm{ml} & 85 \% \text { Phosphoric Acid }\end{array}$

filled up to $1000 \mathrm{ml}$ with distilled water, filtered through paper filters

Micro BCA Protein Assay Reagent Kit (Perbio Science Deutschland GmbH, Bonn) was used to determine the protein concentration in the dialyzed elution fractions. $1 \mathrm{ml}$ of protein sample or standard was added to $1 \mathrm{ml}$ of Working Reagent and mixed well. After 60 min incubation at $60^{\circ} \mathrm{C}$, the absorbance at $562 \mathrm{~nm}$ was measured vs. water or a suitable buffer reference. A standard curve was prepared by measuring absorbance of the following standards: $0.0 \mu \mathrm{g}, 0.5 \mu \mathrm{g}, 1.0 \mu \mathrm{g}, 2.5 \mu \mathrm{g}, 5.0 \mu \mathrm{g}, 10 \mu \mathrm{g}, 20 \mu \mathrm{g}$ of BSA.

\subsubsection{SDS Polyacrylamide Gel Electrophoresis (SDS-PAGE)}

Protein fractions after each step of preparation were analyzed by SDS-PAGE (Laemmli, 1970). The proteins were separated in vertical gel electrophoresis apparatus (MiniPROTEAN 3 Cell, BIO-RAD) filled with electrophoresis buffer. The composition of separating and stacking gels were as described below. Polymerization was started by adding ammonium peroxidisulfate (APS). 
Separating gel (Lower gel) $(10 \%, 2$ mini gels, $10 \mathrm{ml})$

$4.14 \mathrm{ml}$ distilled water

$2.5 \mathrm{ml} \quad 4 \times$ lower Tris-buffer $(1.5 \mathrm{M}$ Tris-HCl, $\mathrm{pH} 8.8,0.4 \%(\mathrm{w} / \mathrm{v}) \mathrm{SDS})$

$3.3 \mathrm{ml}$ acrylamide stock $(29.9 \%(\mathrm{w} / \mathrm{v})$ acrylamide, $0.8 \% \quad(\mathrm{w} / \mathrm{v}) \quad \mathrm{N}, \quad \mathrm{N}$ -

Bisacrylamide)

$50 \mu 1 \quad 10 \%(\mathrm{w} / \mathrm{v})$ APS

$12 \mu 1 \quad$ TEMED

Stacking gel (Upper gel) (4\%, 2 mini gels, $5 \mathrm{ml})$

$3.00 \mathrm{ml}$ distilled water

$1.25 \mathrm{ml}$ 4×upper Tris-buffer (0.5 M Tris-HCl, $\mathrm{pH} 6.8,0.4 \%(\mathrm{w} / \mathrm{v}) \mathrm{SDS})$

$670 \mu \mathrm{l} \quad$ acrylamide stock $(29.9 \%(\mathrm{w} / \mathrm{v})$ acrylamide, $0.8 \%(\mathrm{w} / \mathrm{v}) \quad \mathrm{N}, \quad \mathrm{N}$ -

Bisacrylamide)

$30 \mu 1 \quad 10 \%(\mathrm{w} / \mathrm{v})$ APS

$10 \mu 1 \quad$ TEMED

Before loading into the wells, protein samples were combined with sample buffer and heated for $5 \mathrm{~min}$ at $95^{\circ} \mathrm{C}$. The electrophoresis was performed at $15 \mathrm{~mA}$ for $20 \mathrm{~min}$, then switched to $25 \mathrm{~mA}$ and continued for $1 \mathrm{~h}$. Afterwards gels were either stained with Coomassie or subjected to Western Blot analysis (2.7.6).

Electrophoresis buffer: $\quad 25 \mathrm{mM}$ Tris- $\mathrm{HCl}, \mathrm{pH} 8.3$

$182 \mathrm{mM}$ Glycine

$0.1 \%(\mathrm{w} / \mathrm{v}) \mathrm{SDS}$

$2 \times$ SDS sample buffer: $\quad 1.25 \mathrm{ml} \quad 1 \mathrm{M}$ Tris-HCl, $\mathrm{pH} 6.8$

$\begin{array}{ll}2 \mathrm{ml} & 20 \%(\mathrm{w} / \mathrm{v}) \mathrm{SDS} \\ 2 \mathrm{ml} & \text { Glycerol } \\ 1 \mathrm{ml} & \text { B-Mercaptoethanol } \\ 1 \mathrm{mg} & \text { Bromophenolblue } \\ 3.75 \mathrm{ml} & \text { water }\end{array}$

To estimate the molecular weight of analyzed proteins, Protein Molecular Weight Marker (MBI Fermentas) was used: 


$\begin{array}{lr}\text { B-galactosidase } & 116.0 \mathrm{kDa} \\ \text { Bovine serum albumin } & 66.2 \mathrm{kDa} \\ \text { Ovoalbumin } & 45.0 \mathrm{kDa} \\ \text { Lactate dehydrogenase } & 35.0 \mathrm{kDa} \\ \text { Restriction endonuclease Bsp98I } & 25.0 \mathrm{kDa} \\ \text { B-lactoglobulin } & 18.4 \mathrm{kDa} \\ \text { Lysosyme } & 14.4 \mathrm{kDa}\end{array}$

\subsubsection{Coomassie staining}

Coomassie Blue staining method (Meyer and Lamberts, 1965) was used in order to detect protein bands separated in the gels. Gels were submerged in Coomassie staining solution for $30 \mathrm{~min}$ to allow the dye to bind to proteins. Afterwards gels were submerged in the destaining solution to remove the excess of the dye. The gels were incubated in several batches of the destaining solution until the background became transparent.

Coomassie staining solution:

$0.2 \%(\mathrm{w} / \mathrm{v})$ Coomassie Brilliant Blue R-250

$40 \%(\mathrm{v} / \mathrm{v})$ methanol

$10 \%(\mathrm{v} / \mathrm{v})$ acetic acid.

Destaining solution:

$30 \%(\mathrm{v} / \mathrm{v})$ methanol

$10 \%(\mathrm{v} / \mathrm{v})$ acetic acid

\subsubsection{Western Blot analysis}

Proteins separated by SDS-PAGE electrophoresis were transferred to nitrocellulose membrane (Macherey-Nagel, Düren) in a transfer apparatus Mini Trans-Blot Cell (BioRad, München) filled with blotting buffer (25 mM Tris-HCl, pH 8.5, $250 \mathrm{mM}$ Glycin). The transfer cassette was assembled according to manufacturer's instructions. Transfer of the proteins was performed at $80 \mathrm{~V}$ for $45 \mathrm{~min}$, at ca. $8^{\circ} \mathrm{C}$. Afterwards the membrane was submerged for 2 minutes in a Fast Green solution $(0.1 \%$ Fast Green in $1 \%$ acetic acid $(\mathrm{v} / \mathrm{v}))$ to visualize protein bands. The bands of the protein molecular weight marker were marked with a pencil and the membrane was destained with $0.1 \mathrm{M} \mathrm{NaOH}$. The membrane 
was washed briefly with TBS buffer $(10 \mathrm{mM}$ Tris $\mathrm{HCl}, 150 \mathrm{mM} \mathrm{NaCl}, \mathrm{pH} 8.0)$ and incubated overnight in blocking buffer $(3 \%$ BSA in TBS buffer $(\mathrm{w} / \mathrm{v}))$ at $4{ }^{\circ} \mathrm{C}$ with agitation. Afterwards the membrane was washed four times for $5 \mathrm{~min}$ in TBST buffer (TBS buffer $+0.1 \%(\mathrm{v} / \mathrm{v})$ Tween 20$)$ before $15 \mathrm{ml}$ of primary antibody dilution (1:1000 anti-His mouse IgG (Qiagen) in TBST buffer) were added. After 2 hours incubation at RT on a platform shaker, antibody dilution was removed, washing of the membrane was repeated as described before and $15 \mathrm{ml}$ of secondary antibody dilution (1:10000 anti-mouse IgG-HRP in TBST buffer) were added. Incubation was continued for 1 hour and then membrane washing was repeated for a third time. Proteins containing histidine stretches were visualized via chemiluminescence reaction catalyzed by the horseradish peroxidase (HRP) coupled to the secondary antibody. For that purpose reagents of an ECL-Kit (Amersham Bioscience, Freiburg) were applied and the membrane was exposed to X-ray film for about $1 \mathrm{~min}$. The film was subsequently developed in an Optimax X-Ray Film Processor.

\subsubsection{Enzyme activity assays}

General scheme of the assay for fatty acid activating enzymes:

${ }^{14} \mathrm{C}$-fatty acid + acceptor $(\mathrm{CoA}$ or $\mathrm{ACP})+\mathrm{ATP} \rightarrow{ }^{14} \mathrm{C}$-fatty acid-acceptor $+\mathrm{AMP}+\mathrm{PPi}$

Acyl-CoA synthetase and acyl-acyl carrier protein (ACP) synthetase activities were assayed by measuring the incorporation of $\left[1-{ }^{14} \mathrm{C}\right]$ fatty acids into acyl-CoA or acyl-ACP, respectively. The reaction was terminated by applying an aliquot of the incubation mixture to a filter disk and washing the disk twice with an organic solvent. Acyl-CoA/ACP is not soluble in the organic solvent and remains retained on the disk, whereas free fatty acids are extracted into the organic phase. After washing, the disks were recovered and dried. The amount of $\left[1-{ }^{14} \mathrm{C}\right]$ acyl-CoA/ACP present was determined by liquid scintillation measurements.

\subsubsection{Acyl-ACP synthetase activity}

The acyl-ACP synthetase activity was measured according to a modified method described previously (Rock and Cronan, 1981). The assay was conducted in $1.5 \mathrm{ml}$ microcentrifuge tubes in a volume of $40 \mu \mathrm{l}$. The assay mixture contained $2.5 \mathrm{mM}$ Tris- $\mathrm{HCl}, \mathrm{pH} 8.0,2 \mathrm{mM}$ dithiothreitol (DTT), $10 \mathrm{mM} \mathrm{MgCl} 2,5 \mathrm{mM} \mathrm{ATP,} 10 \mathrm{mM} \mathrm{LiCl,} 2 \%$ (v/v) Triton X-100, 15 $\mu \mathrm{M}$ ACP, $30 \mu \mathrm{M}\left[1-{ }^{14} \mathrm{C}\right]$ fatty acid (specific activity $53.7-60 \mathrm{mCi} / \mathrm{mmol}$ ) and a defined 
amount of protein sample. The reaction was initiated by addition of the protein sample and incubated for $30 \mathrm{~min}$ at $37^{\circ} \mathrm{C}$. The assay was stopped by transferring the whole reaction mixture to a Whatman filter paper disc. The filters were dried and washed twice with chloroform : methanol : acetic acid $(3: 6: 1)$ to remove non converted substrate (nonactivated fatty acid). The filter disks were dried again and counted in $6 \mathrm{ml}$ of scintillation solution (Liquid Scintillation Analyzer 1900 TR, Fa. Canberra Packard). One unit of acylACP synthetase activity is defined as the amount of protein required to produce $1 \mathrm{nmol}$ of $\left[1-{ }^{14} \mathrm{C}\right]$ acyl-ACP per minute (Rock and Cronan, 1981).

\subsubsection{Acyl-CoA synthetase activity}

The acyl-CoA synthetase activity assay was performed in the same way than the acyl-ACP synthetase activity assay. The composition of the assay mixture was as described previously (Joyard and Stumpf, 1981), with minor changes. In detail: $100 \mathrm{mM}$ Tris-HCl, $\mathrm{pH}$ 8.0, $10 \mathrm{mM} \mathrm{MgCl} 2,5 \mathrm{mM}$ ATP, $2.5 \mathrm{mM}$ DTT, $0.5 \mathrm{mM} \mathrm{CoA}, 2 \%$ Triton X-100, $30 \mu \mathrm{M}$ $1-\left[{ }^{14} \mathrm{C}\right]$ fatty acid (specific activity $53.7-60 \mathrm{mCi} / \mathrm{mmol}$ ) and protein sample in a final volume of $40 \mu 1$.

\subsection{Fatty acids and lipids analysis}

\subsubsection{Fatty acids extraction from cyanobacteria cells and culture medium}

For analysis of fatty acids profiles in cells and culture medium $8 \mathrm{ml}$ aliquots of cultures at $\mathrm{OD}_{750}$ ca. 4.7 were collected. Cells were harvested by centrifugation and washed twice with $1 \mathrm{ml} 0.1 \mathrm{M} \mathrm{NaHCO}$. Extraction of fatty acids (free or esterified to lipids) was performed by chloroform:methanol method (Bligh and Dyer, 1959) as follows:

Extracellular supernatant fraction: $8 \mathrm{ml}$ of supernatant were transferred to a $100 \mathrm{ml}$ round bottom flask. Beyond this step, only glass equipment was used for the extraction. To each sample, $10 \mathrm{ml}$ chloroform, $20 \mathrm{ml}$ methanol and $0.5 \mathrm{ml} 1 \mathrm{M} \mathrm{HCl}$ were added. $15 \mu \mathrm{g}$ of 17:0 were added as an internal standard for free fatty acids. Samples were extracted by shaking at $4^{\circ} \mathrm{C}$ over night. Afterwards, $10 \mathrm{ml}$ chloroform was added and the samples were mixed for $1 \mathrm{~min}$. After extraction $10 \mathrm{ml}$ of $0.9 \% \mathrm{NaCl}$ were added and the samples were shaken 
thoroughly. Flasks were left on the bench for phase separation to occur. The lower phase was transferred with a Pasteur glass pipette to a new $100 \mathrm{ml}$ round bottom flask and the volume was reduced to around $2 \mathrm{ml}$ by evaporation with a rotary evaporator (Rotavapor R200, Büchi; Flawil, Switzerland). The remaining volume was transferred to a $10 \mathrm{ml}$ tube with grounded neck and dried under a stream of nitrogen. The extracts were resuspended in $100 \mu \mathrm{l}$ chloroform:methanol (1:1) and stored at $-20^{\circ} \mathrm{C}$.

Cellular pellet fraction: cells were resuspended in residual liquid of the medium and transferred to $10 \mathrm{ml}$ tubes with grounded necks. Beyond this step, only glass equipment was used for the extraction. To each sample $3 \mathrm{ml}$ chloroform:methanol (1:1), $50 \mu 11 \mathrm{M}$ $\mathrm{HCl}$ and a defined amount of internal standard were added; $15 \mu \mathrm{g}$ 17:0 as a standard for free fatty acids and $20 \mu \mathrm{g}$ tri17:0 as a standard for lipid bound fatty acids. Samples were extracted by shaking at $4^{\circ} \mathrm{C}$ overnight; afterwards $1.5 \mathrm{ml}$ chloroform were added and samples were mixed for $1 \mathrm{~min}$. After extraction $0.67 \mathrm{ml}$ of $0.9 \% \mathrm{NaCl}$ were added, samples were shaken thoroughly and phases were separated by centrifugation at $2000 \times \mathrm{g}$. The lower phase was transferred to a new glass tube and dried under a stream of nitrogen. The extracts were resuspended in $100 \mu \mathrm{l}$ chloroform:methanol $(1: 1)$ and stored at $-20^{\circ} \mathrm{C}$.

Before subjecting to gas chromatography fatty acids were derivatized to their methyl esters $(2.8 \cdot 3 \cdot 1-2)$.

\subsubsection{Extraction of lipopolysaccharide}

Lipopolysaccharides were extracted from the cells of Synechocystis sp. PCC 6803 using the LPS Extraction Kit (Intron Biotechnology, Molecular Solutions Europe, London, UK) according to manufacturer's protocol and subjected to acidic methanolysis (2.8.3.3).

\subsubsection{Fatty acids derivatization}

\subsubsection{Methylation of free fatty acids}

The methylation of free fatty acids (op den Camp et al., 2003) was performed as follows: $40 \mu \mathrm{l}$ of the chloroform:methanol (1:1) extracts (2.8.1) were transferred to new $10 \mathrm{ml}$ 
tubes with grounded necks and dried under a stream of nitrogen. $400 \mu 1$ methanol and $10 \mu 1$ of $0.1 \mathrm{~g} / \mathrm{ml}$ EDAC methanol solution were added and the tubes were shaken shortly. After 2 hours incubation at RT the reaction was stopped by addition of $200 \mu 10.1 \mathrm{M}$ Tris- $\mathrm{HCl}$, $\mathrm{pH} 7.5$.

In order to extract methyl esters $1 \mathrm{ml}$ hexane was added, the tubes were mixed at high speed and then centrifuged for 2 min at $1000 \times g$ to achieve phase separation. The upper phase was transferred to $1.5 \mathrm{ml}$ microcentrifuge tubes and dried under a stream of nitrogen. The extracts were resuspended in $12 \mu \mathrm{l}$ acetonitrile. The walls of the tubes were washed carefully with the solvent by pipetting.

\subsubsection{Transmethylation of esterified fatty acids}

The transmethylation of esterified fatty acids (Hornung et al., 2002) was performed as follows: $40 \mu \mathrm{l}$ of the chloroform:methanol (1:1) extracts $(2.8 .1)$ were transferred to $2 \mathrm{ml}$ microcentrifuge tubes and dried under a stream of nitrogen. $333 \mu 1$ methanol:toluene $(1: 1)$ and $167 \mu 10.5 \mathrm{M} \mathrm{NaOCH}_{3}$ (methanol solution) were added. After 20 min incubation at RT the reaction was stopped by addition of $500 \mu 11 \mathrm{M} \mathrm{NaCl}$ and $50 \mu 137 \% \mathrm{HCl}$. In order to extract the methyl esters $1 \mathrm{ml}$ hexane was added, the tubes were mixed at high speed and then centrifuged for $1 \mathrm{~min}$ at $5000 \mathrm{x} g$ for phase separation. The upper phase was transferred to $1.5 \mathrm{ml}$ microcentrifuge tubes and dried under a stream of nitrogen. The extracts were resuspended in $15 \mu \mathrm{l}$ acetonitrile. The walls of the tubes were washed carefully with the solvent by pipetting.

\subsubsection{Acidic methanolysis}

Acidic methanolysis (Miquel and Browse, 1992) was performed as follows: LPS pellet (2.8.2) was scraped from the microcentrifuge tube walls and transferred to a glass screwcap tube. $1 \mathrm{ml}$ of FAME (fatty acid methyl ester) solution $\left(2.75 \% \mathrm{H}_{2} \mathrm{SO}_{4}\right.$ in methanol $+2 \%$ dimethoxypropane) was added and the tube was incubated in a water bath at $80^{\circ} \mathrm{C}$ for 1 hour. Afterwards $1.5 \mathrm{ml} 0.9 \% \mathrm{NaCl}$ and $1 \mathrm{ml}$ hexane were added and the tube was mixed at high speed to extract methyl esters. After centrifugation at $3000 \times \mathrm{x}$ the hexane phase was transferred to a tube with a grounded neck and dried under a stream of nitrogen. Then $1.5 \mathrm{ml}$ water:hexane (1:1) mixture was added and the extraction was repeated. The hexane phase was run through a column made of a glass Pasteur pipette stopped with a small 
amount of cotton and filled with about $0.3 \mathrm{~g} \mathrm{Na}_{2} \mathrm{SO}_{4}$. The eluate was dried under a stream of nitrogen and the extract was resuspended in $12 \mu 1$ acetonitrile.

\subsubsection{Gas chromatography (GC)}

The methylated fatty acids, dissolved in acetonitrile, were subjected to analysis by gas chromatography using the following conditions:

Chromatographer: $\quad$ Agilent GC 6890 Series

Column: $\quad$ DB-23, $30 \mathrm{~m} \times 250 \mu \mathrm{m}$

film thickness $0.25 \mu \mathrm{m}$ (Agilent, Waldheim)

Split: $\quad 15: 1$ (for derivatives of free fatty acids)

60:1 (for derivatives of esterified fatty acids)

Injection volume: $\quad 2 \mu \mathrm{l}$ (for derivatives of free fatty acids)

$1 \mu 1$ (for derivatives of esterified fatty acids)

Carrier gas: $\quad \operatorname{Helium}(1 \mathrm{ml} / \mathrm{min})$

Temperature program: $\quad 150^{\circ} \mathrm{C} 1 \mathrm{~min}$

$$
\begin{aligned}
& 150^{\circ} \mathrm{C}-160^{\circ} \mathrm{C}, 10^{\circ} \mathrm{C} / \mathrm{min} \\
& 160^{\circ} \mathrm{C}-200^{\circ} \mathrm{C}, 6^{\circ} \mathrm{C} / \mathrm{min} \\
& 200^{\circ} \mathrm{C}-250^{\circ} \mathrm{C}, 25^{\circ} \mathrm{C} / \mathrm{min} \\
& 250^{\circ} \mathrm{C}, 4 \mathrm{~min}
\end{aligned}
$$

Detector: $\quad$ FID

Evaluation of the obtained signals was performed with ChemStation-software (Agilent, Waldheim).

\subsubsection{Gas chromatography-mass spectrometry}

The analysis of the hydroxy fatty acids was carried out using Agilent 5973 Network mass selective detector connected to Agilent 6890 gas chromatograph. Electron energy of $70 \mathrm{eV}$, an ion source temperature of $230{ }^{\circ} \mathrm{C}$ and a temperature of $260{ }^{\circ} \mathrm{C}$ for the transfer line were used. 


\subsubsection{Thin layer chromatography (TLC)}

Thin layer chromatography was used to separate different lipid classes. $10 \mu 1$ samples of lipid extracts (2.8.7) were applied on $1 \mathrm{~cm}$ lines on Silica Gel $60(20 \times 20 \mathrm{~cm})$ plate (Merck, Darmstadt) about $1.5 \mathrm{~cm}$ from the base and with $1 \mathrm{~cm}$ distance from the sides and between each sample. The plate was developed in the solvent (aceton:toluene:water (91:30:8)) until the solvent forehead reached $3 / 4$ of the plates height. Afterwards the plate was dried under the hood and lipids were visualized (2.8.7).

\subsection{7 ${ }^{14} \mathrm{C}$ labeling experiments}

For feeding experiments cyanobacterial cells were collected from $10 \mathrm{ml}$ cultures at $\mathrm{OD}_{750}$ ca. 1.0, resuspended in $2 \mathrm{ml}$ of fresh BG11 medium and transferred to $2 \mathrm{ml}$ microcentrifuge tubes. Radio-labeled fatty acids were individually added in amount corresponding to about $0.22 \mu \mathrm{Ci}$ and the tubes were placed on a platform shaker under light. After $50 \mathrm{~min}$ incubation $0.5 \mathrm{ml}$ from each culture were transferred to a new microcentrifuge tube and the cells were collected by centrifugation at $3000 \mathrm{x} \mathrm{g}$. The remaining $1.5 \mathrm{ml}$ were further incubated and after $18.5 \mathrm{~h}$ an additional aliquot of $0.5 \mathrm{ml}$ were recovered from each culture and treated as described before. $0.4 \mathrm{ml}$ of the supernatant was added to $6 \mathrm{ml}$ scintillation liquid and counted in a scintillation analyzer to determine the radioactivity present in the culture medium, whereas the residual supernatant was discarded. Cell pellets were washed twice with $0.1 \mathrm{M} \mathrm{NaHCO}_{3}$. Total lipid extracts were prepared from cell pellets using chloroform:methanol method. In detail, $1.5 \mathrm{ml}$ chloroform:methanol $(2: 1)$ and $50 \mu 11 \mathrm{M} \mathrm{HCl}$ were added to the cell pellets in $2 \mathrm{ml}$ microcentrifuge tubes and lipids were extracted for $4 \mathrm{~h}$ under shaking. Afterwards $500 \mu \mathrm{l}$ $0.45 \% \mathrm{NaCl}$ was added, the tubes were mixed briefly and centrifuged at $2000 \mathrm{~g}$ for 2 min for phase separation. The lower phase was transferred to a new tube and dried under a stream of nitrogen. Extracts were resuspended in $20 \mu 1$ chloroform:methanol (1:1). Different lipid classes were separated by TLC and were visualized by fluorography. Signals were detected with an image analyzer (FLA-3000, Fujifilm; Tokyo, Japan)

In subsequent experiments only cellular lipids, and not fatty acids remaining in the culture medium, were analyzed. In these cases cultures were incubated for $15 \mathrm{~h}$ after adding the labeled fatty acids and then lipid extracts were prepared from cell pellets. 


\begin{tabular}{lll}
\hline Fatty acid & Abbreviation & Specific activity \\
\hline$\left[1-{ }^{14} \mathrm{C}\right]$ lauric & C $12: 0$ & $57 \mathrm{mCi} / \mathrm{mmol}$ \\
{$\left[1-{ }^{14} \mathrm{C}\right]$ myristic } & C $14: 0$ & $55 \mathrm{mCi} / \mathrm{mmol}$ \\
{$\left[1-{ }^{14} \mathrm{C}\right]$ palmitic } & $\mathrm{C} 16: 0$ & $60 \mathrm{mCi} / \mathrm{mmol}$ \\
{$\left[1-{ }^{14} \mathrm{C}\right]$ stearic } & $\mathrm{C} 18: 0$ & $58 \mathrm{mCi} / \mathrm{mmol}$ \\
{$\left[1-{ }^{14} \mathrm{C}\right]$ oleic } & $\mathrm{C} 18: 1$ & $56 \mathrm{mCi} / \mathrm{mmol}$ \\
{$\left[1-{ }^{14} \mathrm{C}\right]$ linoleic } & $\mathrm{C} 18: 2$ & $55 \mathrm{mCi} / \mathrm{mmol}$ \\
{$\left[1-{ }^{14} \mathrm{C}\right]$ linolenic $9,12,15$} & $\mathrm{C} 18: 3$ & $53.7 \mathrm{mCi} / \mathrm{mmol}$ \\
\hline
\end{tabular}

\subsubsection{Temperature shift experiment}

A liquid culture of Synechocystis sp. PCC 6803 aas knockout mutant was grown in $120 \mathrm{ml}$ BG 11 medium at $30^{\circ} \mathrm{C}$. 24 hours before the temperature shift $100 \mathrm{ml}$ of BG11 medium were added. At $\mathrm{OD}_{750}=3$ the culture was split into two Erlenmeyer flasks; one of them was placed at $22^{\circ} \mathrm{C}$ while the other, for the control, stayed at $30^{\circ} \mathrm{C}$. Cultures were incubated for $37 \mathrm{~h}$ and during this time $8 \mathrm{ml}$ aliquots were collected at five defined time points. Fatty acids were extracted from pelleted cells and from the supernatants (2.8.1) and subsequently, after derivatization (2.8.3), were subjected to GC analysis (2.8.4).

\subsection{Histochemical staining for $\beta$-glucuronidase (GUS) activity}

The GUS reporter system was used to determine the activity of the promoters of $A A E 15$ and $A A E 16$ in different tissues. The constructs containing the promoter of interest fused with a GUS reporter gene were transformed into Arabidopsis. The activity of the promoter resulted in an expression of the GUS reporter gene encoding $\beta$-glucuronidase. Enzyme activity was detected by employing colorless 5-bromo-4-chloro-3-indolyl $\beta$-D-glucuronide cyclohexylammonium salt (X-Gluc) (Warrington, England) as substrate. The $\beta-$ glucuronidase is converting the colorless X-Gluc to the blue 5, 5'-dibromo-4,4'dichloroindigo. Intensive blue color is therefore indicating tissues with promoter activity. Plant samples were submerged in GUS staining solution and vacuum was applied for $5 \mathrm{~min}$ in order to remove air trapped in the leaves. The samples were incubated overnight at $37^{\circ} \mathrm{C}$, then the staining solution was replaced with $70 \%(\mathrm{v} / \mathrm{v})$ ethanol. Ethanol was changed 
several times until chlorophyll was removed. Stained plant material was analyzed under the microscope the staining was documented by a camera.

GUS staining solution:

$100 \mathrm{mM} \quad \mathrm{NaH}_{2} \mathrm{PO}_{4}, \mathrm{pH} 7.0$

$10 \mathrm{mM} \quad$ EDTA, $\mathrm{pH} 7.0$

$0.5 \mathrm{mM} \quad$ Farricyanid

$0.5 \mathrm{mM} \quad$ Ferrocyanid

$2 \mathrm{mM} \quad \mathrm{X}$-Gluc (stock solution: 100mM X-Gluc in DMSO)

$0.1 \%(\mathrm{v} / \mathrm{v}) \quad$ Triton $\mathrm{X}-100$

distilled water

\subsection{Subcellular localization studies}

\subsubsection{DNA precipitation onto gold particles}

$50 \mathrm{mg}$ of gold particles (1 $\mu \mathrm{m}$ Gold Microcarrier; Bio-Rad Laboratories; München) were resuspended in $1 \mathrm{ml}$ of ethanol and mixed for 1 to $2 \mathrm{~min}$. The gold particles were collected by centrifugation at $10000 \mathrm{x} g$ for $10 \mathrm{sec}$ and washed again with $1 \mathrm{ml}$ of ethanol. The washing step was repeated twice. The gold particles were then washed once with sterile water and again resuspended in $1 \mathrm{ml}$ of sterile water. $25 \mu l$ aliquots were prepared in $1.5 \mathrm{ml}$ microcentrifuge tubes and frozen at $-20^{\circ} \mathrm{C}$ for storage. The following steps were carried out on ice. For DNA precipitation one aliquot of gold particles was taken, the following components were added one after the other and the tube was mixed thoroughly for $10 \mathrm{sec}$ to $2 \mathrm{~min}$ after the addition of each individual compound: 4 to $6 \mu$ of plasmid DNA (1 $\mu \mathrm{g} / \mu \mathrm{l}$ ) (final concentration about $40 \mathrm{ng} / \mu \mathrm{l}$ ), $25 \mu \mathrm{l}$ of $2.5 \mathrm{M} \mathrm{CaCl}_{2}$ (final concentration about $1 \mathrm{M}$ ) and $10 \mu \mathrm{l}$ of $0.1 \mathrm{M}$ spermidine (final concentration about $10 \mathrm{mM}$ ). The DNA was precipitated onto the gold particles by centrifugation at $10000 \times \mathrm{g}$ for $10 \mathrm{sec}$. Subsequently the gold particles were washed twice using $250 \mu 1$ of ethanol and finally resuspended in 60 $\mu 1$ of ethanol. 


\subsubsection{Transformation of onion epidermal cells by bombardment}

The Biolistic-PDS-1000/He Particle Delivery System supplied by Bio-Rad (München) was used to transform onion epidermal cells. The system uses high pressure helium, released by a rupture disk, and partial vacuum to deliver DNA-coated gold microcarriers into cells.

The rupture disk was dipped briefly in $70 \%(\mathrm{v} / \mathrm{v})$ isopropanol and placed in the retaining cap. The retaining cap was tightly secured to the end of the gas acceleration tube. $5 \mu 1$ of DNA-coated gold particles were evenly loaded onto the center of the macrocarrier and allowed to dry for a few minutes. The macrocarrier and a stopping screen were loaded into the microcarrier launch assembly and placed on the top shelf into the chamber. A piece of onion on a Petri dish was placed on the third shelf. The bombardment was carried out using 1100 psi rupture disks and a partial vacuum of 0.1 bar. After shooting onion pieces were incubated for about 24 hours at RT for protein expression.

\subsubsection{Fluorescence microscopy}

Onion epidermal cells were analyzed using fluorescent microscope Olympus BX51 equipped with the following filters: EYFP (F41-028; excitation filter HQ500/20, barrier HQ535/30), ECFP (F31-044; excitation filter D436/20, barrier D480/40). Digital pictures were captured using a CCD camera (ColorViewII) with analySIS3.1 Imaging software. 


\section{Results}

\subsection{Generation of aas knockout mutants in Synechocystis sp. PCC 6803 and Synechococcus elongatus PCC 7942}

In order to investigate the biological function of the AAS in cyanobacteria, aas knockout mutants were generated in the background of Synechocystis sp. PCC 6803 and Synechococcus elongatus PCC 7942. In each individual strain the aas was inactivated by replacing a part of the coding region with a kanamycin resistance cassette via homologous recombination. Since cyanobacteria contain multiple copies of the chromosome per cell, it was essential to establish the complete segregation of the wild type allele. This was achieved by culturing transformed cells under selective pressure for several weeks. The complete replacement of the native genes by genes disrupted with the kanamycin resistance cassette was confirmed by polymerase chain reaction (PCR) (figure 3). The primer pairs for PCR are indicated in figure $3 \mathrm{~A}$ as arrows. In the first reaction (PCR I) primers specific for cyanobacterial DNA were employed (primer 1 and primer 2). Primer 1 was matching the genomic sequence upstream of the position where the kanamycin cassette was inserted, whereas primer 2 was matching the gene fragment deleted in the mutant strain. In the second reaction (PCR II) a primer specific for the kanamycin cassette (primer 3) and a primer specific for the aas gene, downstream of the insertion point of the kanamycin cassette (primer 4), were used. Primers sequences and possible PCR results, indicating presence or absence of an aas wild type copy, and presence or absence of a properly inserted kanamycin cassette in the genome, are presented below.

\section{Synechocystis sp. PCC 6803}

PCR I

Primer 1 CTCTACATCCTAGAAGACAGC (SYN4)

Primer 2 GAATCCAATTCCCGTACTTGGTGC (SYN UP2)

\begin{tabular}{l|l}
\hline Template & Product \\
\hline Wild type & $320 \mathrm{bps}$ \\
aas knockout & no \\
\hline
\end{tabular}


PCR II

Primer 3 GATTCAGTCGTCACTCATGGTG (kan down)

Primer 4 CACAGCCGGGGCACACCGACAATG (SYN2)

\begin{tabular}{l|l}
\hline Template & Product \\
\hline Wild type & no \\
aas knockout & 564 bps \\
\hline
\end{tabular}

Synechococcus elongatus PCC 7942

PCR I

Primer 1 CCGTAATCAGCGTGTAGATGATGG (elotest1)

Primer 2 GATCGAACCGCTGTCCTCTAAGACG (elotest2)

\begin{tabular}{l|l}
\hline Template & Product \\
\hline Wild type & 796 bps \\
aas knockout & no \\
\hline
\end{tabular}

PCR II

Primer 3 GATTCAGTCGTCACTCATGGTG (kan down)

Primer 4 GTGTTCCGCGACAACGTTGCGACG (eloXma_con_r)

\begin{tabular}{l|l}
\hline Template & Product \\
\hline Wild type & no \\
aas knockout & 609 bps \\
\hline
\end{tabular}

The first reaction, using primers specific for the aas gene, showed the absence of wild type gene from all chromosome copies of aas mutants. The second reaction indicated successful insertion of the kanamycin resistance cassette into the chromosome. 
A

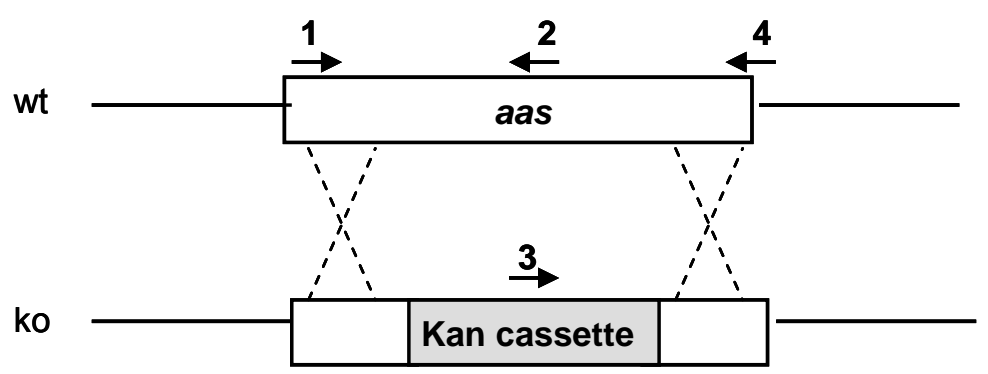

B

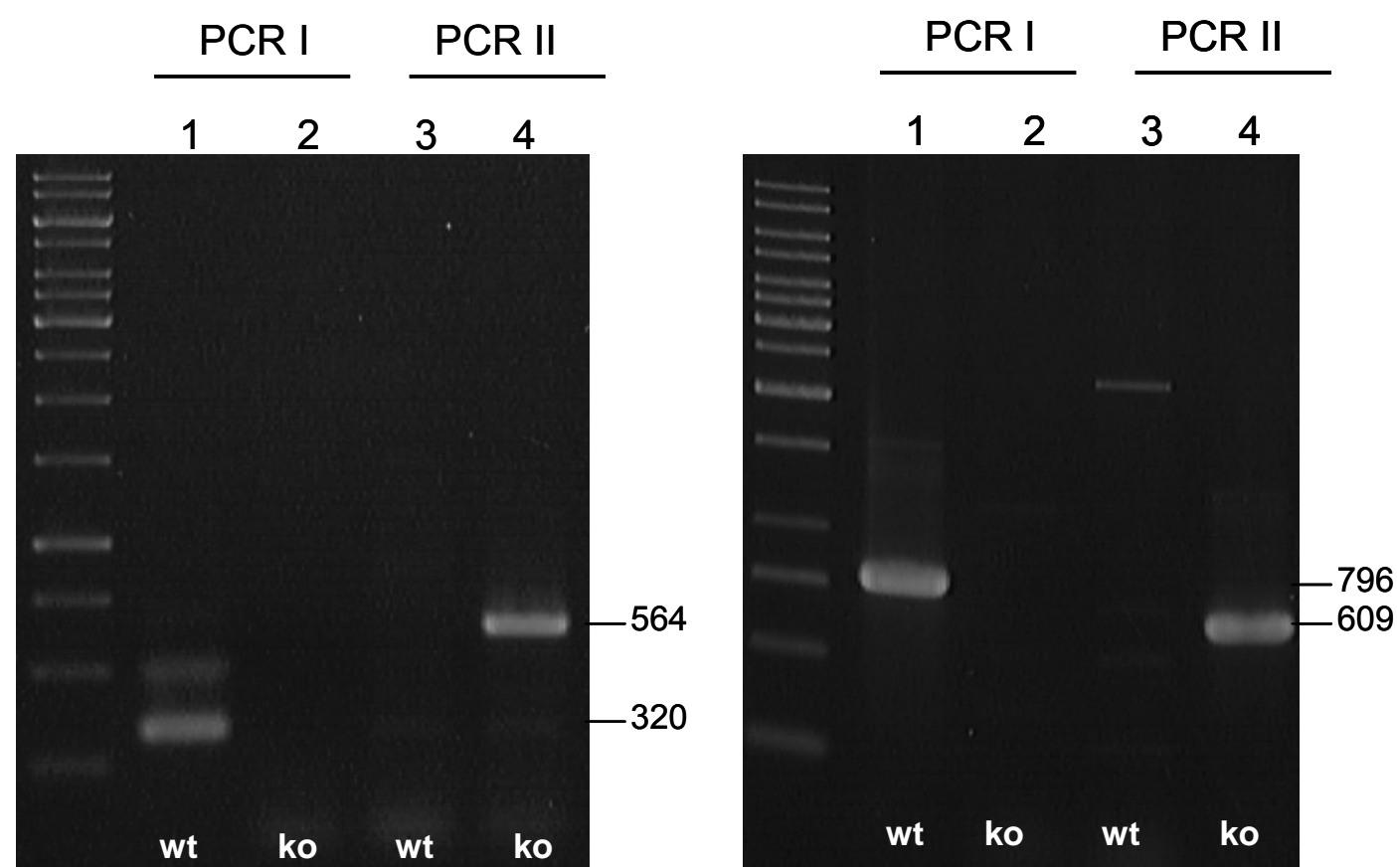

Synechocystis sp. PCC $6803 \quad$ Synechococcus elongatus PCC 7942

Figure 3. Disruption of the aas gene in Synechocystis sp. PCC 6803 and Synechococcus elongatus PCC 7942. (A) Given is the general scheme of aas disruption by a kanamycin resistance (Kan) cassette and primers used for PCR analysis; wt - wild type, ko - aas knockout mutant. (B) Complete disruption of native the aas genes by integrating a Kan cassette in Synechocystis sp. PCC 6803 and Synechococcus elongatus PCC 7942 was confirmed by PCR analysis. Genomic DNA of the wild type (lanes 1 and 3) or the aas-kan mutant (lanes 2 and 4) was used as a template for the PCR with primers specific for the aas gene (primers 1 and 2; lanes 1 and 2) or primers specific for the Kan cassette and aas gene (primers 3 and 4; lanes 3 and 4). The sizes of the obtain products are given to the right in bps. 


\subsection{AAS deficient cyanobacterial cells are unable to utilize exogenous fatty acids}

Like other unicellular organisms many cyanobacteria are capable of utilizing fatty acids from the surrounding media. To study the phenotype of aas deficient strains, the cultures of Synechocystis sp. PCC 6803 and Synechococcus elongatus PCC 7942 wild type strains and of the corresponding mutant strains were grown in identical media containing radiolabeled oleic acid. According to theory, incorporation of exogenous fatty acid into lipids should only be possible in cells which possess an intact mechanism of fatty acid activation. To follow the fate of oleic acid from the media, total lipids were extracted from harvested cells and those extracts were analyzed by thin layer chromatography (TLC; figure 4). In wild type cells the label appeared, as expected, in various lipid classes, thus confirming the presence of an enzyme capable of fatty acid activation. In contrast, the aas knockout mutants were not able to metabolize exogenous oleic acid, as indicated by the absence of labeled lipids. It is important to note that uptake and accumulation of fatty acids did take place in the mutant strains, as shown by the strong presence of labeled free fatty acids in the cellular extracts. The different lipid classes were identified by co-migration of non-labeled lipid standards (not shown). Additional radioactive spots were detected, which migrated above free fatty acids in extracts of wild types and mutants. 


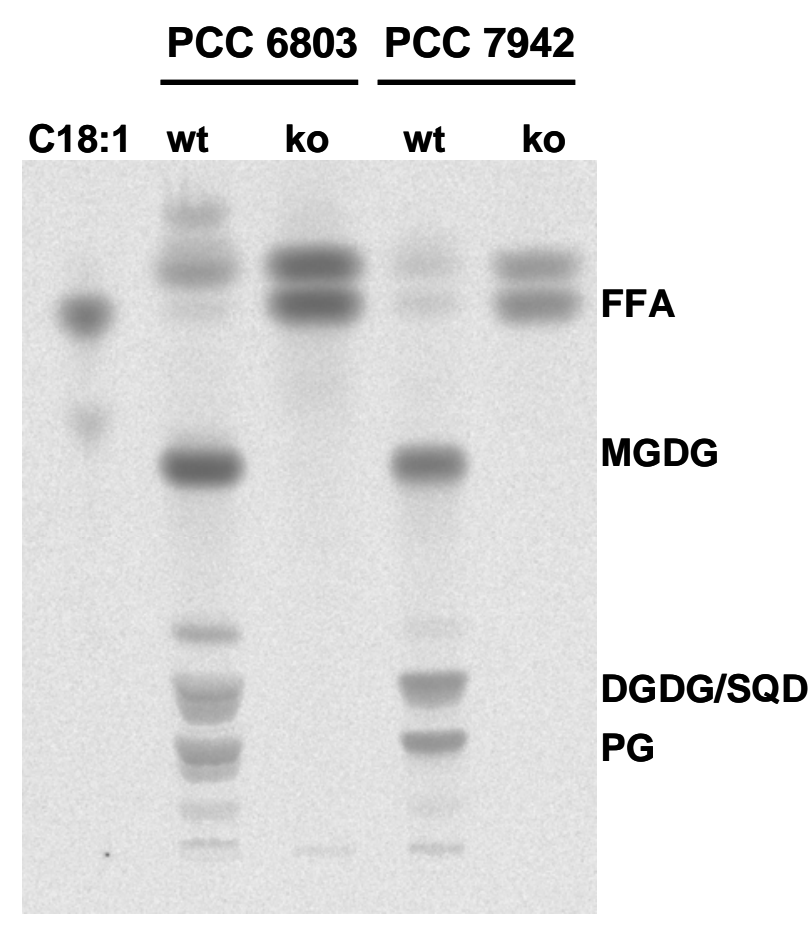

Figure 4. Autoradiography of total lipid extracts from Synechocystis sp. PCC 6803 and Synechococcus elongatus PCC7942 wild types and aas knockout mutants fed with radio labeled oleic acid. Synechocystis sp. PCC 6803 (PCC 6803) and Synechococcus elongatus PCC 7942 (PCC7942) wild type (wt) and aas knockout (ko) cells were incubated with ${ }^{14} \mathrm{C}$ labeled oleic acid (C18:1). Lipids extracted from the cells were separated by TLC using acetone:toluene:water (91:30:8) as solvent system. FFA - free fatty acids, MGDG - monogalactosyl diacylglycerol, DGDG - digalactosyl diacylglycerol, SQDG - sulfoquinovosyl diacylglycerol, PG - phosphatidylglycerol.

A complementation experiment was performed in order to support the obtained results. The aas of Synechococcus elongatus PCC 7942 was introduced to the aas mutant strain of Synechocystis sp. PCC 6803 via homologous recombination according to the scheme presented in figure $5 \mathrm{~A}$. The presence of the complementation cassette in the transformed strain was confirmed by PCR employing isolated genomic DNA as a template (figure $5 \mathrm{~B}$ ). In the first reaction (PCR I) primers specific for the introduced DNA fragment of Synechococcus elongatus 7942 were used (primer 1 and primer 2). In the second reaction (PCR II) primers specific for Synechocystis sp. PCC 6803 fragments were used (primer 3 and primer 4). The second reaction showed not only the presence of the complementing gene but also the absence of the native aas of Synechocystis sp. PCC 6803. Feeding with labeled fatty acids demonstrated that the wild type phenotype was restored in the complemented strain (figure $5 \mathrm{C}$ ). These results clearly demonstrated that the phenotype observed was caused by the introduced aas of Synechococcus elongatus 7942 and not by 
coincidental contamination of the culture with wild type Synechocystis sp. PCC 6803. To exclude the possibility that PCRs products were resulting from unspecific primer hybridization to the sequence of genomic DNA in a host strain, for each primer pair the control reaction utilizing genomic DNA of Synechocystis sp. PCC 6803 as template was performed. Primer sequences and possible PCR results for various DNA templates are presented below.

PCR I

Primer 1 CCGTAATCAGCGTGTAGATGATGG (elotest1)

Primer 2 GATCGAACCGCTGTCCTCTAAGACG (elotest2)

\begin{tabular}{l|l}
\hline Template & Product \\
\hline $\begin{array}{l}\text { Synechocystis sp. PCC 6803 wild type } \\
\text { Synechocystis sp. PCC } 6803 \text { aas }\end{array}$ & no \\
knockout & \\
$\begin{array}{l}\text { Synechococcus elongatus PCC } 7942 \\
\text { aas complementation }\end{array}$ & $796 \mathrm{bps}$ \\
\hline
\end{tabular}

PCR II

Primer 3 CATTGACCTGAAACTAATCATCC (SYN6)

Primer 4 CACAGCCGGGGCACACCGACAATG (SYN2)

\begin{tabular}{l|l}
\hline Template & Product \\
\hline $\begin{array}{l}\text { Synechocystis sp. PCC 6803 wild type } \\
\text { Synechocystis sp. PCC 6803 aas }\end{array}$ & $1490 \mathrm{bps}$ \\
knockout & \\
$\begin{array}{l}\text { Synechococcus elongatus PCC 7942 } \\
\text { aas complementation }\end{array}$ & $4977 \mathrm{bps}$ \\
\hline
\end{tabular}


A

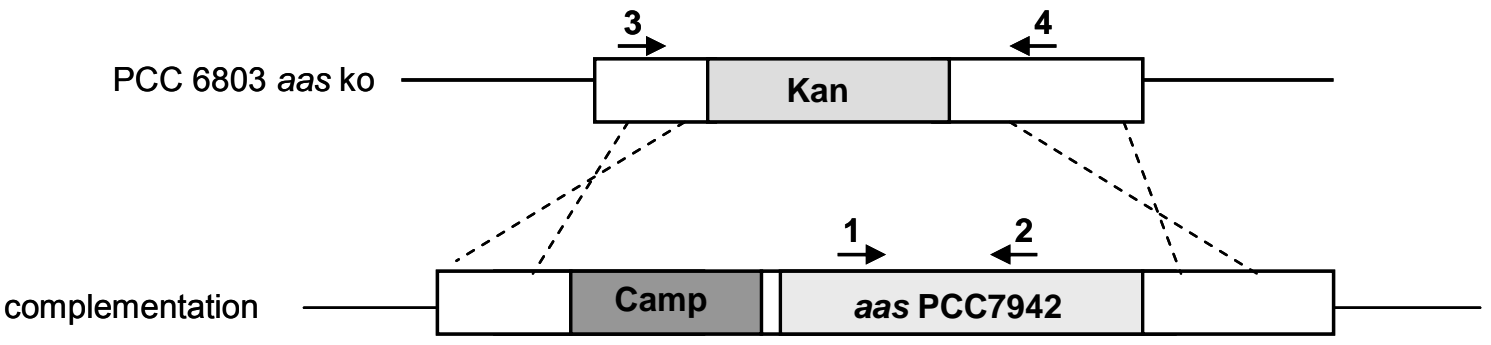

B

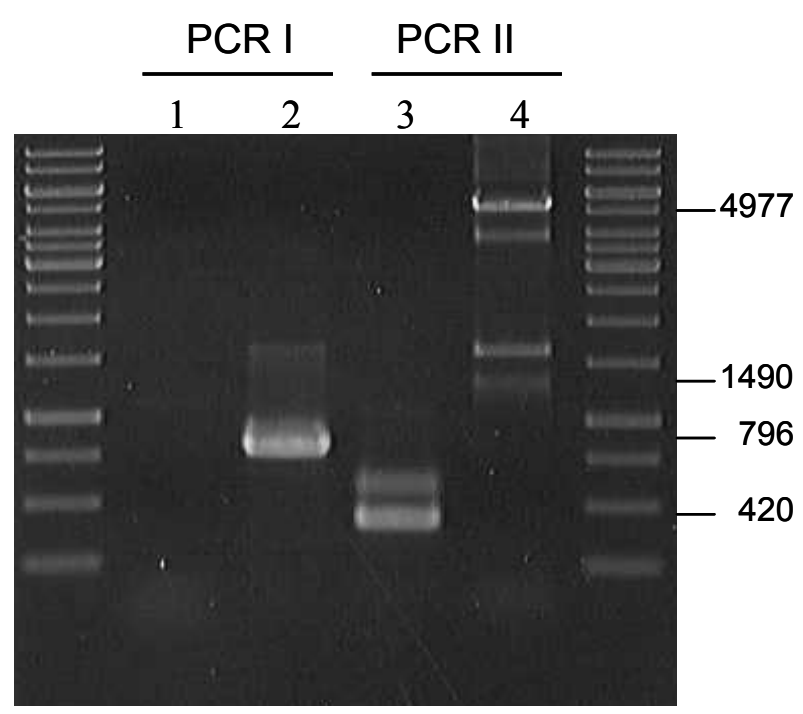

C

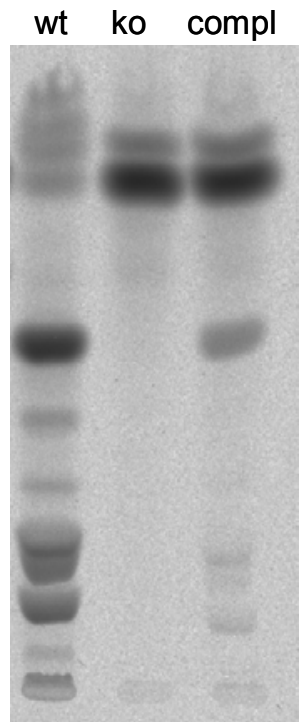

Figure 5. Complementation of the Synechocystis sp. PCC 6803 aas knockout mutant by the aas gene of Synechococcus elongatus 7942. (A) General scheme of homologous recombination introducing aas of Synechococcus elongatus PCC 7942 (aas PCC7942) into Synechocystis sp. PCC 6803 aas knockout. (B) Complementation of Synechocystis sp. PCC 6803 aas knockout with corresponding gene from Synechococcus elongatus PCC 7942 was confirmed by PCR analysis. Genomic DNA of the Synechocystis sp. PCC 6803 wild type (lanes 1 and 3) or aas mutant complemented with aas from Synechococcus elongatus PCC 7942 (lanes 2 and 4) was used as a template for the PCR with primers 1 and 2 (lanes 1 and 2) or primers 3 and 4 (lines 3 and 4) The sizes of the obtained products are given to the right in bps. (C) Autoradiography of total lipid extracts from Synechocystis sp. PCC 6803 wild type (wt), aas knockout mutant (ko) and aas knockout complemented by the corresponding gene from Synechococcus elongatus PCC7942 (compl) fed with ${ }^{14} \mathrm{C}$-labeled oleic acid. 


\subsection{AAS deficient cells of cyanobacteria secrete fatty acids into the medium}

It has been shown in other studies (Michinaka et al., 2003; Scharnewski, 2005) that the deletion of acyl-CoA synthetases in Saccharomyces cerevisiae resulted in a fatty acid secretion phenotype. These strains were compromised in their capacity to activate free fatty acids. The clearly visible differences between liquid cultures of wild type and aas deficient Synechocystis sp. PCC 6803 and Synechococcus elongatus PCC 7942 strains suggested that such a phenotype could be also characteristic for cyanobacteria. The walls of flasks of wild type cultures became overgrown with the cells, whereas this did never happen in flasks of aas knockout mutant cultures. This phenomenon might be explained by the lowered surface tension of the media, resulting from the presence of fatty acids in the cultures of aas knockout mutants. To test this hypothesis media of three independent cultures of each strain, grown to stationary phase, were extracted and analyzed for free fatty acids. And indeed, in a representative experiment, in the culture media of aas deficient Synechocystis sp. PCC 6803 and Synechococcus elongatus PCC 7942 free fatty acids were detected in amounts $16.6( \pm 3.6) \mathrm{nmol} / \mathrm{ml}$ and $31.2( \pm 4) \mathrm{nmol} / \mathrm{ml}$, respectively, while in the culture media of wild type strains no fatty acids were measured. In order to investigate this fatty acid secretion phenotype in some more detail, the profiles of extracellular and intracellular fatty acids were compared (figure 6). The samples were collected from cultures in stationary growth phase. To distinguish between free and esterified fatty acids, cellular samples were split and subjected to two different protocols, leading to either methylation of free fatty acids or transmethylation of esterified fatty acids. Figure 6 A illustrates the fatty acid secretion phenotype in cyanobacteria, which is related to the deletion of AAS activity. The fatty acids detected in the medium reflect the fatty acid composition found in membrane lipids of the individual cyanobacterial strain with exception of one compound, identified later as 3-hydroxymyristic acid. This substance was present in relatively large amounts in media, but was not found in esterified form in the cells.

Comparison of intracellular and extracellular fatty acid profiles showed some general similarities in the fatty acid patterns of distinct fatty acid pools, namely: Patterns of free fatty acids within cells of an individual strain reflected the fatty acid composition found in the membranes. There were also no significant differences in the fatty acid compositions between esterified and free fatty acid pools when wild type and the corresponding aas knockout were compared. Those fatty acids which were found in cells were detected also 
in the medium of aas knockout mutants. Nevertheless, having a closer look on individual fatty acid concentrations in certain pools, several exceptions could be found, which did not follow these general tendencies, but may be indicative for special features of the fatty acid metabolism in cyanobacterial cells.

The first peculiarity, already mentioned above, was the presence of significant amounts of a compound in the media of aas knockout mutants, which was not found in esterified form in any of the strains tested. In the pool of free fatty acids inside the cells of aas deficient Synechocystis sp. PCC 6803 very minor amounts of this substance were detected. Via GCMS analysis this compound was identified to be 3-hydroxymyristic acid, and subsequently its identity was confirmed by co-migration with a standard (figure 7 A). The possible source of the 3-hydroxymyristic acid in the media will be discussed in a separate section.

The second interesting point was related to the presence of $\mathrm{C} \mathrm{18:0} \mathrm{in} \mathrm{distinct} \mathrm{fatty} \mathrm{acid}$ pools. It is worth being noted that the fatty acid profiles in membranes of wild type and corresponding knockout strains were nearly the same and only the presence of C 18:0 in knockout cells made a noticeable difference. It was true for both Synechocystis sp. PCC 6803 and Synechococcus elongatus PCC 7942 that the pools of free fatty acids inside the cells reflected the fatty acid composition of the membranes and the overall concentration of free fatty acids were higher in cells lacking AAS compared to wild type cells. But interestingly, in the aas knockout mutant of Synechocystis sp. PCC 6803 C 18:0 showed up only in the pool of free fatty acids in relatively large amounts.

The last observation that should be mentioned was the shift in the ratio of $\mathrm{C} 16: 0$ to $\mathrm{C} 16: 1$ between intracellular and extracellular fatty acids, occurring in Synechocystis sp. PCC 6803 as well as in Synechococcus elongatus PCC 7942. The following more detailed analysis will focus on only one of both strains, but the results obtained for both of them are summarized in table 1. In Synechocystis sp. PCC 6803 aas knockout cells the ratio of C 16:0 to $\mathrm{C} 16: 1$ was 5.0 in membranes and 3.7 in the pool of free fatty acids inside the cells. Surprisingly, in the culture media C 16:1 showed up in amounts much larger than C 16:0, and the ratio $\mathrm{C} 16: 0$ to $\mathrm{C} 16: 1$ was changed significantly to 0.2 . Interestingly, $\mathrm{C} 16: 0$, which was the most abundant fatty acid within the cells, representing $45 \%$ of total fatty acids in esterified form and $37.5 \%$ in free fatty acid pool, constituted only $3.8 \%$ of total 
extracellular fatty acids. The alterations in the ratio of 16:0 to $16: 1$ seemed to indicate a certain selectivity of the transport mechanism.

A

Fatty acids secreted into medium

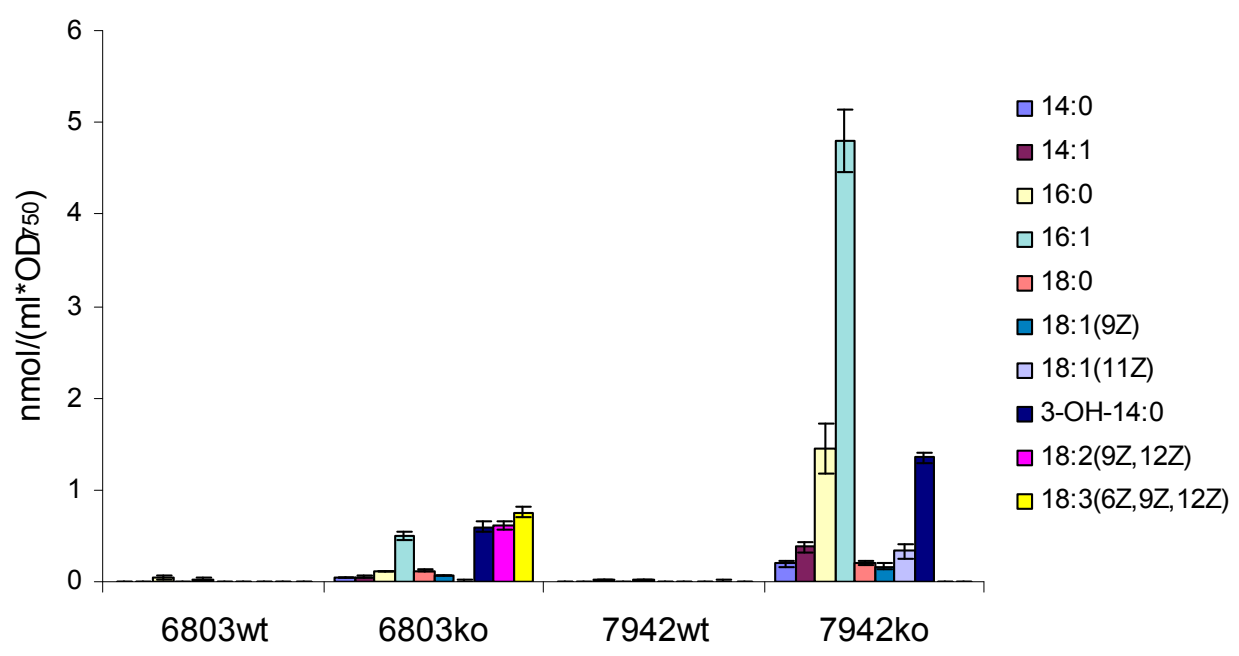

B

Free fatty acids in cells

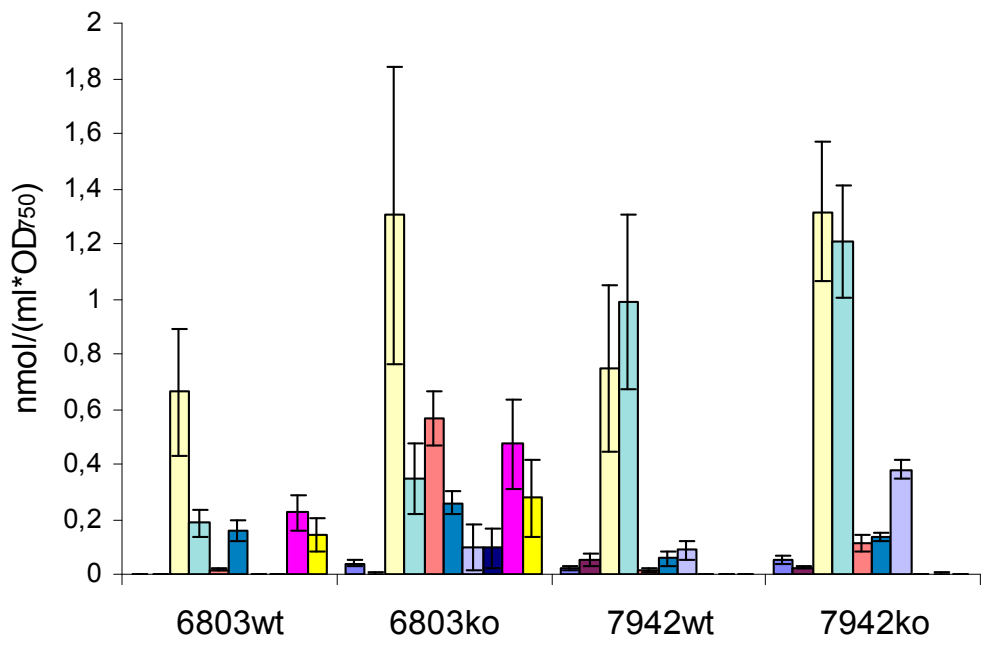

14:0

口 14:1

口16:0

ㄴ16:1

口18:0

18:1(9Z)

口 18:1(11Z)

- 3-OH-14:0

口 18:2(9Z,12Z)

口 18:3(6Z,9Z,12Z) 


$$
\text { C Esterified fatty acids }
$$

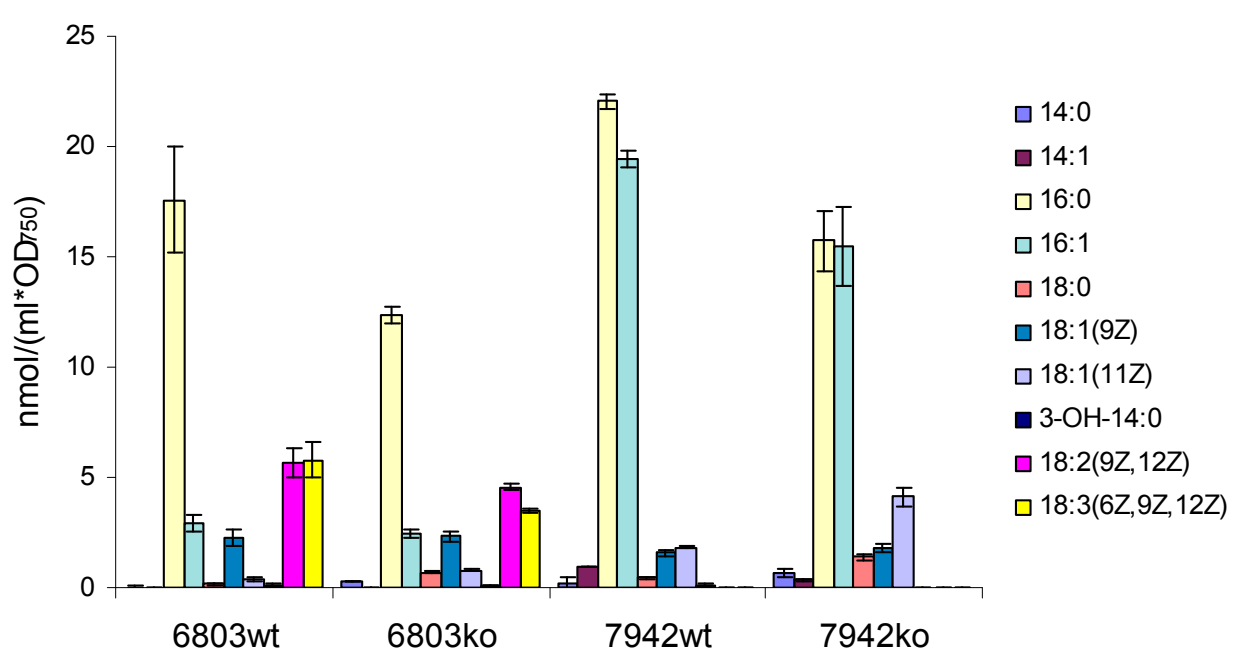

Figure 6. Comparison of fatty acid profiles of cells and the culture medium of different cyanobacterial strains. (A) Free fatty acids in the culture media (B) Free fatty acids within the cells (C) Esterified fatty acids in the cells. Results are shown for Synechocystis PCC 6803 wild type and acyl-ACP synthetase knockout mutant (6803wt, $6803 \mathrm{ko}$ ) as well as for the corresponding strains of Synechococcus elongatus PCC 7942 (7942wt, 7942ko). For each strain three independent cultures were analyzed. The error bars represent the standard deviations.

Table 1 Ratio of C 16:0 to C 16:1 in distinct fatty acids pools of Synechocystis sp. PCC 6803 and Synechococcus elongatus PCC 7942 wild types (wt) and knockout (ko) strains.

\begin{tabular}{|c|c|c|c|c|}
\hline \multirow{2}{*}{\multicolumn{2}{|c|}{}} & \multicolumn{3}{|c|}{ Ratio of C 16:0 to C 16:1 } \\
\cline { 3 - 5 } \multicolumn{2}{|c|}{} & $\begin{array}{c}\text { esterified } \\
\text { FA }\end{array}$ & $\begin{array}{c}\text { FFA in } \\
\text { cells }\end{array}$ & $\begin{array}{c}\text { FFA in } \\
\text { medium }\end{array}$ \\
\hline \multirow{2}{*}{ Synechocystis sp. PCC 6803 } & wt & 6.0 & 3.6 & - \\
\cline { 2 - 5 } & ko & 5.0 & 3.7 & 0.2 \\
\hline \multirow{2}{*}{ Synechococcus elongatus PCC 7942 } & wt & 1.1 & 0.8 & - \\
\cline { 2 - 5 } & ko & 1.0 & 1.1 & 0.3 \\
\hline
\end{tabular}




\subsection{3-hydroxymyristic acid found in the culture media of aas knockout strains is released from lipopolysaccharide}

The detection of 3-hydroxymyristic acid detected in the culture media of AAS deficient strains raised questions about the origin of this compound. 3-hydroxymyristic acid is known to be a component of lipid A, a hydrophobic domain of lipopolysaccharides (LPS) in cell walls of Gram-negative bacteria. The detailed composition of the LPS in the strains employed in this study is not known; nevertheless the LPS was assumed to be the possible source of the unusual fatty acid found in media. To test this hypothesis the LPS from wild type cells of Synechocystis sp. PCC 6803 was extracted and subjected to acidic methanolysis. Resulting methyl esters were analyzed by gas chromatography. One of the signals was identified as 3-hydroxymyristic acid by co-migration with an authentic standard (figure $7 \mathrm{~B}$ ). Thus, it can be considered that 3-hydroxymyristic acid found in the media was released either from mature LPS or from certain steps during its biosynthesis. Three other compounds of LPS, which retained before 3-hydroxymyristic acid, were identified to be C 16:0, C 18:0, and C 18:1 (11Z), whereas signals with retention time after 3-hydroxymyristic acid originated from phenolic compounds of the buffer used for extraction of the LPS.

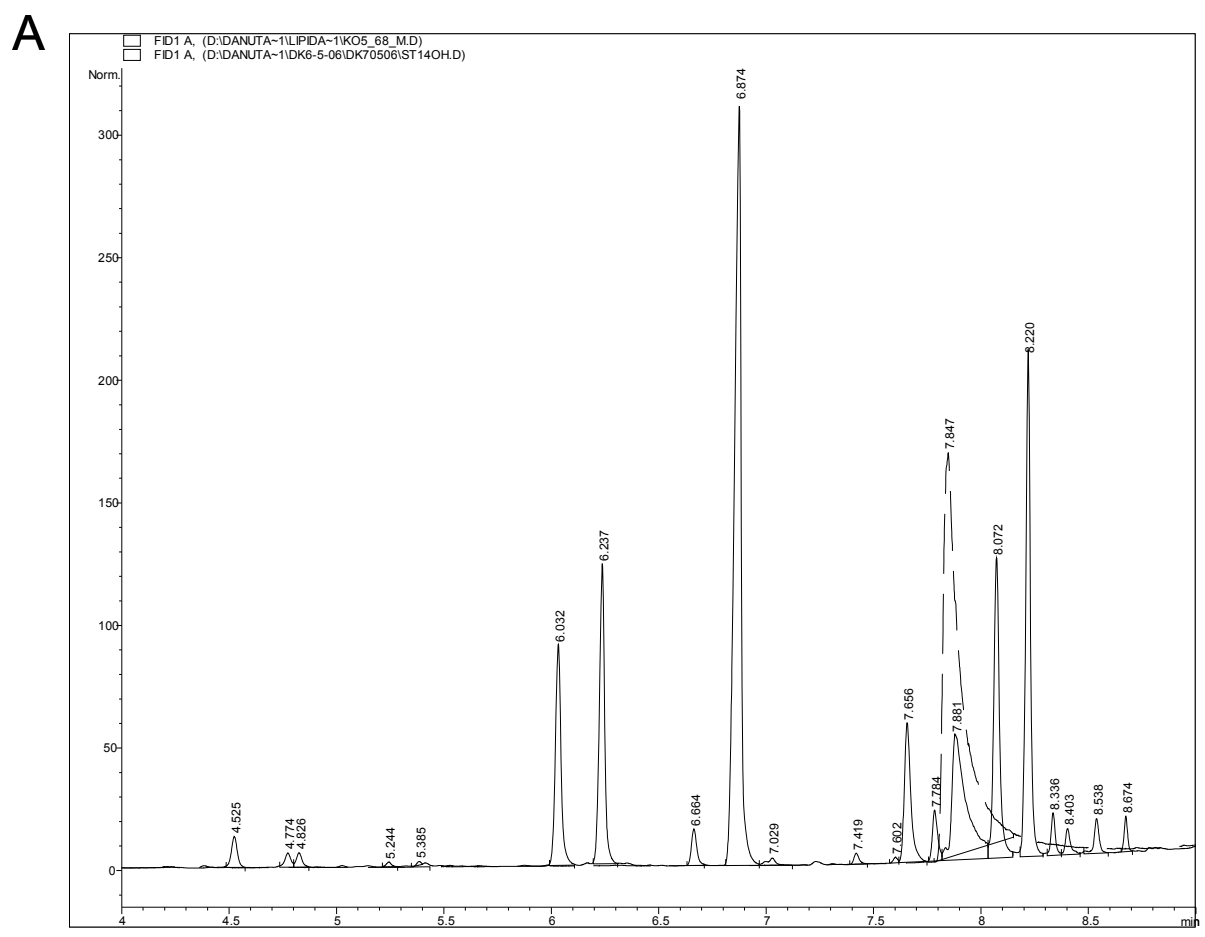




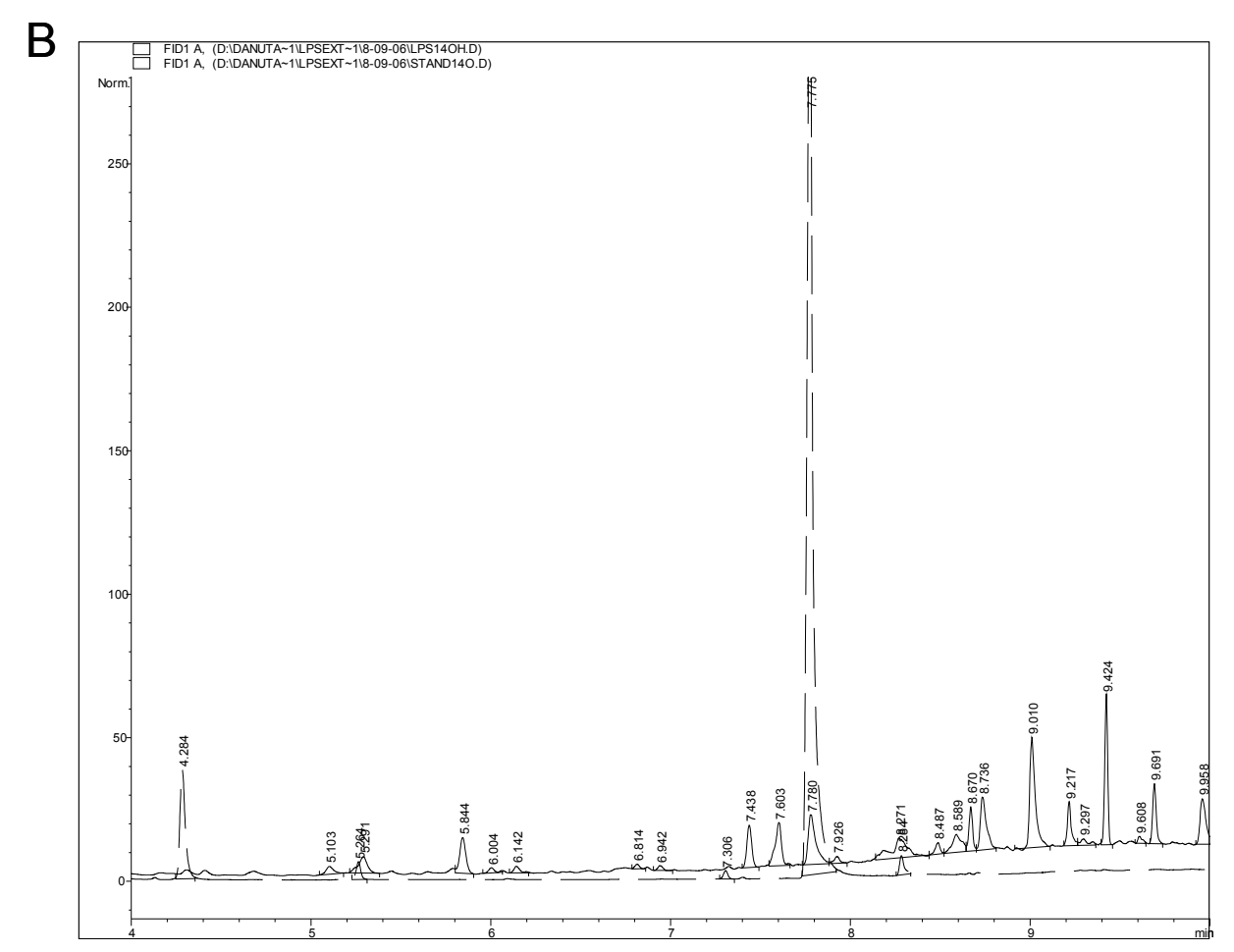

Figure 7. Identification of 3-hydroxymyristic acid. Gas chromatography analysis of methyl esters obtained from culture media (A) and lipopolysaccharides (B) of Synechocystis sp. PCC 6803. The presence of 3-hydroxymyristic acid was confirmed by co-migration with an authentic standard (dotted line).

\subsection{Cyanobacteria cannot accumulate lauric acid}

The significantly different ratios of $\mathrm{C} \mathrm{16:0}$ to $\mathrm{C} 16: 1$ detected inside the cells and in the culture medium suggested already a certain selectivity of the fatty acid export mechanism. Feeding experiments using fatty acids of different chain length provided another hint for this selectivity of the fatty acid transport. Wild type and knockout cells of Synechocystis sp. PCC 6803 were grown in media containing either radio labeled lauric acid or palmitic acid. TLC analysis (figure 8) of the lipids extracted from harvested cells revealed an additional phenomenon to the one described above (3.2). The results seemed to indicate that the mutant strain was not only unable to incorporate lauric acid into lipids but even failed to take up this fatty acid from the medium. Upon closer inspection it became clear that the lack of the band representing free fatty acids is not due to the impaired lauric acid transport into the cell but it results from incapability of cyanobacterial cell to accumulate lauric acid. In wild type cells radioactive label was present in diverse lipid classes, indicating that the import of lauric acid was possible, but the spot representing 
accumulation of free fatty acids was slightly above the standard for lauric acid on the TLC plate. In knockout mutant cells the label did not appear in lipid classes and there was only a hardly visible spot corresponding to free fatty acids. In contrast to lauric acid, palmitc acid was accumulated by cells of both wild type and mutant strains. In both strains one labeled spot migrated together with the fatty acid standard and in the wild type strain the label was present in different lipid classes in addition. The same experiment performed with Synechococcus elongatus PCC 7942 gave comparable results (data not shown).

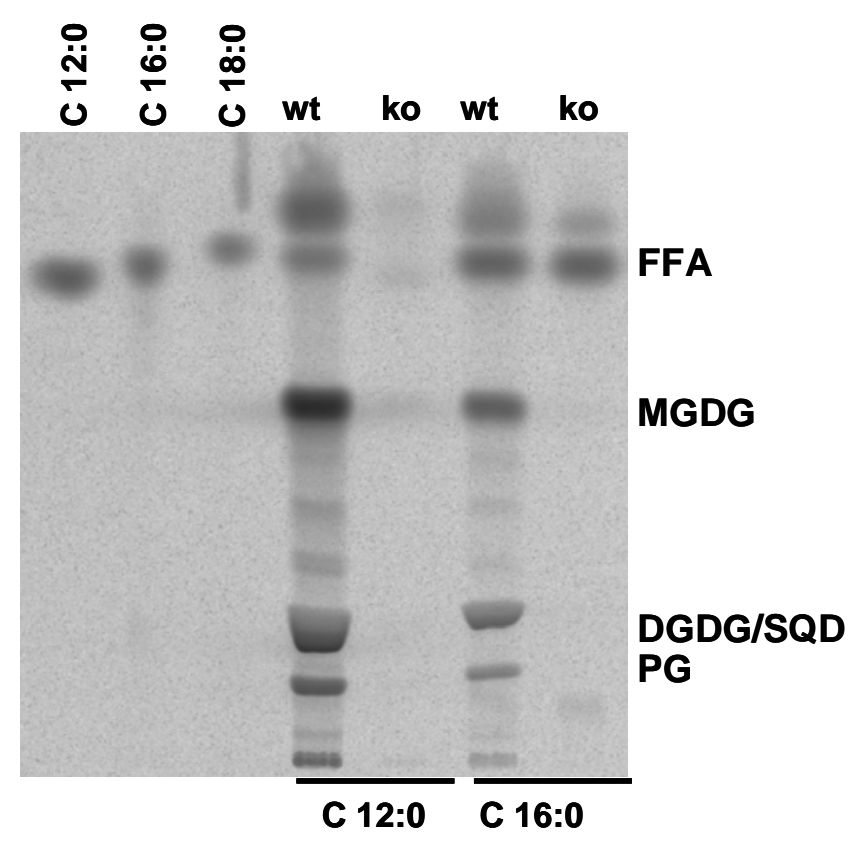

Figure 8. Autoradiography of total lipid extracts from Synechocystis PCC 6803 wild type (wt) and the aas knockout mutant (ko) fed with radio labeled lauric acid or with palmitic acid. Lipids were separated by TLC using acetone:toluene:water (91:30:8) as solvent system. FFA - free fatty acids, MGDG - monogalactosyl diacylglycerol, DGDG - digalactosyl diacylglycerol, SQDG - sulfoquinovosyl diacylglycerol, PG - phosphatidylglycerol.

\subsection{Fatty acids uptake depends on the length of carbon chain}

The previous experiment showed that depending on their chain length the destination of the acquired fatty acids might be different. In order to gain more information about characteristics of the fatty acid uptake in general and the influence of the fatty acid chain length on this process, a broader range of substrates was used and the studies based on feeding cells with labeled fatty acids were extended as follows. The cells were fed with 2 nmol fatty acids per $\mathrm{ml}$ culture. After $50 \mathrm{~min}$ and $19.3 \mathrm{~h}$, respectively, the radioactivity remaining in the culture medium was counted and subtracted from the total amount, which 
Results

59

was added to the culture. The difference was assumed to be taken up by the cells. Figure 9 presents results obtained for wild type and the alas knockout mutants of Synechocystis sp. FCC 6803 and Synechococcus elongatus PCC 7942 fed with various fatty acids spanning the length of the carbon chain from 12 to 16 carbon atoms. The results obtained for stearic acid are not much different from those for palmitic acid and are not presented here. On the pie chart the white zones represent the percentage of labeled fatty acids measured in culture media, whereas black zones represent the radioactivity calculated to be taken up by the cells. It is possible that certain inaccuracy occurred, since fatty acids could have attached unspecificly to the surface of cells but were considered as intracellular pool. Nevertheless, this should not influence the results in general, as for each experiment cultures of the same optical density were used.

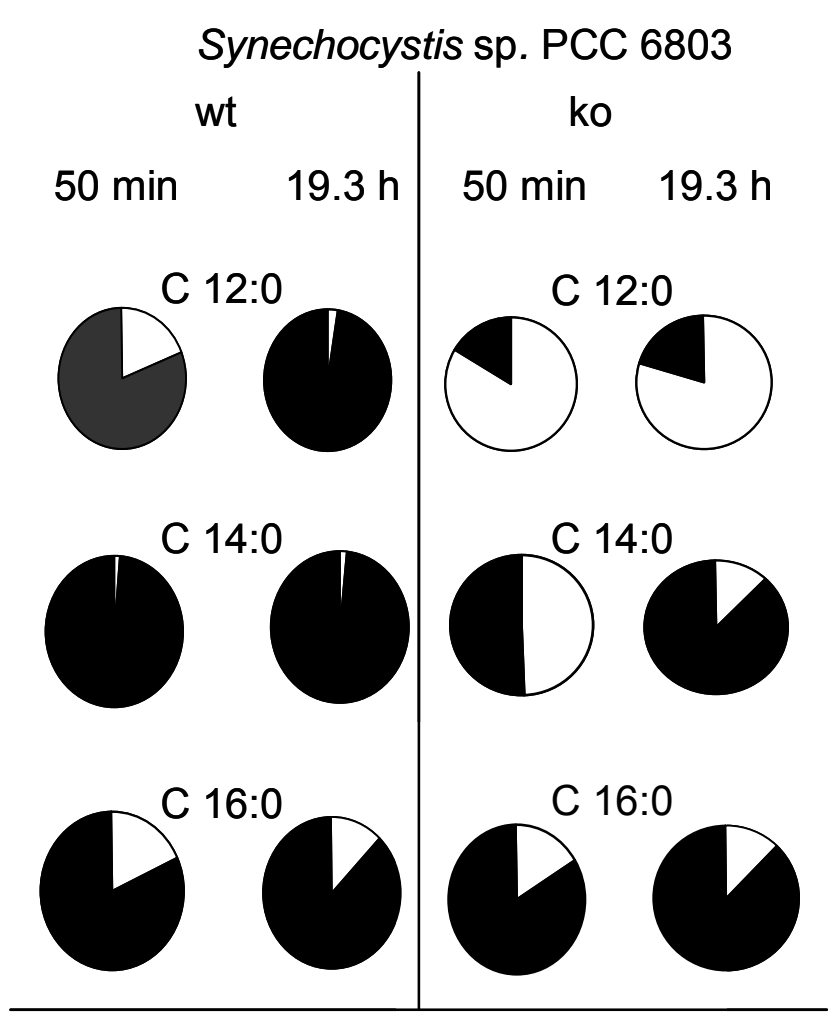




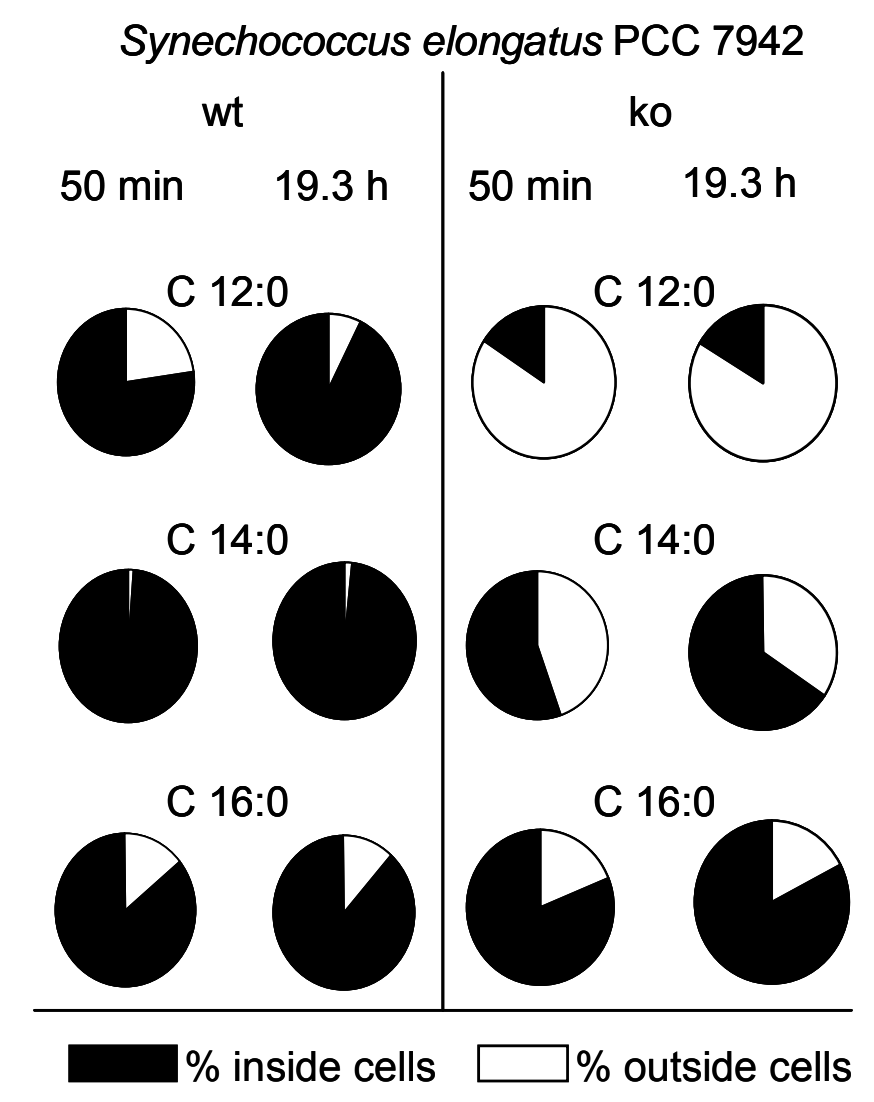

Figure 9. Rate of fatty acids uptake. ${ }^{14} \mathrm{C}$-labeled fatty acids were added individually to wild type (wt) or aas knockout (ko) cultures of Synechocystis sp. PCC 6803 and Synechococcus elongatus PCC 7942 and the radioactivity remaining in the media was measured after incubation of $50 \mathrm{~min}$ and $19.3 \mathrm{~h}$, respectively.

The first striking observation was the difference in the uptake of medium chain fatty acids compared to long chain fatty acids. As an example the results obtained for wild type and the aas knockout mutant of Synechocystis sp. PCC 6803 fed with lauric and palmitic acid will be presented in more detail. Radioactivity measured in the media upon feeding of lauric acid comprised in wild type cultures $18.9 \%$ after 50 min and $2.4 \%$ after $19.3 \mathrm{~h}$ based on the total amount which was fed to the cells. In mutant cultures the corresponding values were much higher: $83.3 \%$ and $78.9 \%$, respectively. In contrast, when palmitic acid was fed to cells, there was no significant difference between wild type and knockout mutant in the rate of fatty acid uptake. After 50 minutes incubation $18 \%$ and $16.3 \%$ of the total amount added to the cultures was found in the media of wild type and knockout cells. The values measured after 19.3 hours were the same for both strains and constituted $12.3 \%$ of the initial amounts. Comparable results were obtained for Synechococcus elongatus PCC 7942. 
For two reasons a separate remark should be made about myristic acid uptake. First, for both wild type strains the uptake of myristic acid was much more efficient compared to any other fatty acid tested. After $50 \mathrm{~min}$ incubation $98.6 \%$ of radioactivity fed was accumulated by the cells. Second, similar to lauric acid there was a difference in the uptake rate between wild type and aas knockout strains, however, in contrast to lauric acid the amounts of myristic acid in the culture media of aas knockout mutants were depleting during incubation. In aas mutant of Synechocystis PCC $680349.1 \%$ was measured in the medium after $50 \mathrm{~min}$ incubation and $12.5 \%$ after $19.3 \mathrm{~h}$. In the aas mutant of Synechococcus elongatus PCC 7942 it was $44.7 \%$ and $34.8 \%$, respectively.

The kind of measurements that were performed did not distinguish between free fatty acids accumulated by the cells and fatty acids incorporated into lipids. In order to follow the fate of the added fatty acids, cells were extracted and analyzed by TLC (not shown). The results were in agreement with the phenomena described above, namely: In knockout mutant strains, unlike in wild type strains the label was not incorporated into diverse lipid classes. Moreover spots of relatively high intensities representing free fatty acids were detected when either knockout mutant strains or wild type strains were fed with C 16:0 or C 18:0, but were weaker in case of the mutant strains fed with C 14:0 and were hardly detectable when C 12:0 was used for feeding. The spots representing free fatty acids in wild type strains fed with medium chain fatty acids migrated slightly above their corresponding standards.

\subsection{Respond to temperature shift from $30^{\circ} \mathrm{C}$ to $22^{\circ} \mathrm{C}$}

In the studies presented so far it was shown that there is a certain pool of free fatty acids in cells of cyanobacteria and that these fatty acids reflect their composition in membranes. In aas knockout mutants the overall concentration of free fatty acids was higher than in the corresponding wild type strains and, moreover, a fatty acid secretion phenotype was observed (figure 4). However, it was not clear under which conditions fatty acids were released from membrane lipids before being secreted into the culture medium. In order to follow the fatty acid turnover within the cell it was essential to establish an intracellular marker. Since it is known that cold shock induces the expression of $\omega 3$-desaturase in Synechocystis sp. PCC 6803 (Los and Murata, 1999), an experiment was designed, in which the growth temperature of the aas knockout mutant was lowered from $30^{\circ} \mathrm{C}$ to $22^{\circ} \mathrm{C}$ and the newly generated $\omega 3$-unsaturated fatty acids were used as markers. For 
measurement of the concentration of $\mathrm{C} 18: 3(9 \mathrm{Z}, 12 \mathrm{Z}, 15 \mathrm{Z})$ and $\mathrm{C} 18: 4$ in distinct fatty acid pools the first sample was collected at "time point 0 ", referring to the point when the temperature was lowered and the following after 8, 14, 25, 31 and 37 hours. Figure 10 presents an increase in esterified $\omega 3$-unsaturated fatty acids concentrations in the course of time and a concomitant increase in the pool of free fatty acids in the cell. This finding supports the idea that the release of fatty acids applies not to dispensable fatty acids of somewhat minor value for the cell but to exactly those molecules which represent the typical profile found in membrane lipids. The experiment also showed that even those fatty acids are released which have been generated just very recently. 


\section{Esterified fatty acids}

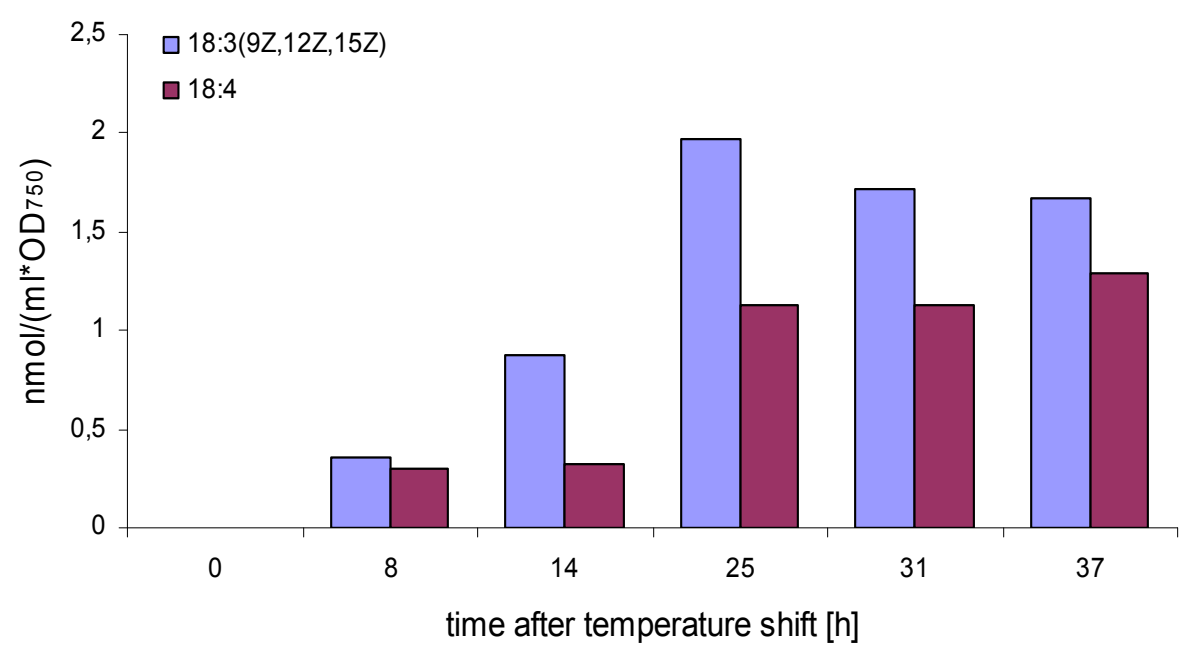

Free fatty acids in cells

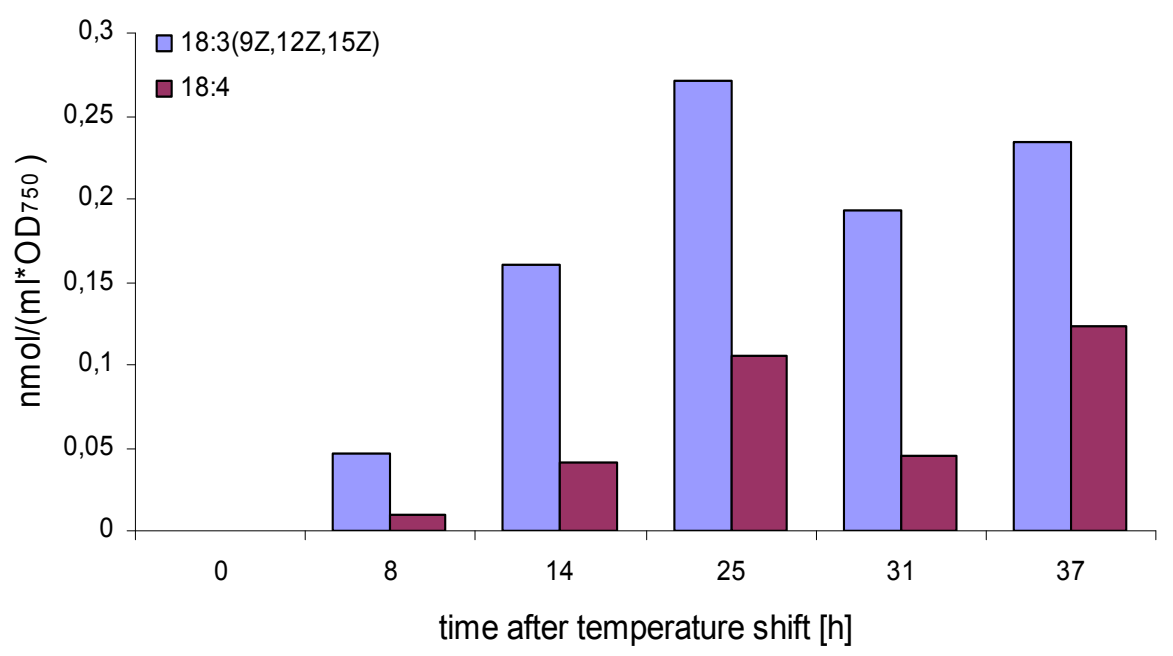

Figure 10. Respond to cold shock. Changes in the concentrations of $\omega 3$-unsaturated fatty acids in the aas knockout mutant of Synechocystis sp. PCC 6803 in the pool of esterified fatty acids (A) and the pool of free fatty acids (B) after temperature shift from $30^{\circ} \mathrm{C}$ to $22^{\circ} \mathrm{C}$.

\subsection{Subcellular localization of AAE15 and AAE16}

According to Target P prediction (Emmanuelsson et al., 2000), both AAE15 and AAE16 carry a plastidial targeting sequence. In order to prove plastidial localization of the enzymes a N-terminal $262 \mathrm{bp}$ fragment of AAE15 and a N-terminal $214 \mathrm{bp}$ fragment of $A A E 16$ were cloned in-frame in front of the sequence of EYFP and under the control of the constitutive $35 \mathrm{~S}$ promoter. The constructs were transformed into onion epidermal cells by 
particle bombardment for transient expression. Onion cells were co-transformed with an ACP-ECFP fusion construct to provide a positive control for plastidial localization. Subcellular localization of the expressed proteins was analyzed by fluorescent microscopy. By this means the plastidial localization of both fusion proteins AAE15 $1-262$-EYFP and AAE16 ${ }_{1-214}$-EYFP was confirmed by co-localization with an ACP-ECFP fusion protein (figure 11). From this experiment it was concluded that AAE15 and AAE16 are both localized in plastids.
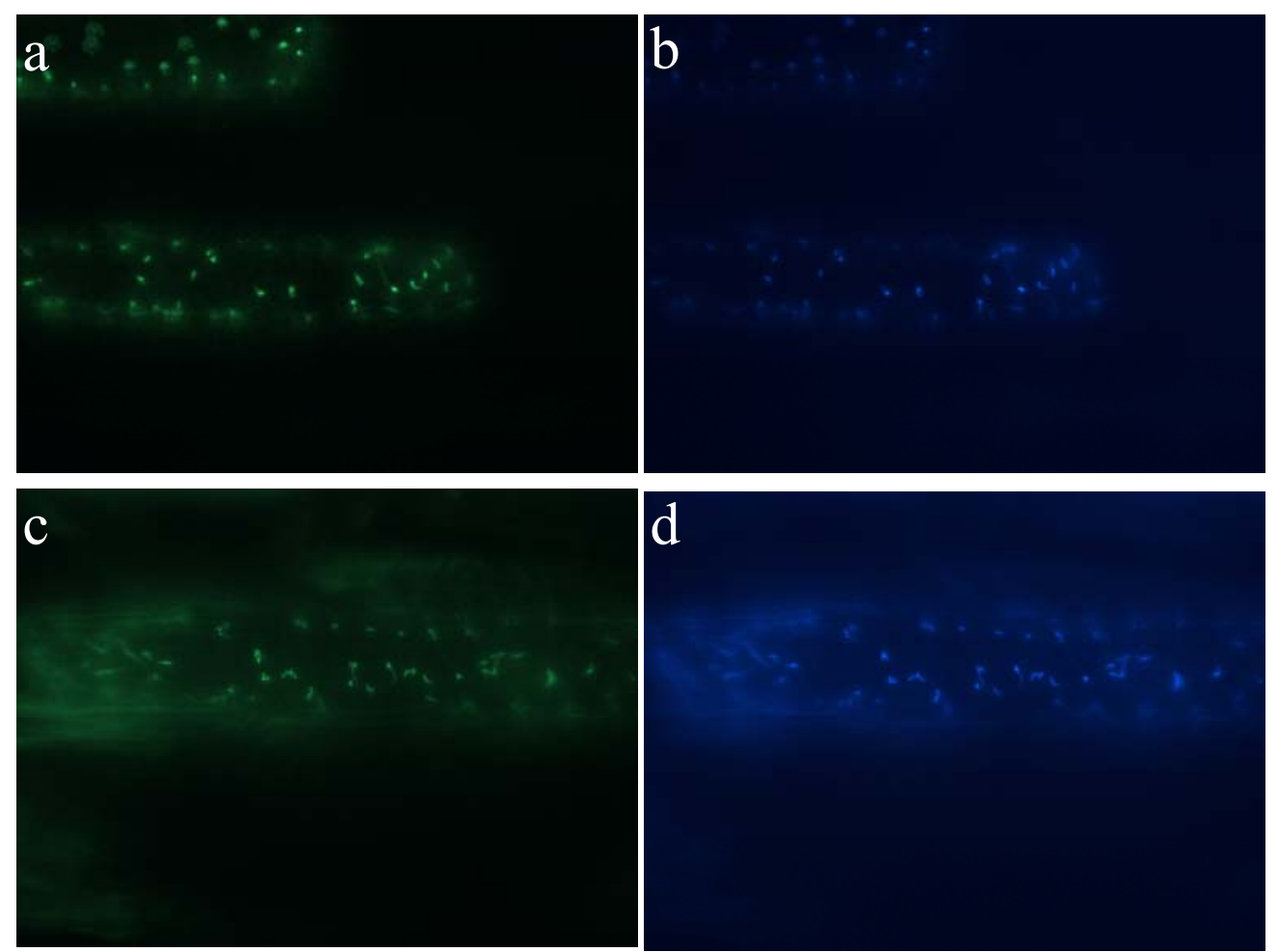

Figure 11. Subcellular localization of AAE15 and AAE16 in onion epidermal cells. Onion epidermal cells were co-transformed biolistically with AAE-EYFP and ACP-ECFP fusion constructs and subcellular protein targeting was analyzed by fluorescent microscopy using an appropriate filter set. Plastidial localization of AAE15 (a) and AAE16 (c) was confirmed by co-localization with an ACP-ECFP fusion protein (b,d).

\subsection{Heterologous expression and purification of AAE15 and AAE16}

To determine the enzymatic activity of AAE15 and AAE16, both proteins were expressed in a Baculovirus system containing an N-terminal synthetic His-tag. Initially, for both genes, constructs carrying either the complete ORF or the gene devoid of the predicted plastidial targeting sequence were cloned and introduced into Sf9 insect cells for protein 
expression. Initial immunoblot analysis showed that extracts from Sf9 cells expressing the complete ORF of either of both genes resulted in no or only weak expression (data not shown). The removal of the predicted plastidial targeting signal on the other hand led to a significant increase of the expression levels. Thus, in the following study only truncated versions of both genes, named $A A E \Delta 15$ and $A A E \triangle 16$, were used. Figure 12 presents immunoblot analysis of crude extracts, membrane fractions and pure His-tagged protein fractions from cells expressing AAE $\Delta 15$ or AAE $\Delta 16$. Both constructs yielded fusion proteins of the expected size of approximately $79 \mathrm{kDa}$.

A

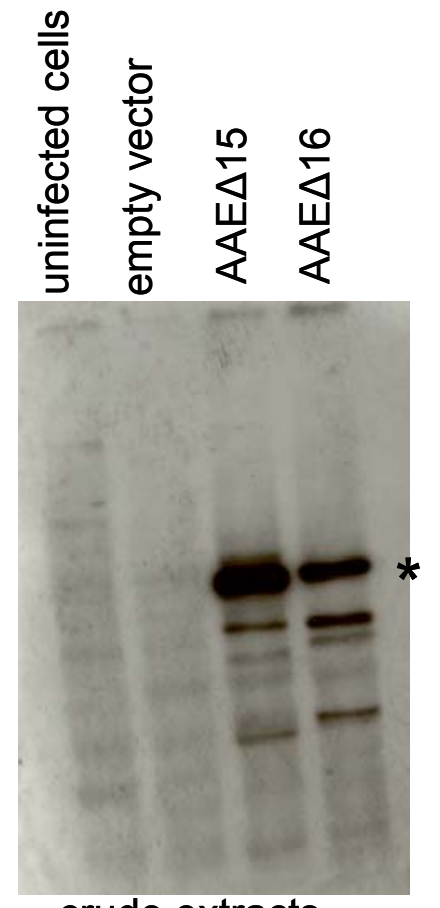

crude extracts
B

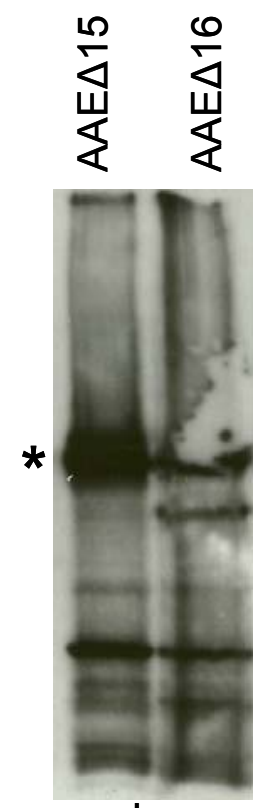

membranes
C

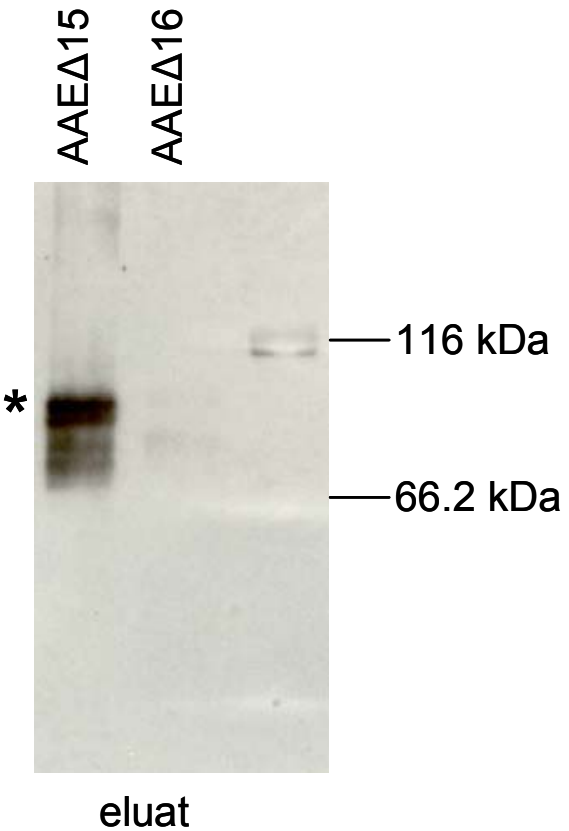

eluat

Figure 12. Western blot analysis of His-tagged AAE $\Delta 15$ and AAE $\Delta 16$ from Arabidopsis. Samples of whole cell lysates $(10 \mu \mathrm{g})(\mathrm{A})$, isolated membrane fractions (B) and purified protein (C) were subjected to immunoblot analysis. The positions and sizes of molecular mass standards are indicated to the left of the immunoblot. The AAE proteins are marked with asterisks.

Figure $12 \mathrm{~A}$, which is representative for all overexpression experiments that were performed, indicates that expression level of AAE $\Delta 15$ was higher than the expression level of AAE $\Delta 16$. Nevertheless, amounts of both proteins were sufficient to carry out further purification. Analysis of membrane fractions enriched in expressed proteins is presented in 
figure $12 \mathrm{~B}$. Membranes were subjected to the same protocol of solubilization, and proteins released were purified by ion metal affinity chromatography. Surprisingly the obtained results were very different for both proteins. Whereas it was possible to obtain highly pure fractions of AAE $\Delta 15$ by this procedure the same method resulted in a complete loss of the AAE $\Delta 16$. Detection of the His-tagged proteins in the eluted fractions is presented on figure $12 \mathrm{C}$.

\subsection{Acyl-ACP synthetase activity assays}

In order to establish enzymatic activity, purified AAE $\Delta 15$ was subjected to the acyl-CoA synthetase and to the acyl-ACP synthetase activity assays in vitro, in which radioactive labeled lauric acid was used as a substrate. The results (not shown) demonstrated unequivocally that the enzyme displayed acyl-ACP synthetase activity. These results were supporting findings published by Koo and co-workers (Koo et al., 2005). Because AAE15 and AAE16 are $77 \%$ identical on amino acid level, it was reasonable to expect that AAE16 may show acyl-ACP synthetase activity as well. Since it is possible that there are different substrate specificities among AA15 and AAE16, nine different fatty acids were tested in AAS activity assays, ranging in carbon chain length from 8 to 18 carbons containing 0 to 3 double bonds. In all experiments performed by Koo et al. only medium chain fatty acids were tested as the major focus of the study was the elongation of exogenous fatty acids. For that reason any potential AAS activity of AAE16 toward long chain fatty acids might have been missed. Since it was not possible to obtain AAE16 purified to homogeneity, crude protein extracts of lysed cells were utilized to analyze substrate specificity of AAE $\Delta 15$ and AAE $\Delta 16$. The assays were conducted in the presence of ATP, ACP and [1-

$\left.{ }^{14} \mathrm{C}\right]$ labeled fatty acid. Crude extracts from uninfected cells and cells infected with virus carrying empty vector were used as a control. As presented in figure 13, AAE $\Delta 15$ demonstrated acyl-ACP synthetase activity with substrate specificity towards medium length chain fatty acids, whereas AAE $\Delta 16$ was not active under the conditions employed. For AAE $\Delta 15$ activity of 150,239 and $361 \mathrm{pmol} / \mathrm{min} / \mathrm{mg}$ total protein was detected, when decanoic, lauric and myristic acid were employed as substrates, respectively. Values measured in control assays indicated a certain inaccuracy of the method, caused perhaps by improper washing of non converted fatty acids. These fatty acids might have attached unspecificly to components of the extracts from lysed insect cells. To obtain more accurate results, substrate specificity determination was repeated with purified AAE $\Delta 15$. Data 
presented in figure 14 confirmed the medium chain length specificity of the enzyme, but showed also that the enzyme was able to activate other fatty acids with strongly reduced effectiveness.

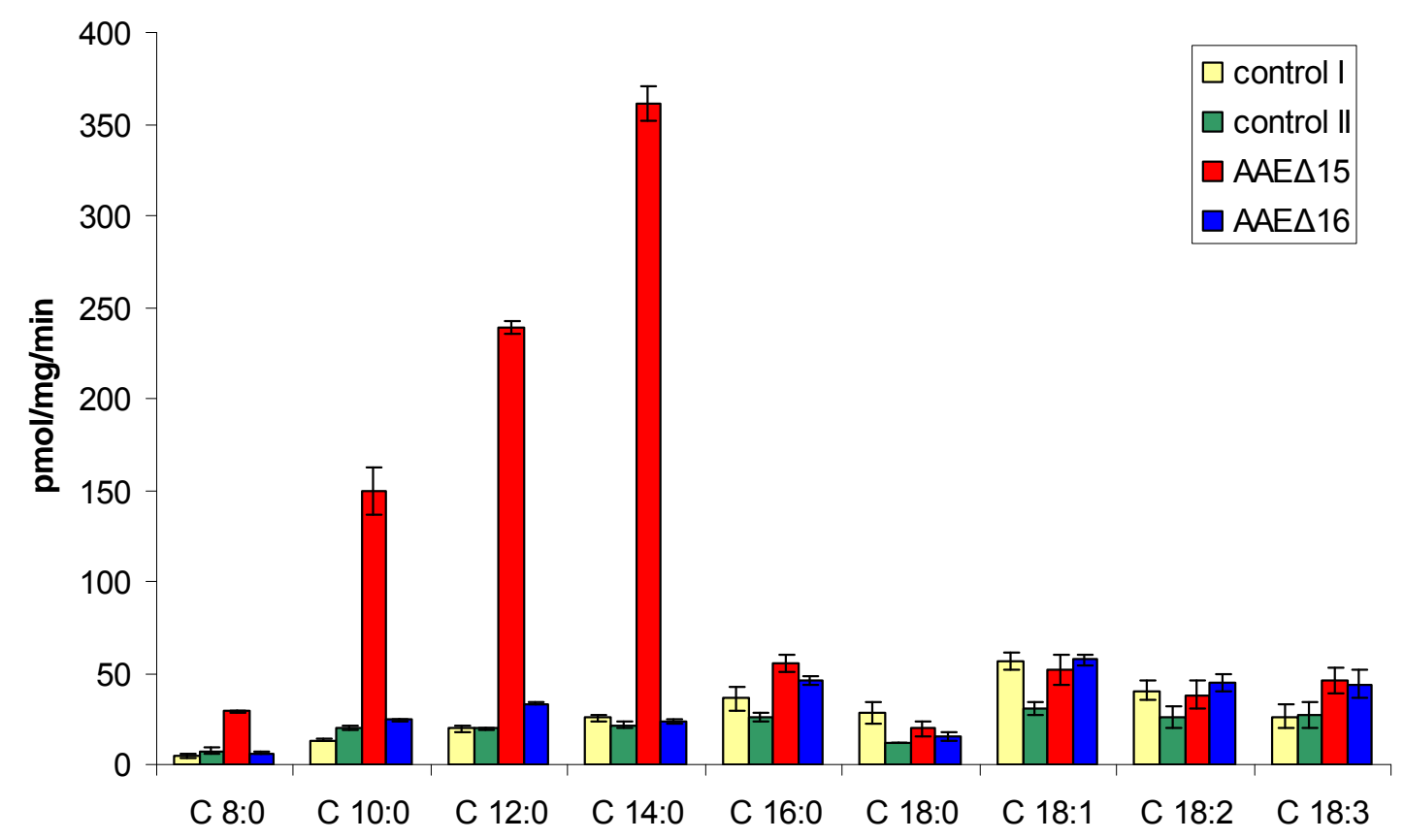

Figure 13. Acyl-ACP synthetase activity and substrate specificity of AAE $\Delta 15$ and AAE $\Delta 16$ expressed in insect cells. Crude extracts of Sf9 cells were incubated with an assay mixture containing ACP, ATP and $\left[1-{ }^{14} \mathrm{C}\right]$ fatty acid for $30 \mathrm{~min}$ at $37{ }^{\circ} \mathrm{C}$. Each measurement was performed in triplicate with error bars indicating standard deviation. AAE $\Delta 15$ and AAE $\Delta 16$ are truncated proteins, lacking the predicted plastidial targeting signal. As controls uninfected cells (control I) and cells infected with the empty vector (control II) were employed as protein source. 


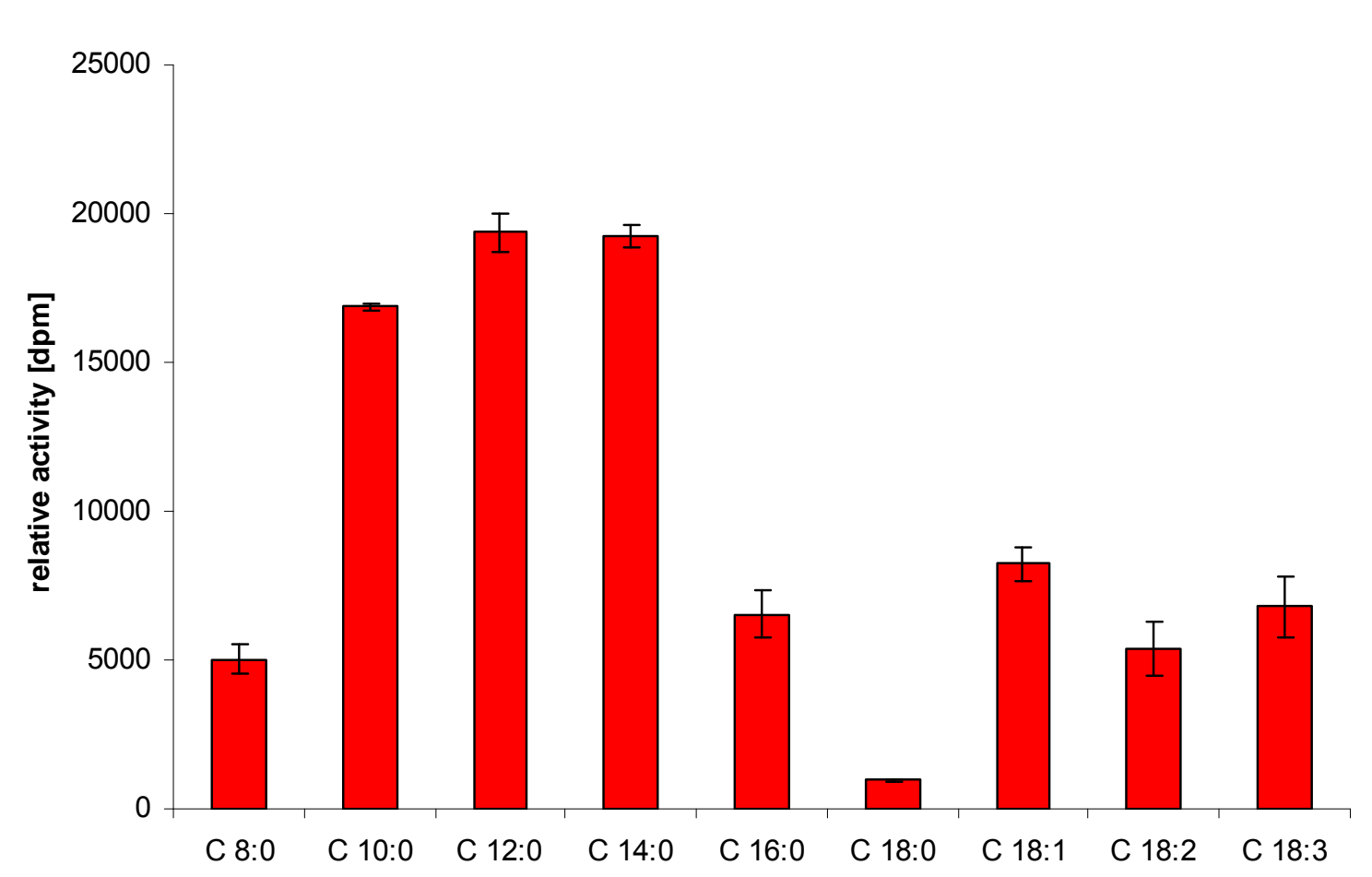

Figure 14. Substrate specificity of AAE $\Delta 15$. Purified AAE $\Delta 15$ was incubated with an assay mixture containing ACP, ATP and $\left[1-{ }^{14} \mathrm{C}\right]$ fatty acid for $30 \mathrm{~min}$ at $37{ }^{\circ} \mathrm{C}$. Each measurement was performed in triplicate with error bars indicating standard deviation.

\subsection{Complementation of Synechocystis sp. PCC 6803 aas knockout with AAEs from Arabidopsis}

Another approach to examine the activity of Arabidopsis AAEs was performed by a complementation experiment. The strain of Synechocystis sp. PCC 6803 devoid of AAS activity was complemented with either of both Arabidopsis genes and tested by feeding with radiolabeled fatty acids for reestablishment of the wild type phenotype. The Arabidopsis genes were introduced into the genome of the Synechocystis sp. PCC 6803 aas knockout mutant via homologous recombination. A schematic representation of the process is shown in figure 15. The constructs for complementation were composed of the promoter sequence from the kanamycin resistance gene, the entire ORF of $A A E 15$ or the sequence of AAE16 devoid of the plastidial targeting signal, the terminator sequence of aas from Synechocystis sp. PCC 6803, and the selection marker. The whole assembly was flanked by fragments of the kanamycin cassette as borders for the retransformation. Arrows on the scheme indicate primer pairs which were used for PCR analysis of the obtained clones. After transformation the cells were maintained on selective media for several weeks and then genomic DNA from several clones were tested by PCR reaction for the presence of 
the Arabidopsis gene. The presence of the complementation cassette in the transformed strain was confirmed by PCR employing isolated genomic DNA as template (figure $15 \mathrm{~B}$ ). In the first reaction (PCR I) primers specific to AAE of Arabidopsis were used (primer 1 and primer 2). In the second reaction (PCR II) primers specific to Synechocystis sp. PCC 6803 sequences, flanking the region of recombination, were used (primer 3 and primer 4). The second reaction proved also the absence of native aas of Synechocystis sp. PCC 6803. To exclude the possibility that PCR products were resulting from unspecific primer hybridization to the sequence of genomic DNA in a host strain, for each primer pair the control reaction utilizing genomic DNA of Synechocystis sp. PCC 6803 as template was performed.

Primers sequences and PCR results predicted for various templates DNA are presented below.

\section{PCR I}

Primers specific for $A A E 15$

Primer 1 CATCGATTCAGATGATACAGCT (AtFAA1sf771)

Primer 2 ACATGCGGCCGCACTGTAGAGTTGATCAATCTC (AtFAA1NotrHis)

Primers specific for $A A E 16$

Primer 1 GCCATCATGGCATGCTTATG (AtFAA2sf933)

Primer 2 CCTCGAGTGCGGCCGCCTACTTGTAGAGTCTTTCTA (FAA2StopNotr)

\begin{tabular}{l|l}
\hline Template & Product \\
\hline Synechocystis sp. PCC6803 wild type & No \\
Synechocystis sp. PCC6803 aas & No \\
knockout & \\
AAE 15 complementation & $1362 \mathrm{bps}$ \\
$A A E 16$ complementation & $1253 \mathrm{bps}$ \\
\hline
\end{tabular}


PCR II

Primer 3 CATTGACCTGAAACTAATCATCC (SYN6)

Primer 4 CACAGCCGGGGCACACCGACAATG (SYN2)

\begin{tabular}{l|l}
\hline Template & Product \\
\hline Synechocystis sp. PCC6803 wild type & $420 \mathrm{bps}$ \\
Synechocystis sp. PCC6803 aas & $1490 \mathrm{bps}$ \\
knockout & \\
AAE 15 complementation & $4965 \mathrm{bps}$ \\
AAE 16 complementation & $4820 \mathrm{bps}$ \\
\hline
\end{tabular}


A

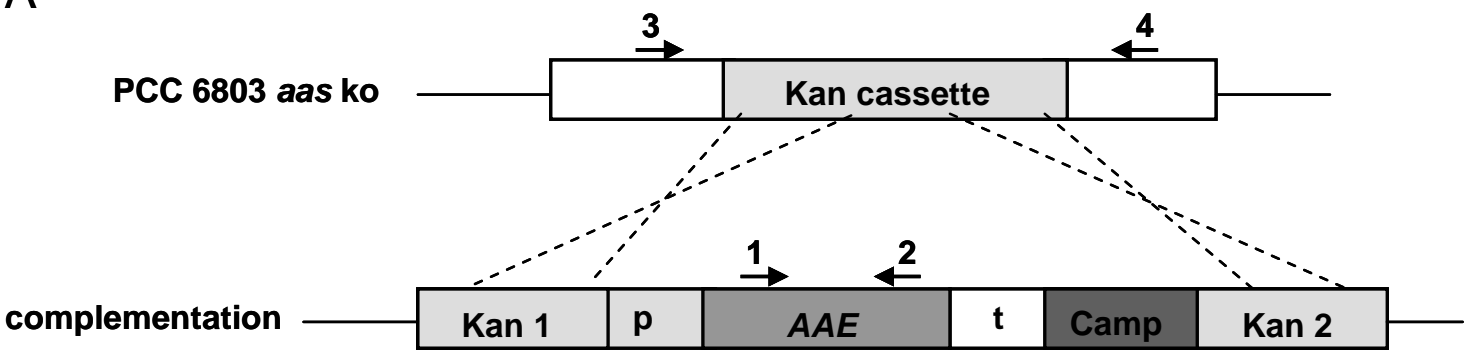

B
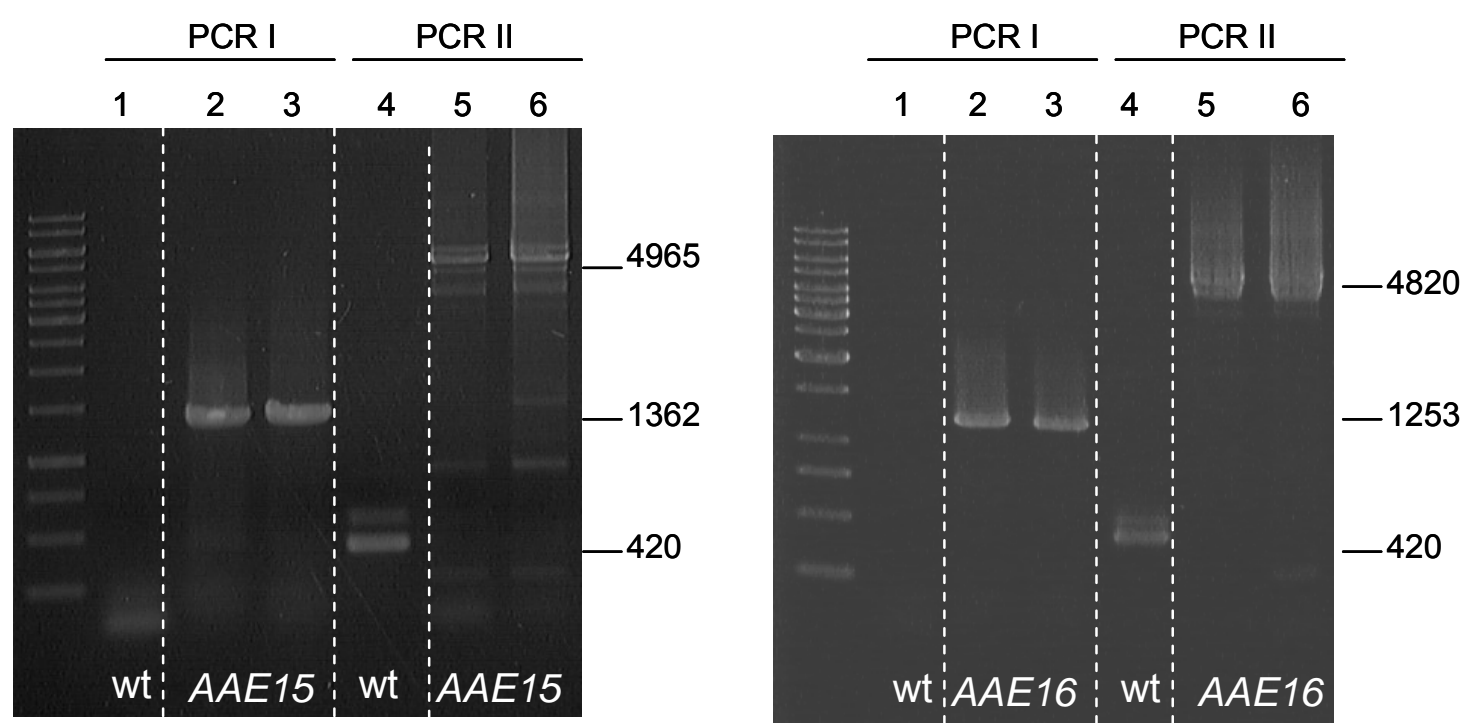

Figure 15. Complementation of Synechocystis sp. PCC 6803 aas knockout with AAEs from Arabidopsis. (A) General scheme of homologous recombination. Kan1, Kan2 - border regions of kanamycin resistance cassette; $\mathrm{p}$ - promoter sequence of kanamycin resistance gene; $A A E$ - gene introduced (either $A A E 15$ or $A A E 16$ ); $\mathrm{t}$ - terminator sequence of aas from Synechocystis sp. PCC 6803; Camp - chloramphenicol resistance cassette. (B) Complementation of Synechocystis sp. PCC 6803 aas knockout with $A A E$ from Arabidopsis was confirmed by PCR analysis (AAE15 - left image and AAE16 right image). Genomic DNA of the Synechocystis sp. PCC 6803 wild type (lanes 1 and 4) or aas mutant complemented with Arabidopsis AAE (lanes 2, 3, 5 and 6; DNA of two independent clones was tested) was used as a template for the PCR with primers 1 and 2 (lanes 1, 2 and 3) or primers 3 and 4 (lines 4, 5 and 6). The sizes of the obtain products are given to the right in bps.

Based on PCR results, clones, in which all copies of knockout cassette were replaced by the complementation cassette, were selected for feeding experiment. Cultures of strains complemented with either of both Arabidopsis $A A E$ genes were grown in media supplemented with labeled fatty acids. Cultures of Synechocystis sp. PCC 6803 wild type 
and of the aas knockout mutant, which had already been tested in this kind of experiment (3.2), served as a positive and a negative control. Six fatty acids different with respect to the length of carbon chain and the level of desaturation were utilized as substrates. Figure 16 presents TLC separation of total lipid extracts prepared from the cells fed with labeled fatty acids. The results clearly showed that complementation with either of both $A A E$ s from Arabidopsis restored the wild phenotype of Synechocystis sp. PCC 6803. The label appeared in different lipid classes indicating that exogenous added fatty acids were activated and further metabolized in cells. Special attention should be paid to the ratio of the intensity of spots representing the accumulated free fatty acids to the intensity of the spots representing lipids. This factor allowed the comparison of the substrate specificity of the native Synechocystis sp. PCC 6803 AAS and the expressed proteins of Arabidopsis as well as substrate specificity of an individual enzyme towards different fatty acids. The lower this ratio is the more fatty acids were incorporated into lipids. The relative values of fatty acid and lipid band intensities are summarized in table 2. For the calculations MGDG was taken as representative for all lipid classes. MGDG is a major constituent of cyanobacterial membranes and was represented by an easily distinguishable spot on TLC plates.

It is worth being noted that the fatty acids substrate specificity of AAE15 for medium chain length determined by in vitro activity assays was confirmed by the feeding experiment presented here. MGDG bands of relative high intensity were detected when the cultures were fed with either C 12:0 or C 14:0. In contrast, there was no MGDG band visible when C 18:0 was used as a substrate for feeding, and only weak bands visible when other long chain fatty acids were employed. These results are also in perfect accordance to results of the in vitro measurements.

A separate remark should be made about Arabidopsis AAE16. Whereas the enzyme was not active in in-vitro activity assays, it showed acyl-ACP synthetase activity with a broad range of substrates in the complementation experiment. All fatty acids tested were activated and incorporated into lipids in Synechocystis sp. PCC 6803 aas knockout strain complemented with $A A E 16$. 


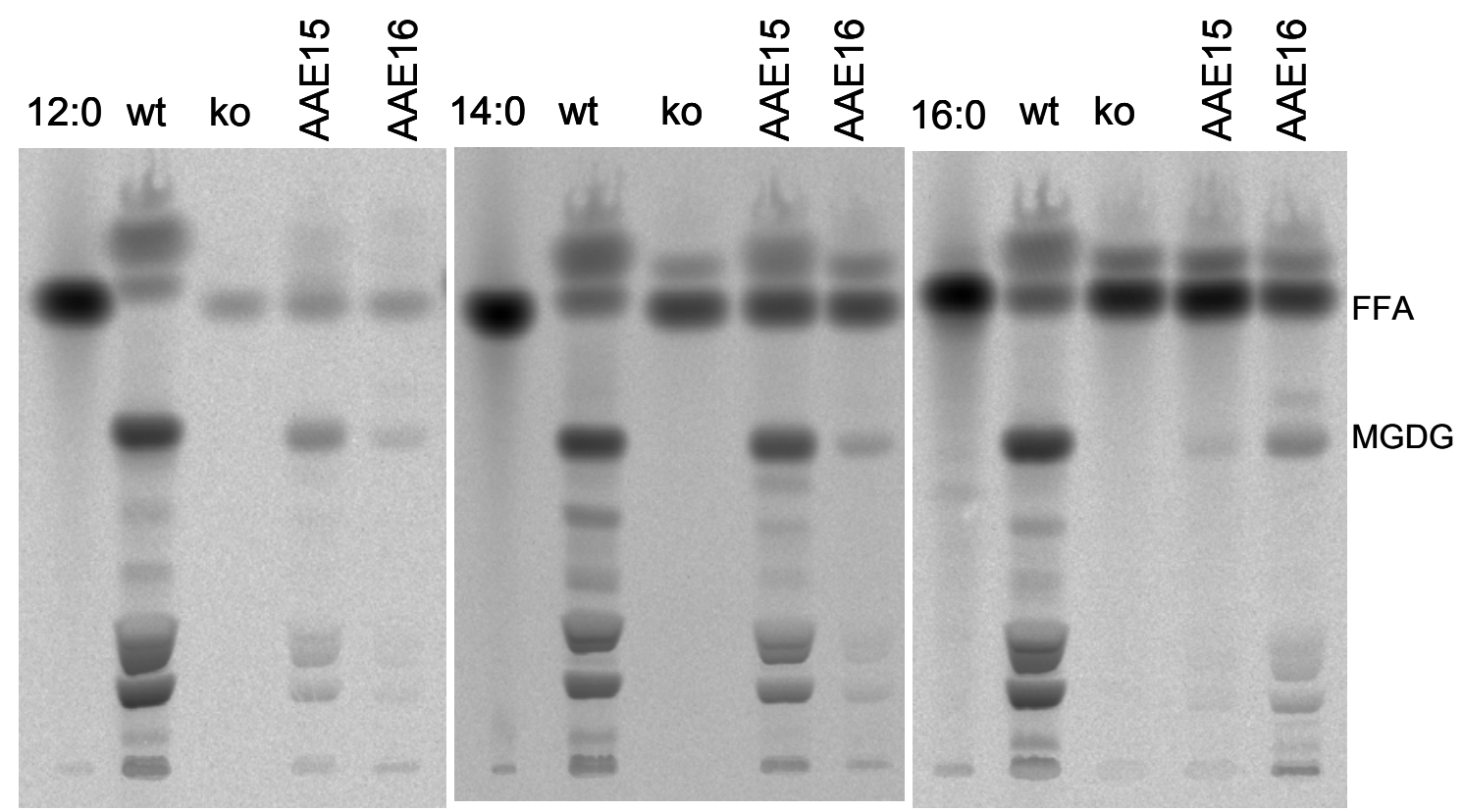

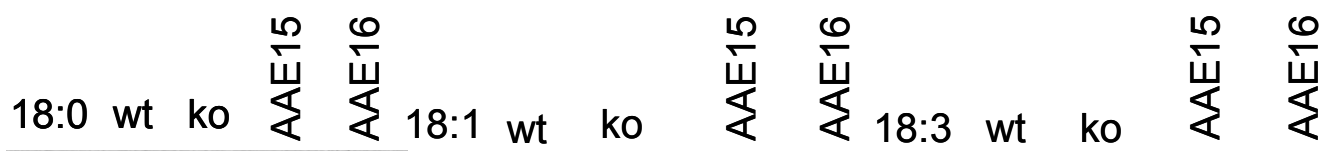

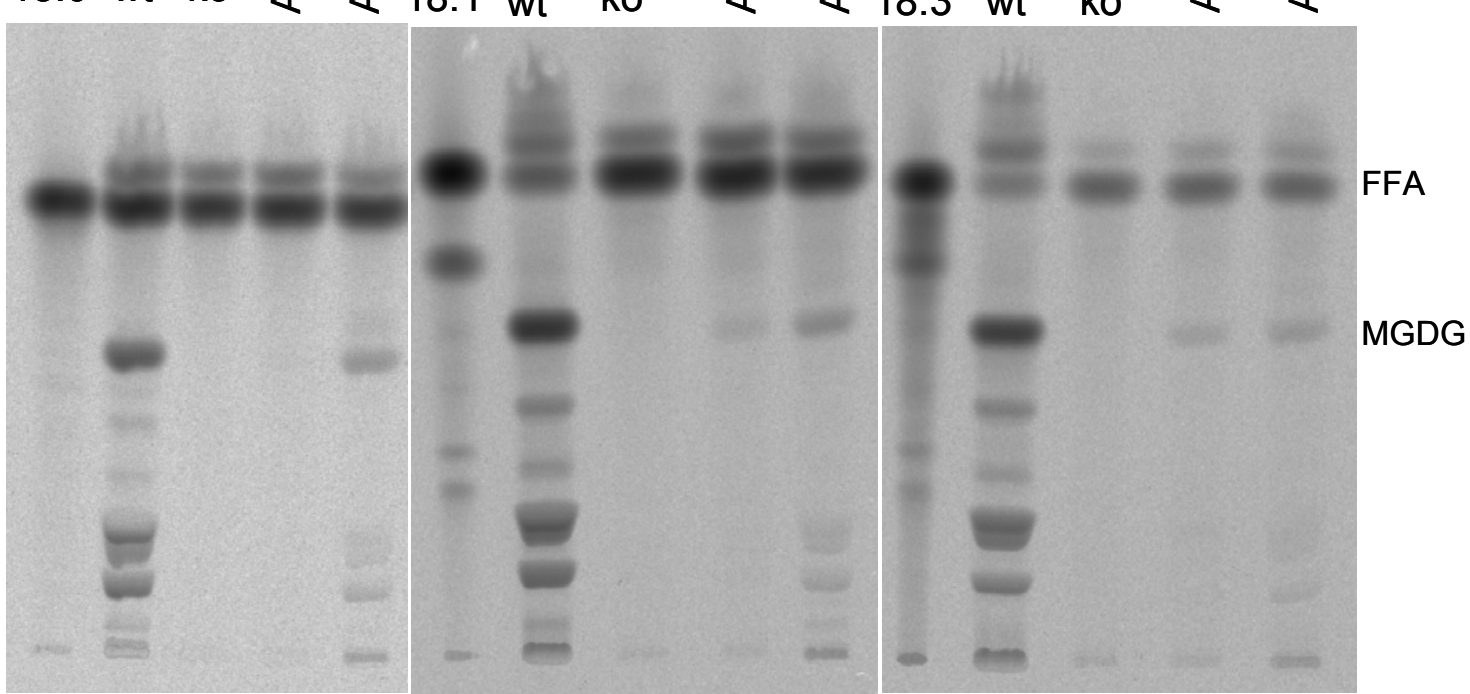

Figure 16. Autoradiography of total lipid extracts isolated from Synechocystis sp. PCC 6803 aas knockout mutant complemented by Arabidopsis AAEs after feeding with radio labeled fatty acids. Cells of Synechocystis sp. PCC 6803 wild type (wt), aas knockout (ko) and knockout complemented with either of AAE gene from Arabidopsis (AAE15, AAE16) were grown in presence of $\left[1-{ }^{14} \mathrm{C}\right]$ labeled fatty acid (12:0 - lauric, 14:0 - myristic, 16:0 - palmitic, 18:0 - stearic, 18:1 - oleic, 18:3 - linolenic). Lipid extracts of harvested cells were separated by TLC. FFA-free fatty acids, MGDG - monogalactosyl diacylglycerol. 
Table 2. Distribution of imported fatty acids between the pools of free- and lipid-bound fatty acids. Amounts of ${ }^{14} \mathrm{C}$ labeled fatty acids in intracellular free fatty acids (FFA) pool and incorporated to monogalactosyl diacylglycerol (MGDG) are expressed as intensities of spots detected on TLC plates. For each strain the ratio of FFA to MGDG was calculated. WT - Synechocystis sp. PCC 6803 wild type; ko - Synechocystis sp. PCC 6803 aas knockout mutant; AAE15, AAE16 - Synechocystis sp. PCC 6803 aas knockout mutant complemented by either of both genes.

\begin{tabular}{|c|c|c|c|c|c|c|c|}
\hline & \multicolumn{2}{|c|}{ C 12:0 } & \multicolumn{2}{|c|}{ C 14:0 } & \multicolumn{2}{|c|}{ C 16:0 } \\
\hline & & intensity & FFA/MGDG & intensity & FFA/MGDG & intensity & FFA/MGDG \\
\hline \multirow[b]{2}{*}{ WT } & FFA & 137.4 & \multirow[b]{2}{*}{0.1} & 82.1 & \multirow[b]{2}{*}{0.3} & 372.4 & \multirow[b]{2}{*}{0.4} \\
\hline & MGDG & 989.7 & & 252.2 & & 968.3 & \\
\hline \multirow[b]{2}{*}{ ko } & FFA & 36.6 & & 273.3 & & 2689.0 & \\
\hline & MGDG & 0.3 & & -0.2 & & 3.2 & \\
\hline \multirow[b]{2}{*}{ AAE15 } & FFA & 49.7 & \multirow[b]{2}{*}{0.9} & 260.9 & \multirow[b]{2}{*}{1.9} & 4171.5 & \multirow[b]{2}{*}{411.4} \\
\hline & MGDG & 57.5 & & 139.6 & & 10.1 & \\
\hline & FFA & 39.7 & \multirow[b]{2}{*}{5.0} & 222.3 & \multirow[b]{2}{*}{38.5} & 1056.8 & \multirow[b]{2}{*}{21.2} \\
\hline AAE16 & MGDG & 7.9 & & 5.8 & & 49.8 & \\
\hline
\end{tabular}

\begin{tabular}{|c|c|c|c|c|c|c|c|}
\hline & \multicolumn{2}{|c|}{ C 18:0 } & \multicolumn{2}{|c|}{ C $18: 1$} & \multicolumn{2}{|c|}{ C 18:3 } \\
\hline & & intensity & FFA/MGDG & intensity & FFA/MGDG & intensity & FFA/MGDG \\
\hline \multirow[b]{2}{*}{ WT } & FFA & 1665.7 & \multirow[b]{2}{*}{8.1} & 88.4 & \multirow[b]{2}{*}{0.3} & 32.6 & \multirow[b]{2}{*}{0.1} \\
\hline & MGDG & 205.7 & & 294.8 & & 223.8 & \\
\hline \multirow[b]{2}{*}{ ko } & FFA & 919.3 & & 642.9 & & 63.2 & \\
\hline & MGDG & 1.2 & & 1.1 & & 0.8 & \\
\hline \multirow[b]{2}{*}{ AAE15 } & FFA & 1090.7 & \multirow[b]{2}{*}{480.5} & 687.1 & \multirow[b]{2}{*}{235.3} & 61.2 & \multirow[b]{2}{*}{19.9} \\
\hline & MGDG & 2.3 & & 2.9 & & 3.1 & \\
\hline \multirow[b]{2}{*}{ AAE16 } & $\overline{\text { FFA }}$ & 913.6 & \multirow[b]{2}{*}{44.6} & 527.8 & \multirow[b]{2}{*}{56.2} & 58.8 & \multirow[b]{2}{*}{11.6} \\
\hline & MGDG & 20.5 & & 9.4 & & 5.1 & \\
\hline
\end{tabular}

\subsection{Expression profiles of $A A E 15$ and $A A E 16$ in Arabidopsis}

Analysis of the expression profiles were carried out to gain information about the possible biological role of AAE15 and AAE16 in Arabidopsis. Data provided by Genevestigator (Zimmermann et al., 2004) were compared with results of the experimental approach employing reporter GUS gene assays. 
Figure 17 presents data on $A A E 15$ and $A A E 16$ gene expression profiles in different developmental stages and different organs of Arabidopsis, provided by Genevestigator (https://www.genevestigator.ethz.ch). According to these data AAE15 is expressed throughout all developmental stages from seedlings to mature siliques, whereas $A A E 16$ is expressed in germinated seeds and in developed flowers and siliques, but not in seedlings, leaves, buds and young flowers.

A

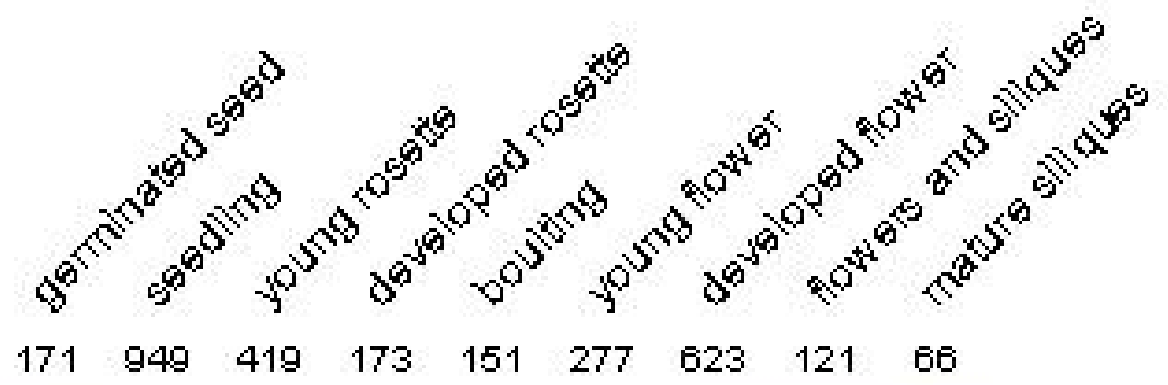

AAE16

AAE15 
B

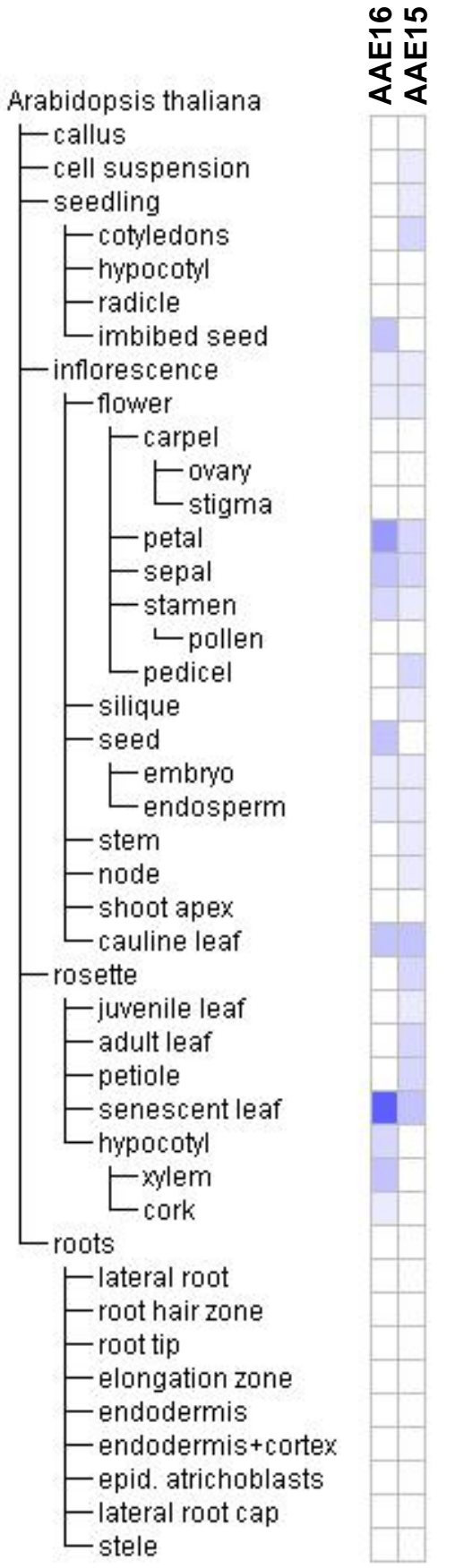

Figure 17. Genevestigator analysis of $A A E 15$ and $A A E 16$ expression profiles based on microarray data from Arabidopsis experiments. (A) Developmental stages of Arabidopsis; (B) Organs of Arabidopsis.

In the second approach, the patterns of AAE15 and AAE16 expression in Arabidopsis were investigated using the promoter sequence of either of both genes to direct the expression of the GUS reporter gene. 
To analyze the expression profile of $A A E 15$, initially a 629 bps fragment upstream of the $A A E 15$ coding region was amplified and cloned into the pBI101.3 vector, which was subsequently used for transformation of Arabidopsis. The functionality of the AAE15 promoter was tested in 7 different lines representing T2 generation. The results of the histochemical staining for GUS activity, which are not presented here, showed that the promoter was active in developed flowers but not in seedlings or leaves. These results were in conflict with results of the Genevestigator analysis. One possible reason for these discrepancies could be the incompleteness of the cloned promoter. Therefore, longer versions of the promoter were amplified and cloned. The length of the promoter was extended in 5' direction by using a forward primer matching to the sequence $1468 \mathrm{bps}$ upstream to the coding region. Additionally two other versions were amplified using either of both forward primers (-629 bps, - $1468 \mathrm{bps}$ ) and a reverse primer moved 55 bps into the coding region. Eventually three new promoter versions of the length of $684 \mathrm{bps}, 1468 \mathrm{bps}$ and $1523 \mathrm{bps}$ were cloned individually into pBI101.3 vector. The activities of these fragments were analyzed in transgenic Arabidopsis plants representing T2 generation. A total of 7 lines transformed with a construct carrying either the 684 bps or the 1469 bps variant of the AAE15 promoter, and 10 lines transformed with the construct carrying the promoter of 1523 bps were analyzed. The observed patterns of GUS activity were the same for all variants of the $A A E 15$ promoter and also identical with those observed before for 629 bps version of the promoter. Representative data are shown in figure 18. Staining was observed only in floral organs and was confined to anthers and ovules in open flowers.

In order to analyze the expression profile of $A A E 16$ a $1321 \mathrm{bps}$ fragment upstream of the $A A E 16$ coding region was amplified and fused with the GUS gene in the vector $\mathrm{pBI} 101.3$, which was subsequently transformed into Arabidopsis plants. Plants of T3 generation were analyzed for GUS activity. Overall 8 independent lines were tested. Representative results are presented in figure 18. There was no GUS activity observed in imbibed seeds but 1 day after imbibition the GUS activity became detectable. The GUS activity was observed also in developing seedlings, but staining occurred mostly in cotyledons and was disappearing in emerging leaves. Roots were not stained at all. A specific staining was observed in floral organs of Arabidopsis. The GUS activity in pollen grains resulted in an intensive blue coloration of anthers in flower buds, but staining was gradually disappearing in open flowers. The blue staining occurred also in sepals. More detailed inspection of Arabidopsis 
organs revealed very characteristic GUS activity in guard cells of sepals, siliques and leaves. Images of these organs are presented in figure 19.
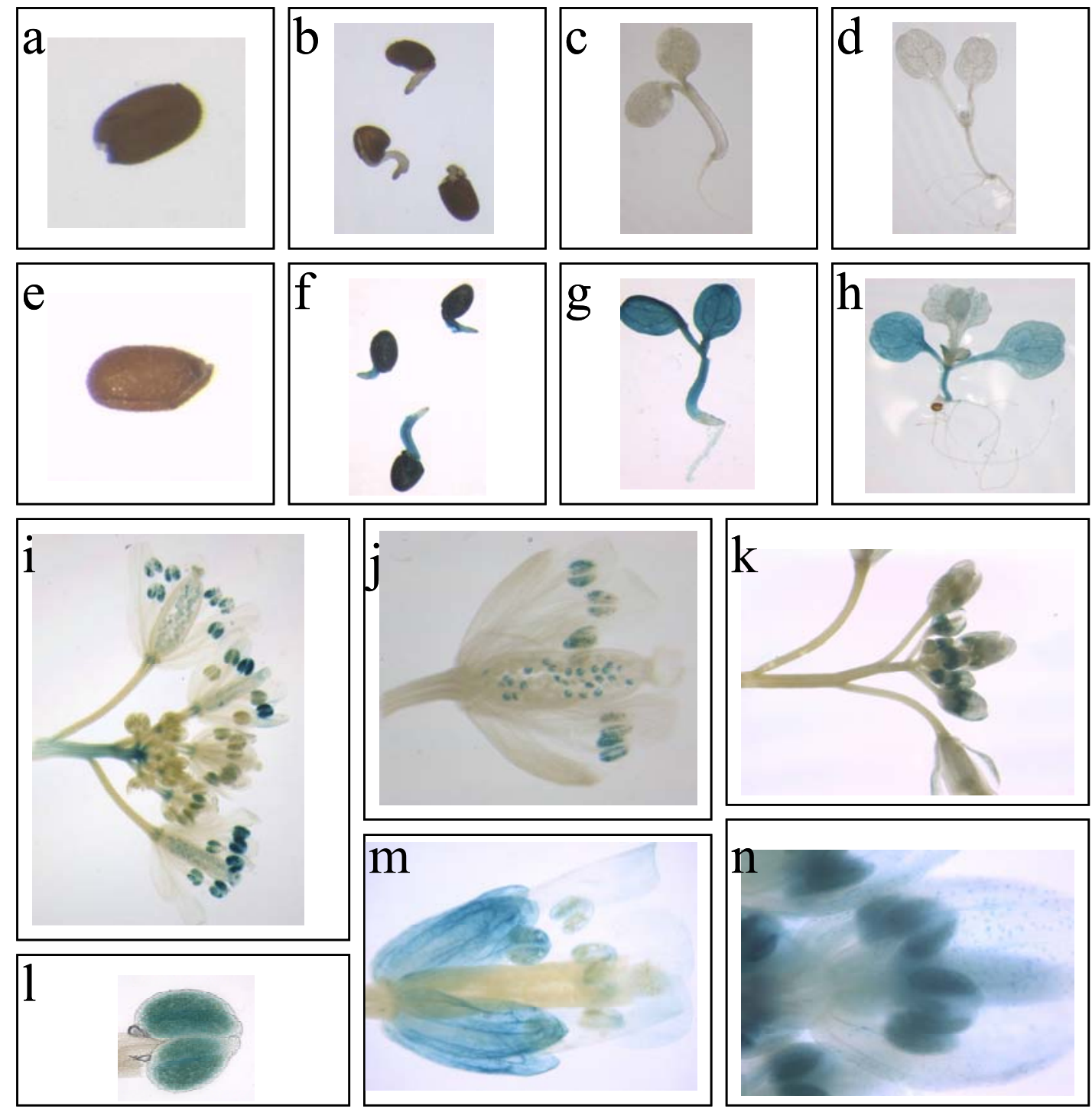

Figure 18. Staining for GUS activity in different tissues of AAE15::GUS and AAE16::GUS transgenic Arabidopsis plants. Germination of seeds and early stages of seedlings development (from left to right: imbibed seed, 1 day after imbibition (DAI), 3 DAI, 9DAI) (a-h), AAE15 a-d, AAE16 e-h; inflorescence and open flower AAE15 (i, j), AAE16 (k, m); close-up of an anther and a closed flower AAE16 $(1, n)$. Representative results of at least 7 independent lines for each construct are presented. 

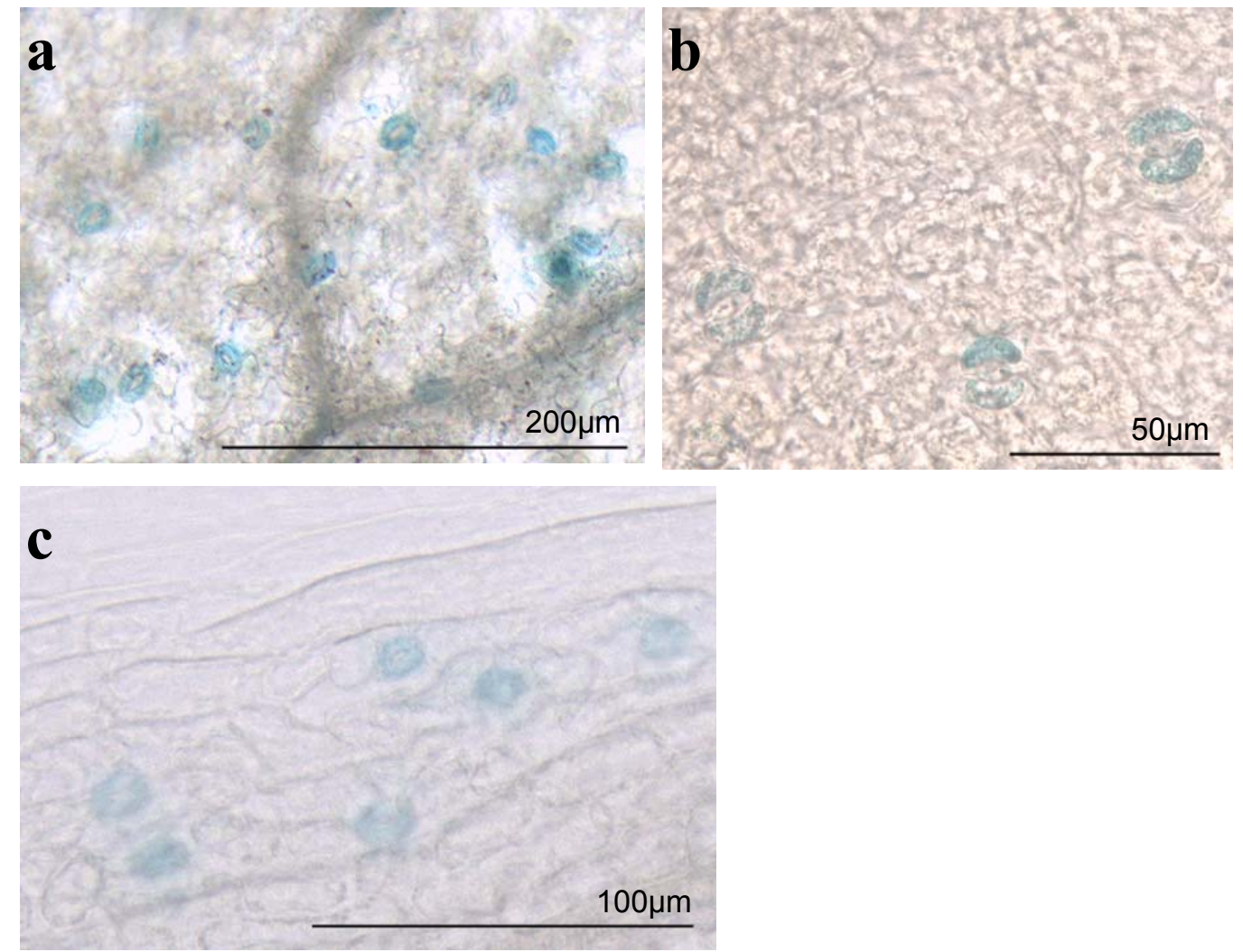

Figure 19. Close-up of guard cells in different tissues of AAE16::GUS transgenic Arabidopsis plants stained for GUS activity. A leaf (a), a silique (b), and a sepal (c). 


\section{Discussion}

The objective of this work was to investigate acyl-ACP synthetase activity in cyanobacteria and plants. Our group has previously identified such an activity in cyanobacteria but its physiological function has not been elucidated. Two sequences, AAE15 and AAE16, with homology to cyanobacterial acyl-ACP synthetases were found in Arabidopsis. Koo et al. (2005) showed that AAE15 encodes a plastidial acyl-ACP synthetase. The conclusions were based on activity assays employing leaf extracts and isolated chloroplasts of Arabidopsis mutants disrupted in the candidate gene. By the same approach no activity could be detected for AAE16.

In the present work we propose a hypothesis about the biological role of AAS activity in cyanobacteria. We furthermore demonstrate that not only the protein encoded by AAE15 but also by AAE16 displays AAS activity in Arabidopsis, but the enzymes differ in substrate specificity as well as in their expression profile. Additionally the present study provides direct proof that both enzymes are localized in plastids.

To address the question on the biological role of AAS activity in cyanobacteria, aas disruptional knockout mutants were generated in the background of two model organisms, Synechocystis sp. PCC 6803 and Synechococcus elongatus PCC 7942. The mutations were introduced by homologous recombination resulting in the replacement of part of the aas open reading frame by an antibiotic resistance gene cartridge. Homozygous aas mutant strains were not compromised in their ability to grow, indicating that AAS activity is not essential for the growth of the cyanobacteria under our culturing conditions. Analyses of the genomes of both cyanobacteria suggested that aas is the only gene responsible for fatty acid activation in these organisms. Therefore, it is highly unlikely that its role can be complemented by another endogenous gene. Further experiments revealed that the deletion of aas resulted in two phenotypes: First, the mutant cells were unable to utilize exogenous fatty acids and second, the mutant cells secreted fatty acid into the culture medium.

It is well known that cyanobacteria are able to acquire fatty acids from the surrounding medium. An experiment employing radio labeled oleic acid showed that wild type cells activated exogenous fatty acids and incorporated them into lipids, whereas aas mutant cells accumulated the free fatty acids but did not metabolize them any further (figure 4). This 
result indicated that apart of de-novo synthesis, AAS is the only other activity feeding into the pool of activated fatty acids in cyanobacteria. These activated fatty acids become available to acyltransferases and can thus be incorporated into lipids and other metabolic pathways. At this point a short discussion on the possible origin of the additional radioactive spots, which migrated above free fatty acid in the extracts of wild type strains as well as of the aas mutant strains is necessary. The spots have not been identified yet, but a recent report about an enzymatic activity able to acylate free fatty acids to alcohols without prior activation to acyl-thioesters (Neal et al., 2006) offers a possible explanation. These activities were found in microsomal preparations of plants and of yeast and it can be speculated that such an activity might be also present in cyanobacteria. Therefore, the additional spots on the TLC plate might represent the corresponding product of such ethylor propyl-esters. Nevertheless, it seemed that the product of such an activity cannot be utilized any further by other enzymes of the lipid metabolism, since the radioactive label in the aas mutant cells stayed trapped in this compound and was not distributed to any other lipid class.

Feeding experiments, employing fatty acids of different chain lengths, led to very interesting observations regarding the capability of the cells to distinguish between different carbon chain lengths of imported fatty acids and to decide about their subsequent destination. Initially, the uptake of lauric acid and palmitic acid were compared. Whereas palmitic acid was accumulated as free fatty acid inside the aas mutant cells lauric acid was barely detectable within these cells. Wild type cells on the other hand incorporated both fatty acids to similar amounts. Taking into account the strong fatty acid secretion phenotype of the aas mutant strains (will be discussed in detail below), one could argue that in these cells the transport of fatty acids out of the cell predominates over the uptake process. However, if this would be true, the same effect should be observed for palmitic acid. But exactly this was not the case. The fact, that the radioactive label was present in diverse lipid classes in wild type cells fed with lauric acid, proved that the uptake of this fatty acid by cyanobacteria is possible in general. After careful analysis of the TLC plates (figure 8), it was observed that wild type cells were also unable to accumulate lauric acid. Referring to the migration of standards, the spot representing the accumulation of free fatty acids in the wild type cells cannot be considered as lauric acid, but as its elongated product namely myristic acid and/or palmitic acid. It can be concluded that cyanobacteria are not able to accumulate lauric acid. In wild type cells, lauric acid seemed to be activated 
directly upon import into the cell to enable elongation and gradual incorporation into the lipids.

Therefore, the most likely scenario to explain our observations is as follows: Since aas mutant cells were not able to activate exogenous fatty acids, they were unable to convert incoming lauric acid to the product which can be stored by the cell by an unknown mechanism. This situation resulted in the export of lauric acid back to the culture medium. Before considering, what could be the role of such mechanism and why it distinguishes especially lauric acid, it should be remarked that fatty acids and their derivatives are well known antimicrobial agents. It has been shown that lauric acid and its monoglyceride have a greater antiviral and antibacterial activity than other medium chain fatty acids. Mostly Gram(+) bacteria and yeast but not Gram(-) bacteria are affected by this agents (Kabara and Vrable, 1977; Kabara, 1984). Sodium salt of lauric acid is also a common ingredient of soaps and detergents. Thus it is possible that cyanobacteria developed a mechanism to recognize lauric acid as a toxic substance and to convert it to a form, which does not affect the cell but can be utilized by enzymes of the lipid metabolism. However, if this is the natural way to deal with lauric acid, the question remains why the export mechanism exists in parallel. Another labeling experiment, comparing uptake rate of medium and long chain fatty acids, revealed that myristic acid undergoes the same pathway as lauric acid. In wild type cells it was elongated (not shown), stored by the cell as free fatty acid and was then incorporated gradually into diverse lipid classes. In contrast, in aas mutant cells the observed uptake was much slower than in wild type most probably due to the coexistent transport in the opposite direction. In general this experiment suggested that cyanobacterial cells are able to acquire exogenous fatty acids even if they possess detergent character and may disturb the cellular integrity. The uptake of the fatty acids is a rather rapid process as long as the toxic fatty acid can be further processed. Those fatty acids, which turn out to be harmful to the cell, can be accumulated only upon activation and subsequent elongation. The fact, that the uptake of myristic acid was much more efficient than that of any other fatty acid tested, seemed to indicate a certain specificity but the mechanism how the cell recognized different fatty acids is not clear yet.

It was an interesting observation that cyanobacterial cells defective in fatty acid activation established an alternative way to deal with unfavorable fatty acids. Other experiments demonstrated that the secretion phenotype of aas mutants was not restricted to medium 
chain fatty acids, but all fatty acids which occur naturally in cyanobacterial cells can be secreted to the medium. Before being able to speculate about the physiological role of AAS activity it was first necessary to gain information about the origin of fatty acids found in the medium. Theoretically there are two possible sources: Fatty acids can be released either in the process of de-novo synthesis or from lipid turnover of membranes. The presence of unsaturated fatty acids in the pool of free fatty acids strongly suggested the release from membrane lipids. It is known that cyanobacterial desaturases are of acyl-lipid type and act only on fatty acids which are coupled by an ester bond to the glycerol backbone of membrane lipids (Murata and Wada, 1995). Therefore, the unsaturated free fatty acids inside the cells as well as in the medium must have been lipid bound earlier on.

Results presented in figure 6 showed that the overall intracellular free fatty acid concentration in aas mutants was higher than in the corresponding wild type strains. A proposed scenario is that in wild type cells fatty acids are released from the membranes and appear temporarily in the pool of free fatty acids inside the cells. From this pool they can be rescued by activation to ACP to become substrates for enzymes of the lipid metabolism again. In the mutant cells on the other hand fatty acids, that have been once cleaved, cannot undergo reactivation and accumulate in the cell. To avoid an accumulation of free fatty acids to a concentration which might disturb membrane integrity, cells devoid of AAS activity secrete the excess of fatty acids to the culture medium. In summary we can propose a model for the fatty acid metabolism in the aas mutant cells where an equilibrium can be established between fatty acids uptake, which is the natural capability of cyanobacteria, and fatty acid secretion, which is enforced by interrupting the recycling pathway.

The careful analysis of fatty acids profiles presented in figure 6 enabled us to speculate about the rate of lipids turnover in cyanobacteria. Special attention should be focused on the presence of C 18:0 in distinct fatty acids pools of Synechocystis sp. PCC 6803. First, to underline the importance of this fatty acids in the strain Synechocystis sp. PCC 6803, it should be noted that most of unsaturated membrane fatty acids are of 18 carbon chain length. The fact that $\mathrm{C} \mathrm{18:0}$ is hardly detectable in the pool of esterified fatty acids indicates that this fatty acid is modified by desaturases directly upon incorporation to membrane lipids. But desaturation must be competitive with deacylation as can be concluded from the large amounts of $\mathrm{C}$ 18:0 detected in the pool of free fatty acids in the aas mutant. The explanation for the absence of free $\mathrm{C}$ 18:0 in cells of wild type Synechocystis sp. PCC 6803 is most likely the AAS activity, which drives a very effective 
recycling process. This recycling transfers the fatty acids back into the lipids where they become substrate for the desaturases.

It can be proposed that fatty acids are being continuously released from membranes and subsequently reactivated by AAS and then returned into lipids, allowing permanent membrane remodeling. It should be pointed out that in the experiment leading to these observations, cells were grown under stable conditions, considered to be optimal for the strains studied, so the proposed mechanism of fatty acids recycling was not induced by any kind of stress conditions.

Data supporting the idea of a permanent release of fatty acids from membranes were obtained by the temperature shift experiment. As shown in figure 10, 13 -unsaturated fatty acids in esterified form appeared after lowering the temperature and their concentration was increasing in the course of time, which is in agreement with a previous report (Los and Murata, 1999). A corresponding increase in the amounts of 13 -desaturase products was observed in the free fatty acid pool indicating a temporally tightly coupled mechanism of fatty acid modification and release.

The reason why the observations related to metabolism of $\mathrm{C}$ 18:0 were not made for the second strain used in our study, Synechococcus elongatus PCC 7942, is most likely the different significance of C 18 fatty acids in the membrane composition of this strain. Synechococcus elongatus PCC 7942 contains only saturated and monounsaturated fatty acids and the major unsaturated fatty acid is C 16:1 (Murata et al., 1992). Therefore it is receivable that the turnover of $\mathrm{C} 18$ fatty acids has a far less important impact in Synechococcus elongatus PCC 7942 compared to Synechocystis sp. PCC 6803. Nevertheless, the similarities between Synechocystis sp. PCC 6803 and Synechococcus elongatus PCC 7942 reflected by the secretion phenotype and the overall increased concentrations of intracellular free fatty acids in both aas mutant strains, allowed us to propose the membrane remodeling mechanism being effective in cyanobacteria in general. The reason for this process is yet unclear but it can be hypothesized that fatty acid cleavage and recycling are necessary for maintaining an appropriate fatty acid profile of membrane lipids. Cyanobacteria belong to the organisms which respond to the changes in environmental temperature by altering the fatty acid composition of their membrane lipids. A continuous fatty acids turnover might improve the ability for rapid adaptation of the cell to changes in environmental conditions. However such an interpretation creates several questions: Why does the cell invest energy for maintaining a permanently switched on fatty 
acid recycling machinery if, in parallel, it possesses sensors for low-temperature perception, which trigger cellular response (Suzuki et al., 2000)?

Another question concerns the fate of the released fatty acids? If we assume that, because of low-temperature conditions, an increased concentration of more unsaturated fatty acids in membranes is required, what would be the sense of the release of newly generated unsaturated fatty acids as shown in figure 10? The low-temperature-induced desaturation in cyanobacteria as a strategy to adapt to the cold has been studied by several groups and is described in quite some detail (for review see: (Murata and Wada, 1995; Los and Murata, 1998)). According to the model given by Murata and Wada, the decrease in temperature results in decrease of membrane fluidity, which induces the signal for enhanced expression of desaturase genes. This leads to accelerated synthesis of desaturases and consequently accelerated desaturation of membrane lipids. As direct effect the membrane fluidity and the physiological activity is recovered. Although the cellular response to a low-temperature signal is relatively quick, the accumulation of unsaturated fatty acids in membranes might be delayed by a couple of hours (Los and Murata, 1999). This scenario offers the possibility that within this time, the proposed lipid remodeling would allow a rapid adjustment of membrane properties. It is difficult to build such a model based only on experiments performed in rather stable laboratory conditions. However, it could be that in natural environment cyanobacterial cells have to face continuous changes in ambient conditions rendering the mechanism of lipid remodeling to be beneficial. The fact that there was no observed delay in growth of wild type strains compared to aas knockout strains (not shown) indicated that the process of fatty acids reactivation is not very costly for the cell.

It seems to be easier to speculate about the meaning of fatty acids turnover when we consider the adaptation not to lower but to the higher temperature. Mechanisms of acclimation to high temperatures are much less understood in cyanobacteria, but it is clear that an increase in the temperature results in a decrease of the level of desaturation in fatty acids of membrane lipids. This process requires the removal of unsaturated fatty acids from the membrane lipids and the acylation of the lipids with saturated fatty acids. For the quick release of the unsaturated fatty acids from the membranes the proposed turnover mechanism would be of use; however it remains unclear also in this case why the fatty acid turnover in the cell is maintained permanently on a high level.

Fatty acid cleavage and recycling as tools of rapid acclimation to the changes in environmental conditions is one of the hypotheses to explain the observed lipid turnover. 
But there might be also a completely different explanation by assuming a role in intracellular lipid trafficking involved in vesicular transport and biogenesis of membranes. Such mechanism could potentially involve strong lipid turnover processes.

Interestingly, comparison of fatty acids profiles (figure 6) indicates that not only fatty acids attached to glycerolipids of the membranes but also 3-hydroxymyristic acid, which is a component of lipid A, undergoes the recycling process. It can be concluded from the presented results that in wild type cells 3-hydroxymyristic acid receives a rapid reactivation upon cleavage and becomes incorporated back into lipid A. Therefore, this component is not detected in either the medium or as a free fatty acid inside the cells. This finding supports the idea that fatty acids turnover does not have to be associated with the regulation of membrane fluidity. According to the model of lipid trafficking in Gram(-) bacteria (Doerrler, 2006) LPS is localized in the outer leaflet of the outer membrane but its precursor, lipid A is synthesized at the inner leaflet of the inner membrane. AAS is considered to be an inner membrane peripheral protein located on the cytoplasmic side of the membrane (Pisareva et al., 2007). If the 3-hydroxymyristic acid is released from mature LPS, there must be a very efficient transport mechanism which transfers the molecule across the periplasm to the inner membrane for reactivation. On the other hand, if 3-hydroxymyristic acid is lost during the biosynthesis of lipid A and AAS activity is deleted, the released fatty acid must be efficiently secreted to the culture medium. In case of a less effective transport it would be detectable in the pool of free fatty acids inside the cells as well.

This observation prompts a discussion about fatty acid transport in cyanobacteria. This issue is difficult to address, since mechanisms of fatty acid transport has not been well characterized in any organism so far and there is still an ongoing discussion whether the transport through the membranes is a passive or an active and protein mediated process. The proposed models of transmembrane movement of the fatty acids, and proteins which are implicated in the fatty acid transport are reviewed by Black and DiRusso (Black and DiRusso, 2003). Here only the model proposed for E. coli will be considered, since E. coli, like cyanobacteria, belongs to Gram(-) bacteria and presents specific structure of the cellular envelope. Therefore, the strategy of fatty acids transport in this group of organisms might be similar. The cell envelope of Gram(-) bacteria is composed of two functionally distinct membranes which are separated by the periplasmic space. Fatty acids on transport have to traverse these three layers of the cellular envelope. The lipopolysaccharide layer in the outer membrane is an efficient barrier for fatty acids therefore there is need for a 
mechanism facilitating fatty acids uptake. Of the proteins characterized to date, only the long-chain fatty acid (12-18 carbons) transport protein FadL, found in E. coli, fulfills all the criteria that define an integral membrane bound fatty acid transporter (Black and DiRusso, 2003). FadL binds exogenous long-chain fatty acids and transports these compounds across the outer membrane. Based on the crystal structure (van den Berg et al., 2004), a transport mechanism which involves spontaneous conformational changes in the hatch domain of FadL was proposed. Passage of the fatty acids through the periplasm is not well understood, but the periplasmic protease Tsp has been shown to be involved in this process (Azizan and Black, 1994). In the inner membrane, FadD catalyzes the formation of long-chain fatty acyl-CoA rendering the process of transport unidirectional. Although cyanobacteria belong to Gram(-) bacteria and theoretically might transport fatty acids according to the same scheme, so far no candidate genes involved in fatty acids transport have been identified. To address this question is a challenging task since the genome of Synechocystis sp. PCC 6803 contains 158 genes which are categorized as putative transport and binding proteins (Ikeuchi and Tabata, 2001). Some of them have proposed functions based on sequence homology, so the search can be narrowed down; but nevertheless there is still large number of putative proteins with unknown substrate specificities and functions.

In summary, there is no obvious homology between Escherichia coli and cyanobacteria regarding fatty acid transport. Therefore, the discussion of the results cannot benefit from established models for fatty acid transport and will be rather speculative. To have a better overview on aspects of this process, it is helpful to recall results of the feeding experiments as well as of the profiles of intra- and extracellular fatty acids of cyanobacterial strains devoid of AAS activity. First it must be remarked again that both import and export of fatty acids were observed. However, export was exclusively detected in aas mutant strains. Travelling in either of both directions requires crossing of the LPS layer, and therefore the presence of a specific transport protein in the outer membrane seems to be very likely. The difference in the uptake rate of myristic acid compared to other fatty acids in cells of wild type strains, the more efficient export of medium chain fatty acids fed to the cells of aas knockout mutant strains and the alteration in the ratio of $\mathrm{C} 16: 0$ to $\mathrm{C} 16: 1$ between the pools of cellular fatty acids and secreted fatty acids seemed to indicate a certain selectivity for the fatty acids transport mechanism in cyanobacteria. However the mechanisms underlying the observed selectivity remained unclear. 
Apart of the fatty acid transport across the membrane, in addition the mechanism of the fatty acid release needs to be elucidated in order to build a complete model of membrane remodeling. So far genes responsible for lipid acyl hydrolase activity in cyanobacteria have not been found. The membranes of cyanobacteria cells are built mostly of glycolipids, MDGD, DGDG, SQD, and to a lower extent of phospholipid, PG (Wada and Murata, 1998). MGDG comprises more than one half of the membrane lipids in cyanobacteria. Hence, it can be assumed that the enzyme responsible for degradation of membrane lipids has galactolipid specificity. But there must be also activity for deacylation of lipid A. The question whether lipid deacylation is performed by one enzyme of broad substrate specificity or if several ones with distinct substrate specificity for diverse lipids and maybe also for sn1 or sn2 positions are acting cannot be answered yet.

On one hand, because of lipid composition, cyanobacteria may be considered analogous to the chloroplast of higher plants. On the other hand the structure of the cell envelope classify them to Gram(-) bacteria. There are some reports indicating the occurrence of specific activities for de-esterification of plastidial galactolipids in plants or lipid A in Gram(-) bacteria, but from sequences homology there are no hints that such activities could be found in cyanobacteria.

In general there is not much known about de-esterification of plastidial galactolipids. Although proteins with galactolipid-hydrolyzing activity have been purified from leaves of several plants, Phaseolus multiflorus (Sastry and Kates, 1964), pole bean (Phaseolus vulgaris; (Anderson et al., 1974), and wheat (Triticum aestivum; (O'Sullivan et al., 1987), the corresponding genes have not been isolated. The gene Vupat1, cloned from cowpea (Vigna unguiculata), was shown to encode a patatin-like protein with galacto-acyl hydrolase activity, but the protein was not predicted to have a chloroplast targeting signal (Matos et al., 2001). Recently DGL, which is a member of the AtPLA $A_{1}-I$ family, was shown to encode a chloroplast-targeted lipase with strong galactolipase and weak phospholipase A1 activity. $D G L$ is involved in jasmonic acid biosynthesis and shows wound inducible expression (Hyun et al., 2008).

A gene (pagL) encoding an outer membrane deacylase that removes the R-3hydroxymyristate moiety of lipid A was identified in Salmonella typhimurium and proposed to be involved in pathogenesis (Trent et al., 2001). The proposed role, however, became questionable after finding pagL homologs in a variety of Gram(-) bacteria, including nonpathogenic species (Geurtsen et al., 2005). 
Presented data clearly demonstrate that the lipids in cyanobacteria undergo strong turnover. The role of AAS in this process seems to be the activation of the released fatty acids and thereby to enable a fatty acid recycling process. Other enzymes participating in the turnover of fatty acids in cyanobacteria remain to be identified and the physiological role of the process remains to be elucidated. Since cyanobacteria are commonly believed to be the ancestors of the chloroplasts, it is intriguing to speculate whether the observed fatty acid turnover or at least some aspects of it are reflected in chloroplasts of plants. The following part of the discussion will focus on the two Arabidopsis genes AAE15 and $A A E 16$, which are homologous to the cyanobacterial aas. Both enzymes are predicted to localize in chloroplasts. In addition the biochemical data provided by Koo and coworkers (2005) indicate that AAE15 is a plastidial enzyme, but so far the direct evidence for the subcellular localization of those enzymes has not been presented. In the present work the plastidial localization of both proteins, AAE15 and AAE16 was demonstrated by expressing EYFP fusion proteins transiently in onion epidermal cells (figure 11).

AAE15 was shown to encode AAS in Arabidopsis by experiments employing leaf extracts or isolated chloroplasts of wild type plants or aae15 plants. aae15 mutant plants displayed around 40-55\% reduced in vitro AAS activity compared to wild type (Koo et al., 2005). Interestingly the same set of assays did not indicate AAS activity of AAE16. In-vitro AAS activity in leaf extracts of aae16 plants was even higher than in leaf extracts of wild type plants. It remained unclear which enzyme of the AAEs family could be responsible for the remaining AAS activity detected in those assays.

In the present work different approaches were used to study the activities encoded by $A A E 15$ and $A A E 16$. On the one hand the proteins were heterologously expressed in insect cells and were subsequently tested in-vitro for AAS activity. On the other hand the corresponding genes were used for complementation studies in a Synechocystis sp. PCC 6803 aas knockout mutant.

Although western blot analysis proved the expression of AAE15 and AAE16 and revealed protein bands of the expected size, only AAE15 displayed AAS activity in-vitro. Nevertheless, AAS activity of AAE16 was proven by the complementation of the aas mutant of Synechocystis. One possible explanation for the inactivity of the heterologously expressed AAE16 could be improper folding or dependency on certain additional factors not present in insect cells. There is no obvious explanation for the different behavior of AAE16 during the purification procedure but it also could be that the protein folding affected its affinity to the resin. 
An important finding of this study is not only that $A A E 16$ encodes an acyl-ACP synthetase like its homolog $A A E 15$, but also that the encoded enzymes possess different substrate specificity. This observation may help to reveal the physiological function of the individual AASs in Arabidopsis. The results of in-vitro enzyme assays, which were confirmed by the complementation experiment in cyanobacteria, demonstrated clearly that AAE15 exhibits a substrate specificity towards medium chain fatty acids with chain length between $\mathrm{C} 10$ and C14. Other saturated fatty acids with chain length of $\mathrm{C} 8$ and $\mathrm{C} 16$ as well as unsaturated fatty acids with chain length of 18 carbons were also accepted but were activated to significantly lower rates. Only stearic acid turned out to be a very poor substrate for AAE15. The results of the complementation experiment in cyanobacteria indicated that AAE16 has much broader substrate specificity. All fatty acids tested were activated at rather similar levels. Admittedly, according to the calculated ratios of FFA to MGDG, lauric acid seems to be the preferred substrate, but it must be kept in mind that cyanobacteria cells are not able to accumulate large amounts of lauric acid and after the uptake this fatty acid is either elongated or secreted back into the medium. Therefore, in this case the value of the FFA to MGDG ratio might be misleading.

Before addressing the question about the in-vivo function of fatty acid activation to ACP in the plastids it must be stressed that neither aae15 and aael6 single knockouts nor the aae15/aae16 double knockout plants presented visible phenotypes under normal growth conditions (Koo et al., 2005). We also tested Arabidopsis plants overexpressing AAE16 or the aas gene of either Synechocystis sp. PCC 6803 or of E. coli. But none of the overexpressing plants showed visible phenotypes under normal growth conditions (data not shown). It is of course possible, and this was one of the hypotheses posed by Koo et al., that AAS activity may become important under certain conditions necessitating significant remodeling of the plastidial membrane systems. De-esterification of chloroplastidial galactolipids had been shown to be induced by drought stress, chilling and senescence (Kaniuga et al., 1999; Matos et al., 2000). The presence of AAS activity in chloroplasts would allow the reactivation of the released fatty acids so it could be that $A A E 15$ and/or $A A E 16$ are induced by those conditions as well. However, this hypothesis requires experimental verification.

The substrate specificity of AAE15 for medium chain fatty acid supports strongly the idea, also given by Koo et al., that the enzyme is involved in "proof reading" of de-novo fatty acid synthesis. During de-novo synthesis fatty acids might be hydrolyzed from ACP by acyl-ACP thioesterase before reaching an appropriate length. In this case a mechanism is 
required, which is able to recapture the prematurely released fatty acids in order to return them to the elongation process. The free fatty acids of medium chain length could otherwise cause destructive impact on membrane integrity.

To get more insight into the biological function of Arabidopsis AASs, expression profiles of $A A E 15$ and $A A E 16$ were investigated in transgenic plants expressing the GUS reporter gene under control of the respective promoters. Surprisingly, the results revealed some strong discrepancies to data provided by Genevestigator. Based on our histochemical GUS staining, AAE15 was only expressed in floral organs but not during early developmental stages and not in leaves as proposed by Genevestigator. In light of the report of Koo et al., it was reasonable to expect the expression of $A A E 15$ in leaves. Moreover, in contrast to microarray-based data higher expression was detected not in the young but in the developed flowers and not in the vegetative parts but in pollen and ovules. The fact that the strong and specific staining occurred in floral organs excluded the possibility that the expression in other organs was not detected due to mistakes of the construct used for plant transformation. One of the explanations for the discrepancies between Genevestigator data and our experimental data could be the insufficient sensitivity of the histochemical staining. It might be possible that in certain organs the genes of interest are expressed on a very low level which cannot be detected by GUS staining but is sufficient to be detected on microarrays. Conflicting results were obtained also for the expression profiles of AAE16. The expression of $A A E 16$ was detected in developing seedlings whereas according to microarrays-based data the gene was expressed in imbibed seeds but not in seedlings. In addition, stronger expression was observed in buds than in open flowers and was found mostly in anthers. It is possible that gene expression in certain organs could not be detected in transgenic promoter-GUS plants due to the lack of regulatory elements present outside of the cloned promoter sequence. We tried to address this problem by extending the length of the potential promoter sequence without receiving other data than before. Therefore, RNA blot analysis will be useful to prove or disprove data obtained from GUS staining and Genevestigator.

The highly specific expression pattern of $A A E 16$ in leaves, siliques and sepals, restricted to guard cells suggests that the encoded AAS activity may be specifically associated with functions of the stomata apparatus. Therefore it is possible that having a closer look on morphology and functions of guard cells would reveal differences between wild type and aae16 plants. 
In this work we propose a mechanism of continuous lipid turnover in cyanobacterial cells. In the proposed model AAS activity enables the recycling of the released fatty acids. However, the question about the physiological role of this process remains open. We speculated that it might be involved in rapid adaptation of the cells to changes in environmental conditions by adjusting membrane fluidity. Another hypothesis was that the fatty acid turnover might be part of lipid trafficking, involving cytoplasmic and thylakoid membranes. Further experiments will be needed to further address the biological role of the observed lipid remodeling.

Another remaining question is if plastids of higher plants reflect the situation found in cyanobacteria. We demonstrated that the homologues proteins AAE15 and AAE16 of Arabidopsis possess AAS activity as well. The fact that there are two genes in the Arabidopsis genome encoding AAS activity with different substrate specificity and different expression profile strongly suggest that they have evolved to fulfill different functions in plants. The question whether in chloroplasts these proteins are involved in a strong lipid turnover process, like in cyanobacteria, is very difficult to address. The reason for these difficulties is the higher complexity of plants cells reflected on the one hand by the compartmentalization of the cell and on the other hand by the presence of a large number of enzymes capable of fatty acid activation. The natural fate of a certain pool of fatty acids synthesized in plastids is to leave these organelles after being released from ACP. Therefore, it would be difficult to distinguish a potential secretion phenotype induced by the deletion of AAS activity from the natural fatty acids flow out of the plastid. Out of the chloroplast free fatty acids are activated by acyl-CoA synthetase, so unlike in cyanobacteria the accumulation of free fatty acid within the cell could not be observed. Nevertheless, it cannot be excluded that in plant cells the lipid turnover within plastids occurs in a similar way as in to cyanobacteria and AAS activity inherited from cyanobacterial ancestors would be necessary for fatty acid reactivation. 


\section{Summary}

All metabolic processes involving fatty acids are preceded by the activation of the fatty acid to form a thioester derivative. Activation by acyl-CoA synthetase is well established whereas only little information is available about the alternative way utilizing ACP as acceptor of the acyl group. The focus of this work was to investigate acyl-ACP synthetase activity in cyanobacteria and plants, two groups of photosynthetic organisms.

In a previous study of our group cyanobacterial AAS was identified and functionally characterized by heterologous expression in Escherichia coli. However, the biological role of this activity within the cell was not determined. Two homologous sequences, AAE15 and AAE16 were found in Arabidopsis. Both of them were investigated by Koo et al. (2005) with respect to their role in the elongation of exogenous fatty acids in chloroplasts, but only for AAE15 the AAS activity was proposed.

To elucidate the biological role of AAS activity in cyanobacteria, aas knockout mutants were generated in the background of Synechocystis sp. PCC 6803 and Synechococcus elongatus PCC 7942. The obtained mutants showed two phenotypes: They were unable to utilize exogenous fatty acids and they secreted endogenous fatty acids into the culture medium. The wild type phenotype was restored by complementation of the aas knockout mutant of Synechocystis sp. PCC 6803 with the corresponding gene from Synechococcus elongatus PCC 7942. The analysis of extracellular and intracellular fatty acid profiles of wild type strains and aas mutant strains showed that fatty acids are released from membrane lipids indicating a strong turnover of these lipids. The AAS activity seemed to be necessary for the reactivation of the released fatty acid thereby enabling their recycling back into the lipid metabolism.

The genome of Arabidopsis encodes two sequences with strong amino acid similarity to the AAS of cyanobacterial origin. For these two proteins termed AAE15 and AAE16 the localization in plastids was confirmed by expression of EYFP fusion proteins in onion cells followed by fluorescent microscopy. To further characterize these proteins, AAE15 and AAE16 were overexpressed in insect cells and analyzed by in-vitro assays. It was shown that AAE15 displays AAS activity with substrate specificity towards medium chain fatty acids. In addition the aas knockout mutant of Synechocystis sp. PCC 6803 was complemented individually with $A A E 15$ and $A A E 16$, and the obtained strains were fed with labeled fatty acids. It was demonstrated that complementation with $A A E 15$ restored the 
wild type phenotype, and the specificity for medium chain fatty acids of the enzyme was confirmed. In addition the complementation experiment gave evidence for AAS activity of AAE16 and indicated its broad substrate specificity. In further studies the expression of AAE15 and AAE16 were analyzed with respect to tissue specificity and to dependence on developmental stage. The histochemical GUS staining indicated highly specific expression profiles for $A A E 15$ and $A A E 16$ in flower organs and additionally for $A A E 16$ in guard cells of different organs. The results revealed some strong discrepancies to microarray-based data provided by Genevestigator. 


\section{References}

Anderson MM, McCarty RE, Zimmer EA (1974) The Role of Galactolipids in Spinach Chloroplast Lamellar Membranes: I. Partial Purification of a Bean Leaf Galactolipid Lipase and Its Action on Subchloroplast Particles. Plant Physiol 53: 699-704

Azizan A, Black PN (1994) Use of transposon TnphoA to identify genes for cell envelope proteins of Escherichia coli required for long-chain fatty acid transport: the periplasmic protein Tsp potentiates long-chain fatty acid transport. J Bacteriol 176: 6653-6662

Black PN, DiRusso CC (2003) Transmembrane movement of exogenous long-chain fatty acids: proteins, enzymes, and vectorial esterification. Microbiol Mol Biol Rev 67: 454-472

Bligh EG, Dyer WJ (1959) A rapid method of total lipid extraction and purification. Canadian Journal of Biochemistry and Physiology 37: 911-917

Bradford MM (1976) A rapid and sensitive method for the quantitation of microgram quantities of protein utilizing the principle of proteine-dye binding. Anal Biochem 72: $248-254$

Bullock WD, Fernandez JM, Hort JMS (1987) XL1-Blue: A high effciency plasmid transformants rec A Escherichia coli strain B-galactoside selection. Biotechniques 5: $376-378$

Byers DM, Holmes CG (1990) A soluble fatty acyl-acyl carrier protein synthetase from the bioluminescent bacterium Vibrio harveyi. Biochem Cell Biol 68: 1045-1051

Clough SJ, Bent AF (1998) Floral dip: a simplified method for Agrobacterium-mediated transformation of Arabidopsis thaliana. Plant J 16: 735-743

Conti E, Franks NP, Brick P (1996) Crystal structure of firefly luciferase throws light on a superfamily of adenylate-forming enzymes. Structure 4: 287-298

Cooper CL, Hsu L, Jackowski S, Rock CO (1989) 2-Acylglycerolphosphoethanolamine acyltransferase/acyl-acyl carrier protein synthetase is a membrane-associated acyl carrier protein binding protein. J Biol Chem 264: 7384-7389

Doerrler WT (2006) Lipid trafficking to the outer membrane of Gram-negative bacteria. Mol Microbiol 60: 542-552

Emmanuelsson O, H., Nielsen H, Brunak S, von Heijne G (2000) Predicting subcellular localization of proteins based on their N-terminal amino acid sequence. J. Mol. Biol. 300: 1005-1016

Fice D, Shen Z, Byers DM (1993) Purification and characterization of fatty acyl-acyl carrier protein synthetase from Vibrio harveyi. J Bacteriol 175: 1865-1870 
Fulda M, Heinz E, Wolter FP (1997) Brassica napus cDNAs encoding fatty acyl-CoA synthetase. Plant Mol Biol 33: 911-922

Gangar A, Karande AA, Rajasekharan R (2001) Purification and characterization of acyl-acyl carrier protein synthetase from oleaginous yeast and its role in triacylglycerol biosynthesis. Biochem J 360: 471-479

Geurtsen J, Steeghs L, Hove JT, van der Ley P, Tommassen J (2005) Dissemination of lipid A deacylases (pagL) among gram-negative bacteria: identification of activesite histidine and serine residues. J Biol Chem 280: 8248-8259

Grigorieva GR, Shestakov SV (1982) Transformation in the cyanobacterium Synechocystis sp6803. FEMS Microbiol Letters 13: 367-370

Groot PH, Scholte HR, Hulsmann WC (1976) Fatty acid activation: specificity, localization, and function. Adv Lipid Res 14: 75-126

Hood E, Gelvin SB, Melchersand LS, Hoekema A (1993) New Agrobacterium helper plasmid for gene transfer to plants. Transgenic research 2: 208-218

Hornung E, Pernstich C, Feussner I (2002) Formation of conjugated $\Delta^{11} \Delta^{13}$-double bonds by $\Delta^{12}$-linoleic acid $(1,4)$-acyl-lipid-desaturase in pomegranate seeds. Eur $\mathrm{J}$ Biochem 269: 4852-4859

Hsu L, Jackowski S, Rock CO (1991) Isolation and characterization of Escherichia coli K-12 mutants lacking both 2-acyl-glycerophosphoethanolamine acyltransferase and acyl-acyl carrier protein synthetase activity. J Biol Chem 266: 13783-13788

Hyun Y, Choi S, Hwang HJ, Yu J, Nam SJ, Ko J, Park JY, Seo YS, Kim EY, Ryu SB, Kim WT, Lee YH, Kang H, Lee I (2008) Cooperation and functional diversification of two closely related galactolipase genes for jasmonate biosynthesis. Dev Cell 14: 183-192

Ikeuchi M, Tabata S (2001) Synechocystis sp. PCC 6803 - a useful tool in the study of the genetics of cyanobacteria. Photosynth Res 70: 73-83

Inoue H, Nojima H, Okayama H (1990) High efficiency transformation of Escherichia coli with plasmids. Gene 96: 23-28

Jackowski S, Jackson PD, Rock CO (1994) Sequence and function of the aas gene in Escherichia coli. J Biol Chem 269: 2921-2928

Jackowski S, Rock CO (1986) Transfer of fatty acids from the 1-position of phosphatidylethanolamine to the major outer membrane lipoprotein of Escherichia coli. J Biol Chem 261: 11328-11333

Jiang Y, Chan CH, Cronan JE (2006) The soluble acyl-acyl carrier protein synthetase of Vibrio harveyi $\mathrm{B} 392$ is a member of the medium chain acyl-CoA synthetase family. Biochemistry 45: 10008-10019 
Joyard J, Stumpf PK (1981) Synthesis of Long-Chain Acyl-CoA in Chloroplast Envelope Membranes. Plant Physiol 67: 250-256

Kabara JJ (1984) Antimicrobial agents derived from fatty acids. Journal of the American Oil Chemists' Society 61: 397-403

Kabara JJ, Vrable R (1977) Antimicrobial lipids: natural and synthetic fatty acids and monoglycerides. Lipids 12: 753-759

Kaczmarzyk D (2004) Identification and functional analysis of acyl-acyl carrier protein synthetases from cyanobacteria Synechocystis sp. strain PCC 6803 and Synechococcus sp. strain PCC 7942. Diploma work

Kaneko T, Sato S, Kotani H, Tanaka A, Asamizu E, Nakamura Y, Miyajima N, Hirosawa M, Sugiura M, Sasamoto S, Kimura T, Hosouchi T, Matsuno A, Muraki A, Nakazaki N, Naruo K, Okumura S, Shimpo S, Takeuchi C, Wada T, Watanabe A, Yamada M, Yasuda M, Tabata S (1996) Sequence analysis of the genome of the unicellular Cyanobacterium Synechocystis sp. strain PCC6803. II. Sequence determination of the entire genome and assignment of potential protein-coding regions. DNA Res. 3: 109-136, 185-209

Kaniuga Z, Saczynska V, Miskiewicz E, Garstka M (1999) Degradation of leaf polar lipids during chilling and post-chilling rewarming of Zea mays genotypes reflects differences in their response to chilling stress. The role of galactolipase. Acta Physiologiae Plantarum 21: 45-56

Koo AJ, Fulda M, Browse J, Ohlrogge JB (2005) Identification of a plastid acyl-acyl carrier protein synthetase in Arabidopsis and its role in the activation and elongation of exogenous fatty acids. Plant J 44: 620-632

Laemmli UK (1970) Cleavage of structural proteins during the assembly of the head of bacteriophage T4. Nature 227: 680-685

Lem NW, Stumpf PK (1984) In Vitro Fatty Acid Synthesis and Complex Lipid Metabolism in the Cyanobacterium, Anabaena Variabilis: II. Acyl Transfer and Complex Lipid Formation. Plant Physiol 75: 700-704

Lessire R, Cassagne C (1979) Direct synthesis of stearoyl-acyl carrier protein from stearate by microsomes from Allium porrum epidermal cells. Plant Sci. Lett. 14: $43-48$

Los DA, Murata N (1998) Structure and expression of fatty acid desaturases. Biochimica et Biophysica Acta 1394: 3-15

Los DA, Murata N (1999) Responses to cold shock in cyanobacteria. J Mol Microbiol Biotechnol 1: 221-230

Matos AR, d'Arcy-Lameta A, Franca M, Petres S, Edelman L, Kader J, Zuily-Fodil Y, Pham-Thi AT (2001) A novel patatin-like gene stimulated by drought stress encodes a galactolipid acyl hydrolase. FEBS Lett 491: 188-192 
Matos AR, d'Arcy-Lameta A, Franca M, Zuily-Fodil Y, Pham-Thi AT (2000) A patatin-like protein with galactolipase activity is induced by drought stress in Vigna unguiculata leaves. Biochem Soc Trans 28: 779-781

Meyer TS, Lamberts BL (1965) Use of coomassie brilliant blue R250 for the electrophoresis of microgram quantities of parotid saliva proteins on acrylamide-gel strips. Biochim Biophys Acta 107: 144-145

Michinaka Y, Shimauchi T, Aki T, Nakajima T, Kawamoto S, Shigeta S, Suzuki O, Ono K (2003) Extracellular secretion of free fatty acids by disruption of a fatty acyl-CoA synthetase gene in Saccharomyces cerevisiae. J Biosci Bioeng 95: 435440

Miquel M, Browse J (1992) Arabidopsis mutants deficient in polyunsaturated fatty acid synthesis. Journal of Biological Chemistry 267: 1502-1509

Mullis KB, Faloona FA (1987) Specific synthesis of DNA in vitro via polymerasecatalyzed chain reaction. Methods Enzymol 155: 335-350

Murashige T, Skoog F (1962) A revised medium for rapid growth and bioassays with tobacco tissue cultures. Physiol Plant 15: 473-497

Murata N, Wada H (1995) Acyl-lipid desaturases and their importance in the tolerance and acclimatization to cold of cyanobacteria. Biochem J 308 ( Pt 1): 1-8

Murata N, Wada H, Gombos Z (1992) Modes of Fatty-Acid Desaturation in Cyanobacteria. Plant and Cell Physiology 33: 933-941

Neal A, Banas A, Banas W, Stahl U, Carlsson AS, Stymne S (2006) Microsomal preparations from plant and yeast acylate free fatty acids without prior activation to acyl-thioesters. Biochim Biophys Acta 1761: 757-764

Ohlrogge J, Browse J (1995) Lipid biosynthesis. Plant Cell 7: 957-970

op den Camp RGL, Przybyla D, Ochsenbein C, Laloi C, Kim C, Danon A, Wagner D, Hideg E, Göbel C, Feussner I, Nater M, Apel K (2003) Rapid induction of distinct stress responses after the release of singlet oxygen in Arabidopsis. Plant Cell 15: 2320-2332

O'Sullivan JN, Warwick NWM, Dalling MJ (1987) A galactolipase activity associated with the thylakoids of wheat leaves (Triticum aestivum L.). Journal of plant physiology 131: 393-404

Pisareva T, Shumskaya M, Maddalo G, Ilag L, Norling B (2007) Proteomics of Synechocystis sp. PCC 6803. The FEBS Journal 274: 791-804

Porter RD (1988) Preparation of total DNA from small-scale cyanobacterial cultures. Methods Enzymol 167: 706-707 
Ray TK, Cronan JE, Jr. (1976) Activation of long chain fatty acids with acyl carrier protein: demonstration of a new enzyme, acyl-acyl carrier protein synthetase, in Escherichia coli. Proc Natl Acad Sci U S A 73: $4374-4378$

Ray TK, Cronan JE, Jr. (1976) Mechanism of phospholipid biosynthesis in Escherichia coli: acyl-CoA synthetase is not required for the incorporation of intracellular free fatty acids into phospholipid. Biochem Biophys Res Commun 69: 506-513

Riggs MG, McLachlan A (1986) A simplified screening procedure for large numbers of plasmid minipreparations. Biotechniques 4: 310-313

Rippka R, Deruelles J, Waterbury JB, Herdman M, Stanier RY (1979) Genetic assignments, strains histories and properties of pure cultures of cyanobacteria. J.Gen.Microbiol. 111: 1-61

Rock CO, Cronan JE, Jr (1981) Acyl-acyl carrier protein synthetase from Escherichia coli. Methods Enzymol 71: 163-168

Rock CO, Cronan JE, Jr. (1979) Solubilization, purification, and salt activation of acylacyl carrier protein synthetase from Escherichia coli. J Biol Chem 254: 7116-7122

Rock CO, Jackowski S (1985) Pathways for the incorporation of exogenous fatty acids into phosphatidylethanolamine in Escherichia coli. J Biol Chem 260: 12720-12724

Sambrook J, Fritsch EF, Maniatis T (1989) Molecular cloning: a laboratory manual, Ed 2nd edn. Cold Spring Harbor Laboratory, Cold Spring Harbor NY

Sanger F, Nicklen S, Coulson AR (1977) DNA sequencing with chain-terminating inhibitors. Proc Natl Acad Sci U S A 74: 5463-5467

Sastry PS, Kates M (1964) Hydrolysis of Monogalactosyl and Digalactosyl Diglycerides by Specific Enzymes in Runner-Bean Leaves. Biochemistry 3: 1280-1287

Scharnewski M (2005) Analyse der Fettsaure-aktivierenden Reaktionen in Mutanten von Saccharomyces cerevisiae. Diploma work

Shanklin J (2000) Overexpression and purification of the Escherichia coli inner membrane enzyme acyl-acyl carrier protein synthase in an active form. Protein Expr Purif 18: 355-360

Shestakov SV, Khyen NT (1970) Evidence for genetic transformation in blue-green alga Anacystis nidulans. Mol Gen Genet 107: 372-375

Shockey JM, Fulda MS, Browse J (2003) Arabidopsis contains a large superfamily of acyl-activating enzymes. Phylogenetic and biochemical analysis reveals a new class of acyl-coenzyme a synthetases. Plant Physiol 132: 1065-1076

Shockey JM, Fulda MS, Browse JA (2002) Arabidopsis contains nine long-chain acylcoenzyme a synthetase genes that participate in fatty acid and glycerolipid metabolism. Plant Physiol 129: 1710-1722 
Suzuki I, Los DA, Kanesaki Y, Mikami K, Murata N (2000) The pathway for perception and transduction of low-temperature signals in Synechocystis. The EMBO Journal 19: 1327-1334

Trent MS, Pabich W, Raetz CR, Miller SI (2001) A PhoP/PhoQ-induced Lipase (PagL) that catalyzes 3-O-deacylation of lipid A precursors in membranes of Salmonella typhimurium. J Biol Chem 276: 9083-9092

van den Berg B, Black PN, Clemons WM, Jr., Rapoport TA (2004) Crystal structure of the long-chain fatty acid transporter FadL. Science 304: 1506-1509

Wada H, Murata N (1998) Lipids in Photosynthesis: Structure, Function and Genetics., Vol 6. Kluwer Academic Publishers, Dordrecht

Williams JGK (1988) Construction of specific mutations in photosystem II photosynthetic reaction center by genetic engineering methods in Synechocystis 6803. Methods Enzymol 167: 766-778

\section{Zimmermann P, Hirsch-Hoffmann M, Hennig L, Gruissem W (2004)}

GENEVESTIGATOR. Arabidopsis microarray database and analysis toolbox. Plant Physiol 136: 2621-2632 


\section{Appendices}

\subsection{List of abbreviations}

AAS acyl-acyl carrier protein synthetase

ACP acyl carrier protein

AMP adenosine 5' monophosphate

APS ammonium peroxy disulfate

ATP adenosine 5' triphosphate

bp base pair

BSA bovine serum albumin

${ }^{\circ} \mathrm{C} \quad$ Celsius's grad

C 8:0 caprylic acid

C 10:0 capric acid

C 12:0 lauric acid

C 14:0 myristic acid

C 16:0 palmitic acid

C 18:0 stearic acid

C 18:1 oleic acid

C 18:2 linoleic acid

C 18:3 linolenic acid

C 18:4 stearidonic acid

3OH-14:0 3-hydroxymyristic acid

$\mathrm{Cm} \quad$ chloramphenicol

$\mathrm{Ci} \quad$ curie

DAI day after imbibition

DGDG digalactosyl diacylglycerol

DMSO dimethyl sulfoxide

DNA deoxyribonucleic acid

dNTP deoxyribonucleotide

dpm disintegrations per minute

DTT dithiothreitol

E. coli Escherichia coli

EDTA ethylenediamine tetraacetic acid 


\begin{tabular}{|c|c|}
\hline ECFP & enhanced cyan fluorescent protein \\
\hline EYFP & enhanced yellow fluorescent protein \\
\hline et al. & and coworkers \\
\hline FA & fatty acid \\
\hline FFA & free fatty acids \\
\hline $\mathrm{g}$ & gram \\
\hline $\mathrm{x} g$ & $\begin{array}{l}\text { multiply by } 9.80665 \mathrm{~m} / \mathrm{s}^{2} \text { (nominal acceleration due to gravity on Earth at } \\
\text { sea level) }\end{array}$ \\
\hline GC & gas chromatography \\
\hline GC-MS & gas chromatography-mass spectrometry \\
\hline $\mathrm{h}$ & hour \\
\hline HEPES & hydroxyethyl-piperazinethane sulfonic acid \\
\hline HRP & horseradish peroxidase \\
\hline IPTG & isopropyl- $\beta$-D-thiogalactopyranoside \\
\hline $\mathrm{kb}$ & kilobase pair \\
\hline $\mathrm{kDa}$ & kilodalton \\
\hline Kan & kanamycin \\
\hline 1 & liter \\
\hline LACS & long-chain acyl CoA-synthetase \\
\hline LB-medium & Luria-Bertani medium \\
\hline m- & milli \\
\hline M & molar \\
\hline MGDG & monogalactosyl diacylglycerol \\
\hline $\min$ & minute \\
\hline MS-medium & Murashige-Skoog medium \\
\hline$\mu-$ & micro \\
\hline n- & nano \\
\hline OD & optical density \\
\hline ORF & open reading frame \\
\hline p- & pico \\
\hline PAGE & polyacrylamide gel electrophoresis \\
\hline PBS & phosphate buffered saline \\
\hline PCR & polymerase chain reaction \\
\hline PG & phosphatidylglycerol \\
\hline
\end{tabular}


$\mathrm{pH} \quad$ potential of hydrogen

$\mathrm{Pi} \quad$ inorganic phosphate

RNA ribonucleic acid

rpm rounds per minute

RT room temperature

SDS sodium dodecylsulfate

sec second

SQDG sulfoquinovosyl diacylglycerol

TEMED N,N,N',N'-tetramethylene diamine

U unit

UV ultraviolet

$\mathrm{v} / \mathrm{v} \quad$ volume to volume

X-Gal 5-bromo-4-chloro-3-indolyl- $\beta$-D-galactopyranoside

X-Gluc 5-bromo-4-chloro-3-indolyl $\beta$-D-glucuronide cyclohexylammonium salt

WT wild type

$\mathrm{w} / \mathrm{v} \quad$ weight to weight 


\subsection{List of primers}

GGAATTCATATGGACAGTGGCCATGGCGCT (MF50)

AGAATTCTCGAGAAACATTTCGTCAATTAAATGTTG (MF51)

ACACGCATGCTTAAATGACTTCTTGTGGAAAG (Elo_kof1_Sph)

AGAGATCTAGAGACGGCACCTCAACTCCTAGGT (Elokor_5520)

ACAGCGGCCGCAAGTCAGCTCTTCACCCCAG (eloProNot2f)

ACAGCGGCCGCGGATGCACTGGATTGGCAC (eloProNot3r)

GATGAACTACACCAGCGGCCGCCATTTCAAGGG (SynQC3221-23fEag)

CCCTTGAAATGGCGGCCGCTGGTGTAGTTCATC (SynQC3221-23rEag)

AGATCCATGGAAATTCGTCTGAAACCT (AtFAA1f1)

AGTACCATGGCTTGCGAGTCAAAGGAAAAAGAA (AtFAA1_47Ncof)

AGTAGCGGCCGCTTAACTGTAGAGTTGATCAATC (AtFAA1NotrStop)

GAATGACCATGGCTTCAACGTCTCTCGGA (AtFAA2fNco)

TCTAGACCATGGCGTGCGAATCCAAGATTCAGGA (AtFAA2_47f)

CCTCGAGTGCGGCCGCCTACTTGTAGAGTCTTTCTA (FAA2StopNotr)

AAGCTTAAAGCTGGATTATTCGTATAACTCA (forward) (AtFAA1PromfHind)

GGATCCTCGTTGAGGAAGAGGCGATGAAGAAG (AtFAA1Promr1Bam)

GATGGATCCTTGCAGATAAGATGAAGATGAGGACTG (AtFAA1Promr2Bam)

TGCAAGCTTCTGTTCCAAGGACACTCAACCTATAC (AtFAA1Pf2Hind)

GGATCCTCGTTGAGGAAGAGGCGATGAAGAAG (AtFAA1Promr1Bam)

GATGGATCCTTGCAGATAAGATGAAGATGAGGACTG (AtFAA1Promr2Bam)

AAGCTTAGAACCGAATCATTCTCCATAACA (AtFAA2PromfHind),

GGATCCGGCTGAGGAGATAAGAGGTTATGA (AtFAA2PromrBam)

AGATCCATGGAAATTCGTCTGAAACCT (AtFAA1f1)

GAACATGT CTCCCGAAAACGAGGAGCTTTC (AtFAA1r262BspLU)

GAATGACCATGGCTTCAACGTCTCTCGGA (AtFAA2fNco)

GAACATGT CCCTTGGCAATGATAAGCGTTC (AtFAA2r214BspLU)

CTCTACATCCTAGAAGACAGC (SYN4)

GAATCCAATTCCCGTACTTGGTGC (SYN UP2)

GATTCAGTCGTCACTCATGGTG (kan down)

CACAGCCGGGGCACACCGACAATG (SYN2)

CCGTAATCAGCGTGTAGATGATGG (elotest1)

GATCGAACCGCTGTCCTCTAAGACG (elotest2) 
GTGTTCCGCGACAACGTTGCGACG (eloXma_con_r)

CCGTAATCAGCGTGTAGATGATGG (elotest1)

GATCGAACCGCTGTCCTCTAAGACG (elotest2)

CATTGACCTGAAACTAATCATCC (SYN6)

CATCGATTCAGATGATACAGCT (AtFAA1sf771)

ACATGCGGCCGCACTGTAGAGTTGATCAATCTC (AtFAA1NotrHis)

GCCATCATGGCATGCTTATG (AtFAA2sf933) 


\subsection{Vector maps}

All plasmid carts were downloaded from: http://www.addgene.org/pgvec1

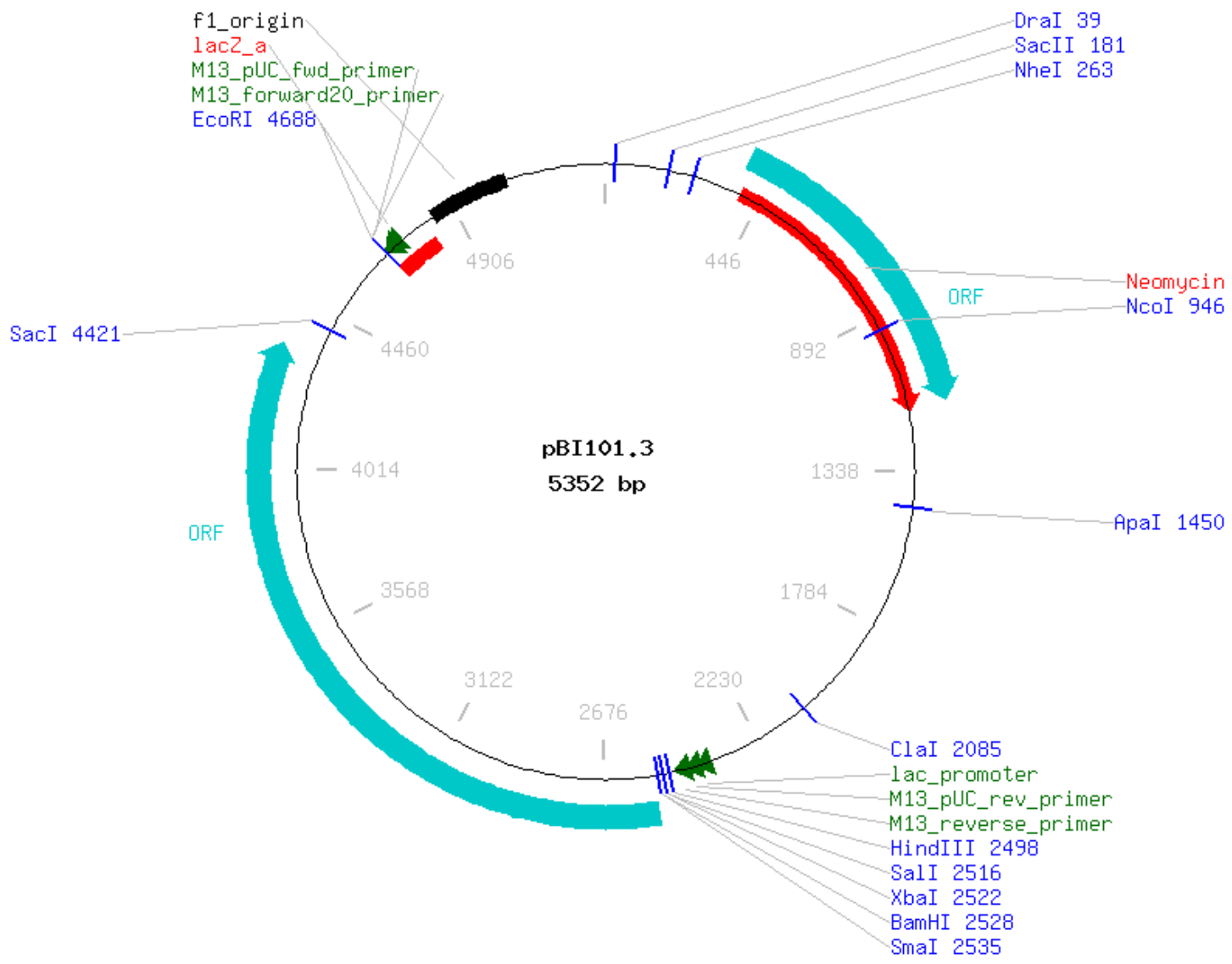




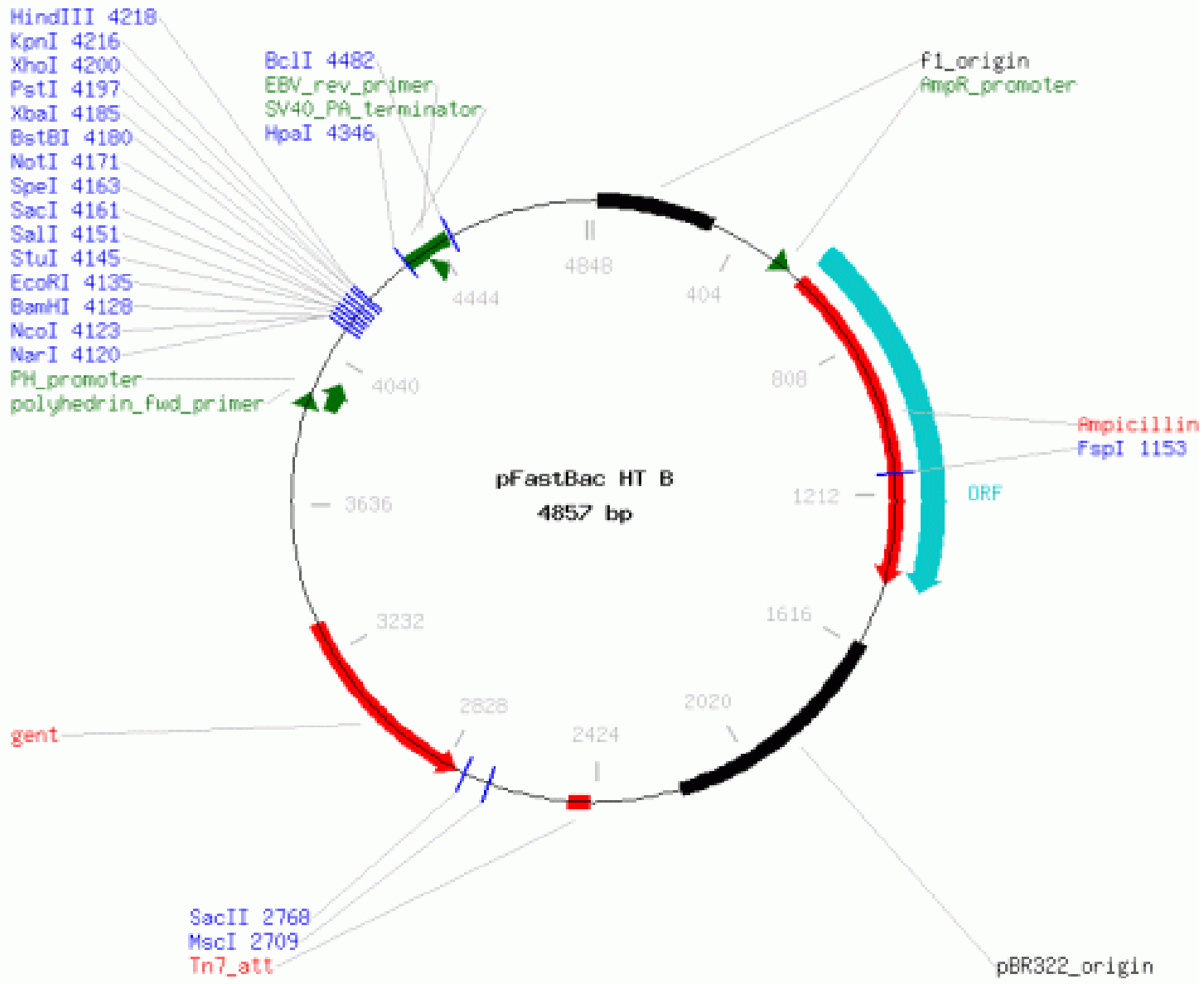


Appendices

108

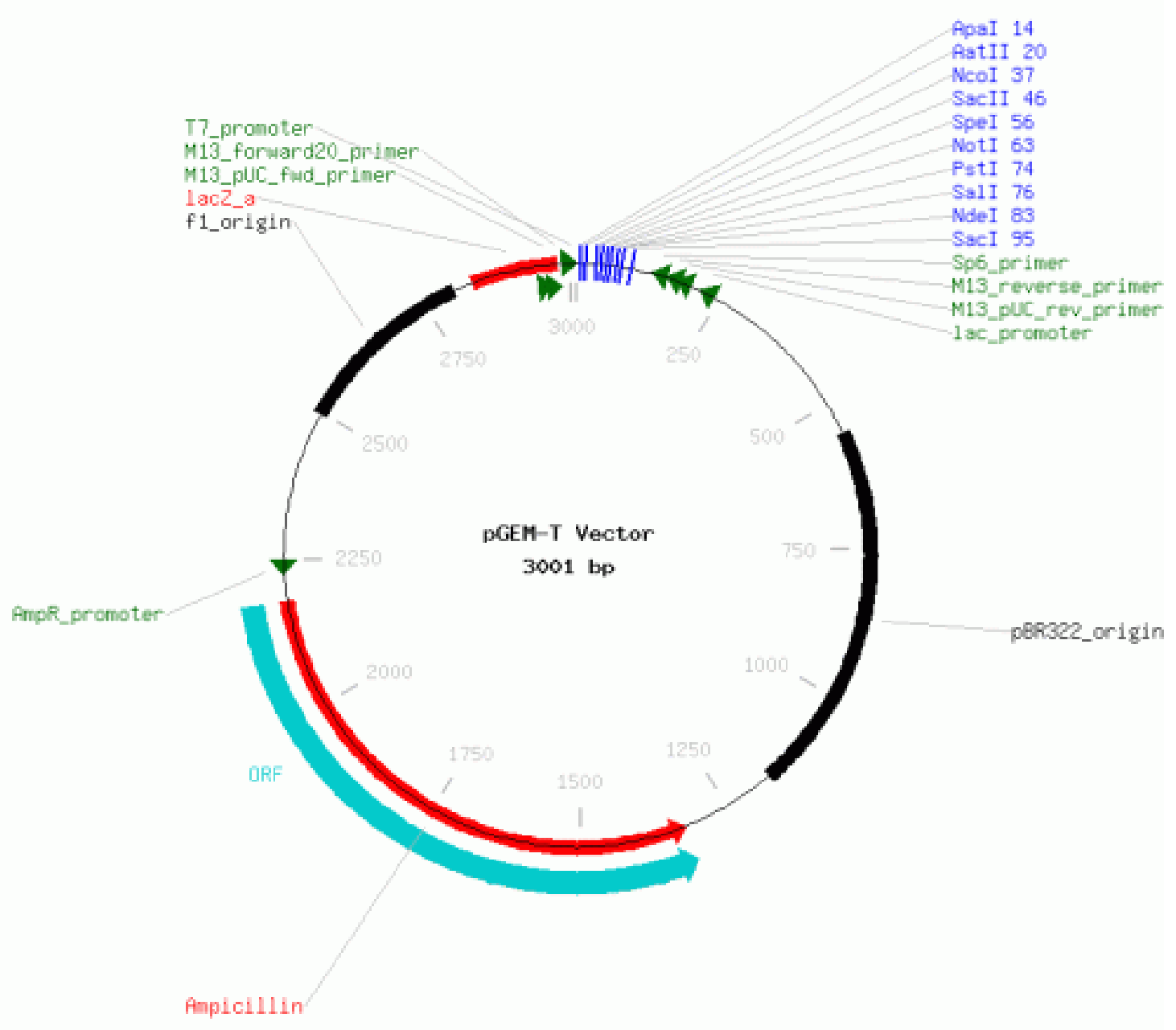




\section{Acknowledgments}

I wish to thank all the people who contributed in many ways to the success of this work.

I would like to express my sincere gratitude to Prof. Dr. Ivo Feussner for accepting me as a $\mathrm{Ph} . \mathrm{D}$. candidate in the department and for his valuable suggestions during this study.

I am very thankful to Prof. Dr. Dieter Heineke for accepting to be on my doctoral committee as the co-referrent.

I am deeply indebted to my supervisor, Dr. Martin Fulda for his constant encouragement, patience and support.

I am particularly thankful to my colleagues and friends, Dr. Annett Struss, Dirk Jessen, Eva-Maria Küch, Gabriel Mora, Michael Scharnewski and Martin Wagner who have created pleasant working environment. I will never forget time we spent together.

I owe gratitude to Karolina Skorzewska, who joined our group as a student of the Socrates/Erasmus Program, for her assistance.

I extend my sincere gratitude to all the people at the Plant Biochemistry Department. I especially thank Dr. Cornelia Göbel, Dr. Ellen Hornung, Dr. Alena Liavonchanka, Dr. Maike Rudolph, Dr. Xuan Wang, Alexandra Andreou, Amina Ibrahim, Heike Lott, Gerhard Mader and Jeanine Reinecke for their friendly advice, help and encouragement.

Gabriel and Alexandra require double thanks for proof-reading of this work.

I have been fortunate to have wonderful friends who have given me support, understanding and heart-warming words, whenever I needed them. I especially thank Luc Hippolyte Dossa, Oxana Fuchs, Hirofumi Goto, Agnieszka and Patryk Lozinscy, Anna Michalska, Govindarajan Nambirajan, Krzysztofa Nowak, Mariusz Tabaczek and Anna Zdyb.

This dissertation is dedicated to my parents, Jadwiga and Henryk, who have given me their love, patience and support. My sincere gratitude goes also to my brother, Pawel. 


\section{Lebenslauf}

Danuta Kaczmarzyk

24.11.1980

geboren in Wroclaw, Polen

Staatsangehörigkeit: polnisch

1987-1995

Besuch der Grundschule in Jelcz-Laskowice

1995-1999

Besuch des Gymnasiums in Jelcz-Laskowice; Schulabschluß: Abitur

$1999-2002$

Lizenziat Studium der Biotechnologie an der Wroclaw Universität

2002-2004

Magister Studium der Biotechnologie an der Wroclaw Universität Diplomarbeit mit dem Thema: „Identification and functional analysis of acyl-acyl carrier protein synthetases from cyanobacteria Synechocystis sp. strain PCC 6803 and Synechococcus sp. strain PCC 7942“ angefertigt in der Abteilung für Biochemie der Pflanze des Albrecht-von-Haller-Instituts für Pflanzenwissenschaften der Universität zu Göttingen, Göttingen

10.2003-2.2004 Erasmus Stipendium an der Georg-August-Universität zu Göttingen

seit Dez. 2004 Doktorandin in der Abteilung für Biochemie der Pflanze des Albrecht-von-Haller-Instituts für Pflanzenwissenschaften der Universität zu Göttingen 